\title{
The Age of Reason: Financial Decisions over the Life-Cycle with Implications for Regulation
}

\section{Citation}

Agarwal, Sumit, John C. Driscoll, Xavier Gabaix, and David Laibson. 2009. The age of reason: financial decisions over the life-cycle with implications for regulation. Brookings Papers on Economic Activity 2:51-117.

\section{Published Version}

doi:10.1353/eca.0.0067

\section{Permanent link}

http://nrs.harvard.edu/urn-3:HUL.InstRepos:4554335

\section{Terms of Use}

This article was downloaded from Harvard University's DASH repository, and is made available under the terms and conditions applicable to Open Access Policy Articles, as set forth at http:// nrs.harvard.edu/urn-3:HUL.InstRepos:dash.current.terms-of-use\#OAP

\section{Share Your Story}

The Harvard community has made this article openly available.

Please share how this access benefits you. Submit a story.

\section{Accessibility}




\title{
The Age of Reason: Financial Decisions over the Life-Cycle with Implications for Regulation
}

\author{
Sumit Agarwal, John C. Driscoll, Xavier Gabaix, and David Laibson* \\ October 19, 2009 \\ Prepared for the Brookings Papers on Economic Activity
}

\begin{abstract}
Many consumers make poor financial choices and older adults are particularly vulnerable to such errors. About half of the population between ages 80 and 89 either has dementia or a medical diagnosis of "cognitive impairment without dementia." We study lifecycle patterns in financial mistakes using a proprietary database that measures ten different types of credit behavior. Financial mistakes include suboptimal use of credit card balance transfer offers, misestimation of the value of one's house, and excess interest rate and fee payments. In a cross-section of prime borrowers, middle-aged adults make fewer financial mistakes than younger and older adults. We conclude that financial mistakes follow a Ushaped pattern, with the cost-minimizing performance occurring around age 53 . We analyze regulatory regimes that may help individuals avoid making financial mistakes. Some of these regimes are designed to address the particular challenges faced by older adults, but much of our discussion is relevant for all vulnerable populations. We discuss disclosure, nudges, financial driving licenses, advanced directives, fiduciaries, asset safe harbors, ex-post and ex-ante regulatory oversight. Finally, we pose seven questions for future research on cognitive limitations and associated policy responses.
\end{abstract}

Keywords: Household finance, aging, financial sophistication, shrouding, credit cards, fees, mortgages, regulation.

*Agarwal: Federal Reserve Bank of Chicago, sagarwal@frbchi.org. Driscoll: Federal Reserve Board, john.c.driscoll@frb.gov. Gabaix: NYU Stern, CEPR and NBER, xgabaix@stern.nyu.edu. Laibson: Harvard University and NBER, dlaibson@harvard.edu. Gabaix and Laibson acknowledge support from the National Science Foundation (DMS-0527518). Laibson acknowledges financial support from the National Institute on Aging (R01AG-021650, R01-AG-1665, P30-AG-012810). The views expressed in this paper are those of the authors and do not represent the policies or positions of the Board of Governors of the Federal Reserve System or the Federal Reserve Bank of Chicago. For their helpful comments we thank the editors, David Romer and Justin Wolfers, and Marco Basetto, Stephane Bonhomme, David Cutler, Giovanni Dell'Ariccia, Ray Fair, Luigi Guiso, Gur Huberman, Erik Hurst, Ulrike Malmendier, Karen Pence, Mitch Petersen, Rich Rosen, Timothy Salthouse, Fiona Scott Morton, Jesse Shapiro, William Sharpe, Paolo Sodini, Nick Souleles, Jon Zinman, and participants at various conferences and seminars. We thank Jacqueline Barrett and Kyle Chauvin for excellent research assistance. 


\section{Introduction}

Most households have accumulated a substantial pool of wealth by the time they retire. For households with a head aged 65-74, median net worth - including net home equity and excluding public and private defined benefit claims - was $\$ 239,400$ in $2007 .^{1}$ Moreover, the amount of wealth accumulation is likely to grow much more quickly than income in the next three decades as more and more households experience a full lifetime of accumulation in defined contribution pension accounts, like 401(k)s. ${ }^{2}$

In addition to their actively accumulated assets, households with a head aged 65-74 also have a complex set of balance-sheet liabilities: $42.9 \%$ have debt secured by a residential property; $26.1 \%$ have installment loans; and $37 \%$ have credit card balances (excluding the float). ${ }^{3}$ Nearly two-thirds $(65.5 \%$ ) of households aged 65-74 have at least one form of debt.

In this paper, we seek to raise a red flag about the increasingly large and complex balance sheets of older adults (age 65 or greater). Substantial retirement savings is critical in light of the length of retirement, the expectation of independent living, and the modest magnitudes of defined benefit flows. However, many older adults are not in a good position to manage their finances, or even to delegate that management. We document this concern in four ways.

First, we review the literature on age-based patterns in cognitive function. Analytic cognitive function appears to decline dramatically over the life-cycle, starting at age 20. One way to summarize this fact, is to consider the relationship between a person's cognitive-function percentile score (measured relative to the total adult population) and that person's age. In the cross-section, average analytic cognitive function falls by about 1 percentile unit for each year of age (from age 20 to age 80$).{ }^{4}$ Many mechanisms explain this pattern, including (confounding) cohort effects, normal aging effects, and dementia. The prevalence of dementia explodes after age 60 , doubling with every 5 years of age. ${ }^{5}$ In the cohort above age 85 , the prevalence of dementia exceeds 30\%. Moreover, many older adults without a strict diagnosis of dementia, still experience substantial cognitive impairment. For example, the prevalence of the diagnosis "cognitive impairment without dementia" is nearly $30 \%$ between ages 80 and $89 .{ }^{6}$ Drawing these facts together, among the population between ages 80 and 89 , about half of the population either has a diagnosis of dementia or cognitive impairment without dementia.

Second, we supplement these existing findings with new longitudinal evidence from the Health and Retirement Survey. Our new evidence eliminates the confound of cohort effects by estimating age effects

\footnotetext{
${ }^{1}$ Survey of Consumer Finances, Federal Reserve Board of Governors, 2007. For households with a head aged 65-74, mean net worth excluding defined benefit accounts was $\$ 1,015,700$ in 2007 . The mean is dominated by the right tail and savings for these households is motivated by many considerations other than retirement (particularly bequests and privately held businesses).

${ }^{2}$ Poterba, Venti and Wise (2007). Only half of the private sector workforce has a DC plan at their current employer. However, current legislative proposals are likely to expand coverage.

${ }^{3}$ Survey of Consumer Finances, Federal Reserve Board of Governors, 2007.

${ }^{4}$ Salthouse (forthcoming) and author's calculations.

${ }^{5}$ Ferri et al (2006).

${ }^{6}$ Plassman et al (2008). They define cognitive impairment without dementia as a Dementia Severity Rating Scale score of 6 to 11 .
} 
that control for person-fixed effects. When we do this, we find even stronger age-based patterns. Our results imply that age-based selection effects are very strong - the most impaired subjects tend to drop out of these surveys - explaining why cross-sectional patterns of cognitive decline understate the true age-based decline.

Third, using a new dataset, we document a link between age and the quality of financial decisionmaking in debt markets. In a cross-section of prime borrowers, middle-aged adults borrow at lower interest rates and pay fewer fees relative to younger and older adults. Averaging across ten credit markets, fee and interest payments are minimized around age 53. The measured effects are not explained by observed risk characteristics. Combining multiple data sets we do not find evidence that selection effects and cohort effects explain our results. The leading explanation for the patterns that we observe is that experience rises with age, but analytical abilities decline with it.

Fourth we review the contributions of other authors who have studied age effects on financial decisionmaking.

Much of the evidence in this paper (and the literature more generally) is not conclusive. There remain some questions about the identification of age, cohort, and time effects. Moreover, even if we were certain that older adults make many suboptimal financial decisions, it is not clear what society should do about.

We next present a discussion of mutually compatible policy options. Our regulatory analysis emphasizes older adults, even though some of our field evidence suggests that young adults are also at risk. We focus on older adults for four reasons. First, older adults have much more at stake since they control far more financial resources (as a fraction of their total net worth) than people in their 20s. Second, older adults cannot bounce back from their mistakes, since cognitive and physical impairments frequently make it difficult to return to work. Third, young adults may make frequent financial mistakes, but they rarely have severe cognitive impairments. Being a foolish 20-year-old credit card user bears little comparison to the financial dangers posed by dementia. For example, we regularly hear stories about friends' aging relatives who lend/give a substantial fraction of their wealth to con artists. Fourth, retirees effectively have fewer regulatory protections than most workers. This is an unintended consequence of our system of defined contribution retirement savings. Defined contribution pension accounts are stringently regulated by the Employee Retirement Income Security Act (ERISA). ${ }^{7}$ However, almost all retirees eventually roll their accumulated balances out of ERISA-regulated accounts into Individual Retirement Accounts (IRA's), which are regulated with a much lighter touch. For example, there is no fiduciary duty for broker-dealer securities firms that manage most IRA accounts. The U.S. currently provides the least regulation for the age group with the greatest vulnerability.

We discuss nine policy options in approximate order from the least paternalistic to the most paternalistic.

\footnotetext{
7 "ERISA requires plans to provide participants with plan information including important information about plan features and funding; provides fiduciary responsibilities for those who manage and control plan assets; requires plans to establish a grievance and appeals process for participants to get benefits from their plans; and gives participants the right to sue for benefits and breaches of fiduciary duty." U.S. Department of Labor, http://www.dol.gov/dol/topic/health-plans/erisa.htm
} 
1. Laissez faire

2. Disclosure

3. Libertarian paternalism (e.g., advice, defaults, and other "nudges")

4. "Driving" license

5. Advanced directives

6. Fiduciary

7. Protected assets

8. Presumed regulatory approval of financial products

9. Requirement for explicit regulatory approval of financial products

We discuss the pros and cons of these different regulatory models, without arguing for adoption of any one of them. We believe that natural experiments are needed to determine the efficacy of these different models. Strong regulatory interventions, like those we have listed above, have the potential to generate large social costs and benefits.

Before concluding, we identify seven critical research questions that need to be answered before policymakers can identify an optimal regulatory design. These questions highlight how little we currently know about the financial choices of older adults.

The rest of the paper is organized as follows. Section 2 discusses medical and psychological evidence on changes in cognitive function over the lifecycle. Section 3 discusses evidence from the HRS on age-based changes in cognitive function, controlling for person-fixed effects. Section 4 discusses evidence on debt markets from a new proprietary database. Section 5 discuss the broader literature on economic decisionmaking over the lifecycle. Section 6 is an analysis of ten policy frameworks. Section 7 concludes by posing seven questions for future research, covering both household behavior and optimal regulation.

\section{Psychological and Medical Evidence on Cognitive Decline Among Older Adults}

Analytic cognitive function can be measured in many different ways, including tasks that evaluate working memory, reasoning, spatial visualization, and cognitive processing speed. Figure 1 (Salthouse, forthcoming), illustrates these kinds of tasks.

Analytic function shows a robust age pattern in cross-sectional datasets of adults (Cattell 1987; Salthouse, 2005; and Salthouse, forthcoming). ${ }^{8}$ Adults in their early 20's are on average about 0.7 standard

\footnotetext{
${ }^{8}$ The most abstract cognitive capabilities are often referred to as fluid intelligence. The application of learned concepts is often referred to as crystalized intelligence. See Cattell (1987).
} 

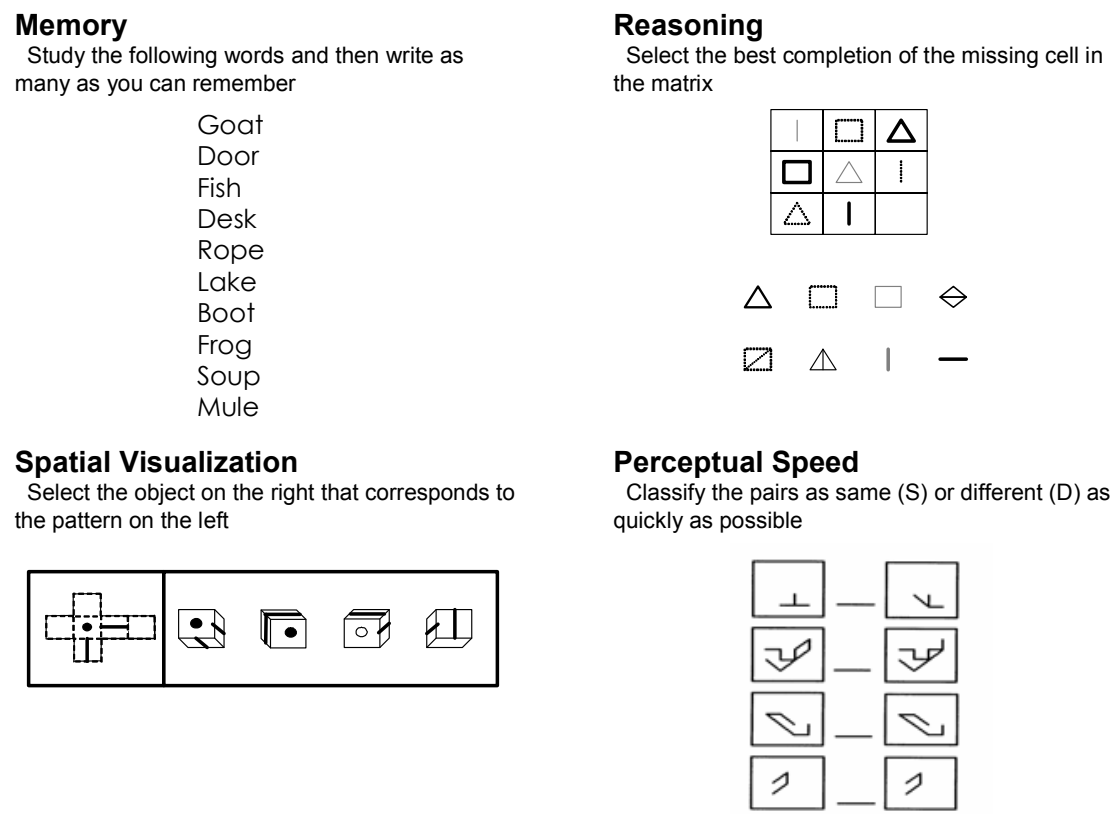

Figure 1: Four tasks used to measure cognitive function. Source: Salthouse (forthcoming).

deviations above the adult mean for analytic cognitive function. Adults in their early 80's are on average about 1.0 standard deviation below the adult mean. This implies a decline of one percentile per year of age (after age 20). ${ }^{9}$ This decline is remarkably smooth from age 20 to age 90 (see Figure 2). The measured age-related pattern in analytic performance results from age effects, cohort effects (Flynn, 1984), and selection effects. We return to the issue of identification of age effects in the next section of the paper, where we report new evidence from the Health and Retirement Survey.

Neurological pathologies represent one important pathway for age effects in older adults. For instance, dementia is primarily attributable to Alzheimer's Disease (60\%) and vascular disease (25\%). The prevalence of dementia doubles with every five additional years of lifecycle age (Ferri et al., 2006; Fratiglioni, De Ronchi, and Agüero-Torres, 1999). ${ }^{10}$ For example, Table 1 reports that the prevalence of dementia in North America rises from 3.3 percent for adults ages 70-74, to 6.5 percent for adults ages 75-79, to 12.8 percent for adults ages 80-84, to 30.1 percent for adults at least 85 years of age (Ferri et al. 2006).

Many older adults also suffer from a less severe form of cognitive impairment, which is diagnosed as "cognitive impairment without dementia." For example, the prevalence of this diagnosis rises from 16.0 percent for adults ages 71-79, to 29.2 percent for adults ages 80-89. All told, about half of the adults in

\footnotetext{
${ }^{9}$ This assumes a Gaussian distribution.

${ }^{10}$ There is also growing literature that identifies age-related changes in the nature of cognition (see Park and Schwarz, 1999; and Denburg, Tranel, and Bechara 2005). Mather and Carstensen (2005) and Carstensen (2006) identify age-variation in cognitive preferences. Subjects with short time horizons or older ages attend to negative information relatively less than subjects with long time horizons or younger ages.
} 


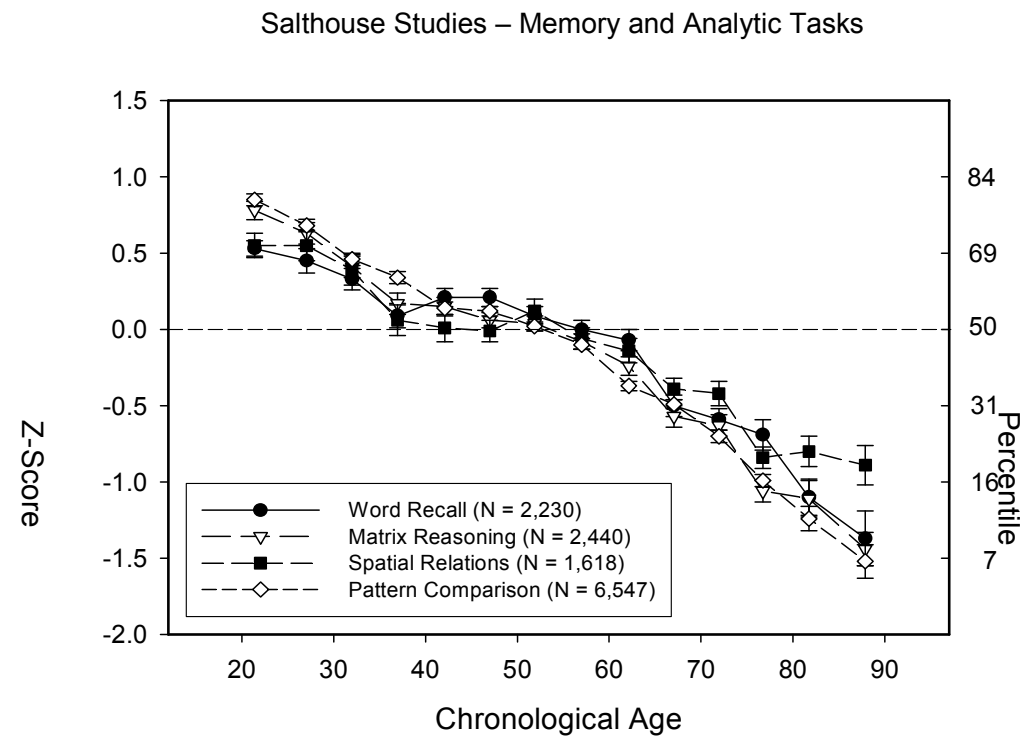

Figure 2: Age-normed results from four different cognitive tests. The $Z$-score represents the age-contingent mean, measured in units of standard deviation relative to the population mean. More precisely, the $Z$-score is (age-contingent mean minus population mean) / (population standard deviation). Source: Salthouse (forthcoming).

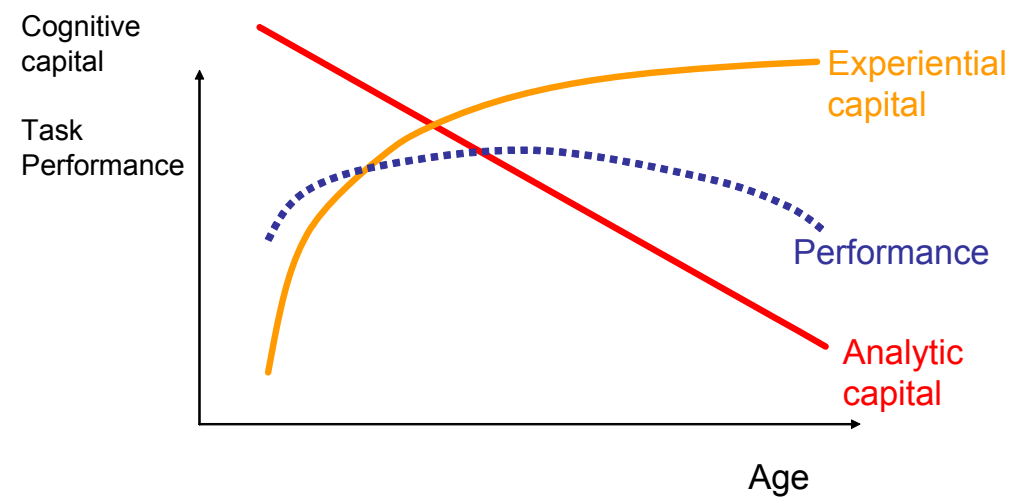

Figure 3: Hypothesized relation between general task performance and age. Analytic capital declines with age and experiential capital increase with age. This generates the hypothesis that general task performance (which uses both analytic and experiential capital) first rises and then declines with age. 


\begin{tabular}{cc}
$\begin{array}{c}\text { Prevalence of Dementia in North America } \\
\text { Age }\end{array}$ & $\begin{array}{c}\text { Prevalence in percent } \\
\text { Percent confidence interval })\end{array}$ \\
\hline $60-64$ & 0.8 \\
& $(0.6-1.0)$ \\
$65-69$ & 1.7 \\
& $(1.5-1.9)$ \\
$70-74$ & 3.3 \\
& $(2.7-3.9)$ \\
$75-79$ & 6.5 \\
& $(5.5-7.5)$ \\
$80-84$ & 12.8 \\
& $(11.8-13.8)$ \\
$85+$ & 30.1 \\
& $(27.9-31.3)$ \\
\hline
\end{tabular}

Table 1: Prevalence of Dementia in North America; percent of population by age group, with 95 percent confidence interval in parentheses. Source: Ferri et al (2006).

their 80's suffer either from dementia or cognitive impairment without dementia.

Age-driven declines in analytic function are partially offset by age-related increases in experience (which is sometimes called wisdom). ${ }^{11}$ Most day-to-day tasks rely on both analytic and experiential human capital - e.g., buying the right amount of milk at the grocery store. For most tasks, we hypothesize that net performance is hump-shaped with respect to age. Formally, this would result from the following conditions (1) general task performance is determined by the sum of analytic capital and experiential capital, (2) experiential capital accumulates with diminishing returns (e.g., if $m<n$, the $n$ 'th learning experience generates less experiential capital than the $m$ 'th experience), and (3) analytic capital falls linearly (or concavely) over the lifecycle. Then general task performance will be hump-shaped with respect to age. Consequently, middle-aged adults may be at a decision-making sweet spot - they have substantial amounts of practical experience and have not yet had significant declines in analytic cognitive function. Figure 3 illustrates this case. As expected, all experience-based cognitive tests - e.g., vocabulary and other knowledge-based tests - follow a hump-shaped pattern (Salthouse 2004).

\section{Evidence from the HRS}

The medical/psychological evidence on age-based patterns in cognitive function (reviewed in the previous section) is confounded by cohort effects and selection effects. In any cross-section of subjects, the older subjects are older, and they are also born in a different cohort. Moreover, they are affected by different

\footnotetext{
${ }^{11}$ Experience may either be directly acquired or it may be indirectly acquired from peers. As social networks are built up over the lifecycle, external sources of experience become better and better developed. However, such social networks tend to fray as individuals retire and leave well-developed work-based networks. Peer mortality also contributes to a late-life decline of social networks. These channels suggest that experiential knowledge embodied in social networks follows a concave lifecycle pattern.
} 


\begin{tabular}{lc}
$\begin{array}{c}\text { Prevalence of "Cognitive Impairment Without Dementia" } \\
\text { Age }\end{array}$ & $\begin{array}{c}\text { Prevalence in percent } \\
\text { (95 percent confidence interval) }\end{array}$ \\
\hline $71-79$ & 16.0 \\
& $(11.5-20.5)$ \\
$80-89$ & 29.2 \\
& $(24.3-34.1)$ \\
$90+$ & 38.8 \\
& $(25.6-52.0)$ \\
Total & 22.0 \\
& $(18.5-22.5)$ \\
\hline
\end{tabular}

Table 2: Prevalence of "Cognitive Impairment Without Dementia"; percent of population by age group, with 95 percent confidence interval in parentheses. Source: Erratum for Plassman et al. (2008).

selection mechanisms. For example, older adults have more time to participate in surveys. But they also have more health problems (both physical and mental) that cause them to drop out of surveys.

In light of these problems, it is useful to analyze data that follows individuals longitudinally. The Health and Retirement Study (HRS) is an excellent source for such analysis for cognitive variables (Ofstedal et al 2005; McArdle et al 2009). Beginning in 1992, the HRS has surveyed about 30,000 nationally representative Americans over the age of 50. These longitudinal surveys are conducted every two years (all subjects were not interviewed in every wave). For reasons of data comparability, we use the 1993 wave and all of the waves from 1995-2006. ${ }^{12}$

Our analysis proceeds in two parallel ways. We provide a "naive" analysis (mirroring the methods in the previous section). We simply plot mean performance by (rounded) age, ignoring the potential role of cohort and selection effects. We plot our naive profiles in blue.

We also report a parallel analysis that we refer to as the "control" analysis. The control analysis traces out the performance trajectory using only intra-individual differences. We calculate the slope at age $a$ as the average slope for all subjects who are observed in adjacent ${ }^{13}$ survey waves straddling $^{14}$ age $a$. In other words, the slope at integer age $a$ is calculated as,

$$
\frac{1}{N_{\Omega(a)}} \sum_{i \in \Omega(a)} \frac{x_{i, w+1}-x_{i, w}}{A_{i, w+1}-A_{i, w}},
$$

where $x_{i, w}$ is the task performance of subject $i$ in HRS wave $w, A_{i, w}$ is the decimal age of subject $i$ in wave $w, \Omega(a)$ is the set of subjects who appear in adjacent waves at ages straddling age $a$, and $N_{\Omega}$ is the cardinality of $\Omega$. Note that this average slope implicitly controls for person fixed effects, since the slope is

\footnotetext{
${ }^{12}$ See http://hrsonline.isr.umich.edu/sitedocs/userg/dr-006.pdf for a complete description of the cognitive scales in the HRS.

${ }^{13}$ In our notation, responses at dates $t$ and $t^{\prime}$ are adjacent if (i) $\left|t^{\prime}-t\right| \leq 5$ years, and (ii) the respondent does not answer the same question at another date $t^{\prime \prime}$ between $t$ and $t^{\prime}$.

For example, if a specific question was not included in the 2004 wave, but was included in the 2002 and 2006 waves (and the respondent answered the question on those waves), then the adjacent responses would be in 2002 and 2006.

${ }^{14}$ Two decimal ages $A<A^{\prime}$ straddle integer age $a$ iff $A<a<A^{\prime}$.
} 
calculated by averaging individual slopes.

We then trace out the lifecycle trajectory using these average slopes, starting from the value of the naive analysis at an "initial" age. To reduce sampling noise, the initial age is chosen as the first age for which we have at least 1000 observations in our combined sample (including all of the HRS waves from 1992-2006).

Figure 4a plots naive and control performance in the immediate word recall task. In this task the interviewer reads a list of 10 nouns (e.g., lake, car, army, etc.) to the respondent, and the respondent recalls as many words as possible (in any order). At age 51, the average performance is 6.2 words out of 10. By age 90 , the average (control) performance is 3.0 words out of 10 .

Figure $4 \mathrm{~b}$ plots naive and control performance in the delayed word recall task. In this task, which is conducted after an intervening task that takes about five minutes, the interviewer again asks the subject to recall as many words as possible. At age 51 , the average performance is 5.4 words out of 10 . By age 90 , the average (control) performance is 2.1 words out of 10 .

Figure 4c plots naive and control performance in the serial 7's task. This task asks the respondent to count backwards by 7's from 100. The respondent is scored on a one to five scale, with one point awarded for each successful subtraction. At age 51, the average score is 3.2 out of 5 . By age 90, the average (control) score is 2.2 out of 5 .

Figure $4 \mathrm{~d}$ plots naive and control performance in the Telephone Interview of Cognitive Status (TICS) task. This task asks the respondent ten trivial questions and assigns one point for each correct answer: What is the current year? Month? Day? Day of the week? What do you usually use to cut paper? What do you call the kind of prickly plant that grows in the desert? Who is the current president? Vice president? Count backwards from twenty to ten (twice). At age 63 , the average score is 9.2 out of 10 . By age 90 , the average (control) score is 7.5.

Finally, we present two measures of practical numeracy. 4e plots naive and control performance in response to the question: If the chance of getting a disease is 10 percent, how many people out of 1,000 would be expected to get the disease? At age 53, $79 \%$ answer correctly. By age 90, 50\% answer correctly.

Figure 4f plots naive and control performance in response to the question: If 5 people all have the winning numbers in the lottery and the prize is two million dollars, how much will each of them get? We believe that this question is imprecisely posed, since the logical answer could be either $\$ 2,000,000$ or $\$ 400,000$. However, the results are still interesting, since the fraction answering $\$ 400,000$ (the official correct answer) drops precipitously. At age 53,52\% answer $\$ 400,000$. By age $90,10 \%$ give this answer.

\subsection{ADAMS data}

The Aging, Demographics, and Memory Study (ADAMS) conducts in-person clinical assessments of cognitive function and dementia for a sub-sample of HRS respondents (Langa et al 2005). The ADAMS sample is a much smaller sample than the HRS. Only 300 ADAMS subjects were surveyed twice (in the 2002 and 2004 HRS waves).

In Figure 5 plots naive and control Clinical Dementia Ratings (CDRs) for the ADAMS sample, using 


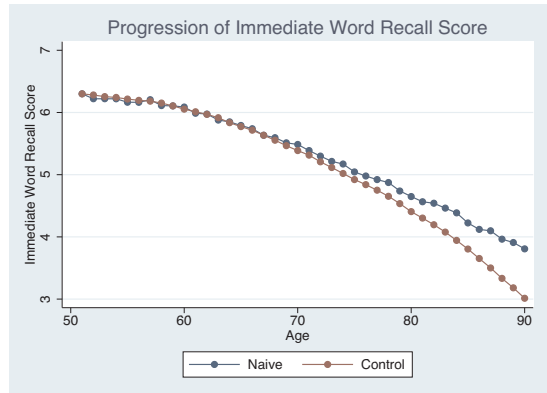

(a)

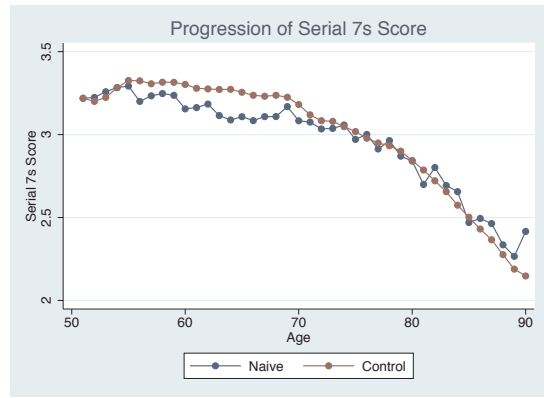

(c)

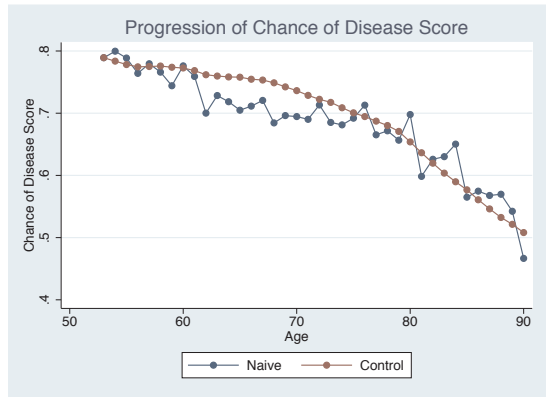

(e)

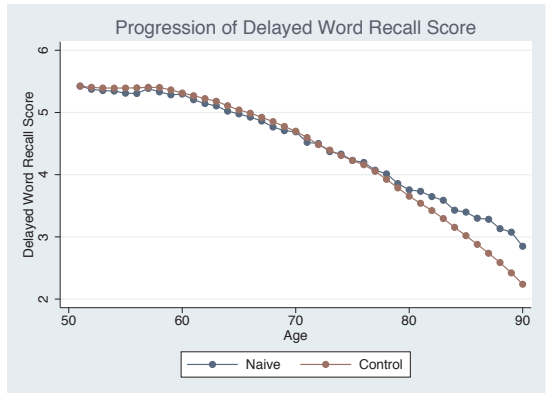

(b)

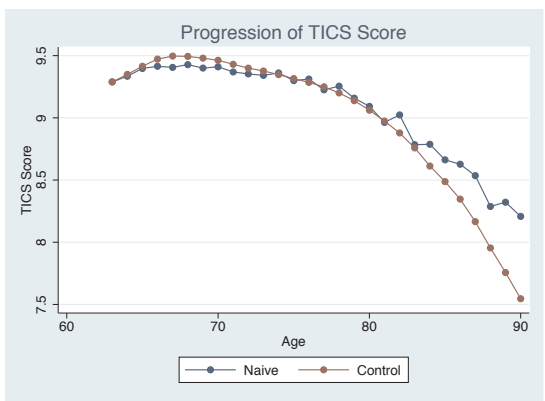

(d)

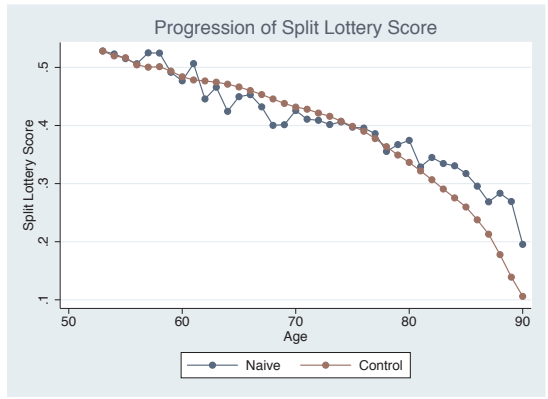

(f)

Figure 4: This figure plots naive and control performance for six simple tasks described in the text. 


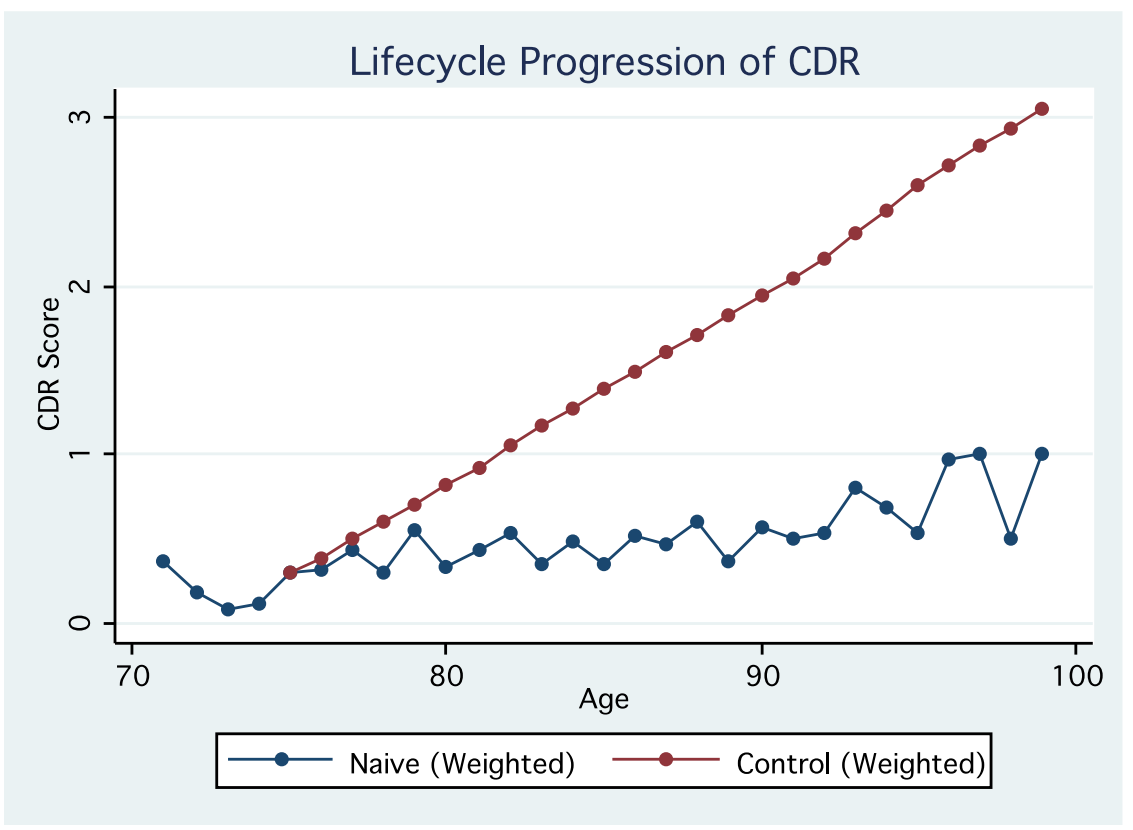

Figure 5: This figure plots naive and control Clinical Dementia Ratings (CDRs).

sampling weights to correct for overrepresentation of certain groups in the study. The CDR score is on a 0 to 4 scale. 0 is healthy. A score of $1 / 2$ represents very mild dementia; 1 represents mild dementia; 2 represents moderate dementia; 3 represents severe dementia; 4 is the highest dementia rating on the scale. ${ }^{15}$ The CDR is scored by a panel of clinicians who are basing their judgment on the entire battery of tests in the ADAMS. Hence, the CDR has a very high signal to noise ratio, since a single score is derived from hundreds of survey questions given to a respondent and his/her caregivers. At age 75 the average score is 0.4 , which is near the threshold for mild dementia. At age 99, the average (control) score is 3.2, implying that the average respondent has severe dementia.

It is also important to emphasize the enormous gap between the naive average and the controlled average in Figure 5. The ADAMS generated a high rate of attrition between its first and second wave. As one would expect, the attrition disproportionately affected subjects experiencing cognitive decline. Hence, the naive averages are highly misleading.

\subsection{Summary of evidence from the HRS}

The HRS data paint a clear picture of declining cognitive function. Moreover, these data series suggest that selection effects may be more important than cohort effects. Cohort effects are predicted to cause the naive profiles to fall more steeply than the control profiles (since older cohorts have fewer educational advantages). Selection effects should cause the naive profiles to fall less steeply than the control profiles

\footnotetext{
${ }^{15}$ http://alzheimer.wustl.edu/cdr/PDFs/CDR_OverviewTranscript-Revised.pdf
} 
(since selection causes the individuals with the lowest levels of cognitive function to exit the sample). Selection bias seems to be more important in the HRS data, since our control profiles are steeper than our naive profiles.

\section{Financial Services and Age: Evidence on the Inverse U-Shape of Per- formance}

We document a U-shaped age-related curve in the prices people pay for ten financial choices: use of credit card balance transfer offers; home equity loans and lines of credit; auto loans; credit card interest rates; mortgages; small business credit cards; credit card late payment fees; credit card over limit fees; and credit card cash advance fees. We discuss three forms of prices paid: higher APRs (Annual Percentage Rates, i.e. interest rates); higher fee payments; and suboptimal use of balance transfer offers.

For each application, we conduct a regression analysis that identifies age effects and controls for observable factors that might explain patterns of fee payments or APRs by age. Thus, unless otherwise noted, in each context we estimate a regression of the type:

$$
F=\alpha+\beta \times \operatorname{Spline}(\text { Age })+\gamma \times \text { Controls }+\epsilon .
$$

Here $F$ is the level of the APR paid by the borrower (or the frequency of fee payment), Controls is a vector of control variables intended to capture alternative explanations in each context (for example, measures of credit risk), and Spline(Age) is a piecewise linear function that takes consumer age as its argument (with knot points at ages 30,40,50, 60 and 70). We then plot the fitted values for the spline on age, with the intercept computed using the sample means for the controls. Regressions are either pooled panel or cross-sectional, depending on the context. ${ }^{16}$

Below, we discuss the nature of the products and the prices paid, briefly document the datasets used, present graphs of fitted values on the spline coefficients, and discuss possible explanations for our findings. We describe the data in the appendix; we provide summary statistics for the data sets and the regression results in the online appendix.

\subsection{Three Financial Choices}

We first examine three financial choices: (1) the use of credit card balance transfer offers; (2) borrowing through home equity loans; and (3) borrowing through home equity lines of credit The U-shaped pattern by age for (suboptimal) balance transfer behavior is a relatively clean example and thereby merits special emphasis. For the other two choices - home equity loans and lines - we are able to tease out the mechanism leading to higher interest payments for younger and older borrowers (namely, mistakes made in estimating house values).

\footnotetext{
${ }^{16}$ As variants, we have tried having knot points at every five years, or replacing the spline with individual dummy variables for age. Results have remained qualitatively and quantitatively similar, showing a U-shape pattern by age.
} 


\subsection{1 "Eureka" Moments: Balance Transfer Credit Card Usage}

Credit card holders frequently receive offers to transfer account balances on their current cards to a new card. Borrowers pay substantially lower APRs on the balances transferred to the new card for a six-to-nine-month period (a 'teaser' rate). However, new purchases on the new card have high APRs. The catch is that payments on the new card first pay down the (low interest) transferred balances, and only subsequently pay down the (high interest) debt accumulated from new purchases.

The optimal strategy during the teaser-rate period, is for the borrower to make all new purchases on her old credit card and to make all payments to her old card. The optimal strategy implies that the borrower should make no new purchases with the new card to which balances have been transferred (unless she has already repaid her transferred balances on that card). Some borrowers will identify this optimal strategy immediately - before making any purchases with the new card. Some borrowers will never identify the optimal strategy. Some borrowers may not initially identify the optimal strategy, but will discover it after one or more pay cycles as they observe their (surprisingly) high interest charges. Those borrowers will make purchases for one or more months, then have a "eureka" moment, after which they will implement the optimal strategy. ${ }^{17}$ We categorize account holders by the speed with which they converge on the optimal strategy (and stop using the "balance transfer" card for new purchases).

About one third of all customers who make a balance transfer do no spending on the new card, thus implementing the optimal strategy immediately. Slightly more than one third of customers who make a balance transfer spend on the new card every month during the promotional period, thus never experiencing a eureka moment. The remaining third of customers experience eureka moments between the first and sixth months.

The left panel of figure 6 plots the frequency of eureka moments for each age group. The plot of those who never experience a eureka moment - that is, who never implement the optimal strategy - is a pronounced U-shape by age. The plot of those who implement the optimal strategy immediately (the "Month One" line) is a pronounced inverted U-shape by age. Plots for eureka moments in the interior of the time space (that is Eureka moments that occur strictly after Month One) are flat. ${ }^{18}$ The No Eureka line implies that the groups with the greatest frequency of maximal confusion are younger adults and older adults. The group with the greatest frequency of optimality is middle-aged adults.

The right panel of figure 6 plots the fitted values of the age splines for the propensity of ever experiencing a "Eureka" moment. Note that, unlike the other figures, higher values indicate a smaller propensity to make mistakes. Consistent with the evidence so far, we observe a performance peak in middle age. ${ }^{19}$ In

\footnotetext{
${ }^{17}$ We thank Robert Barro for drawing our attention to this type of potentially tricky financial product. We also note that changes in regulation proposed in May 2008 by the Federal Reserve, National Credit Union Association and Office of Thrift Supervision would forbid banks from applying payments solely to the balances transferred.

${ }^{18}$ Although the average percent of borrowers for each of the intermediate categories is small-on the order of five percentsumming over all the months yields a fraction of borrowers equal to the one-third of total borrowers.

${ }^{19} \mathrm{We}$ also check for the possibilities that the relatively old and young might have lower levels of debt or less access to credit than the middle aged. We find that neither credit card debt levels nor the number of open credit cards vary in economically or statisically significant ways by age.
} 


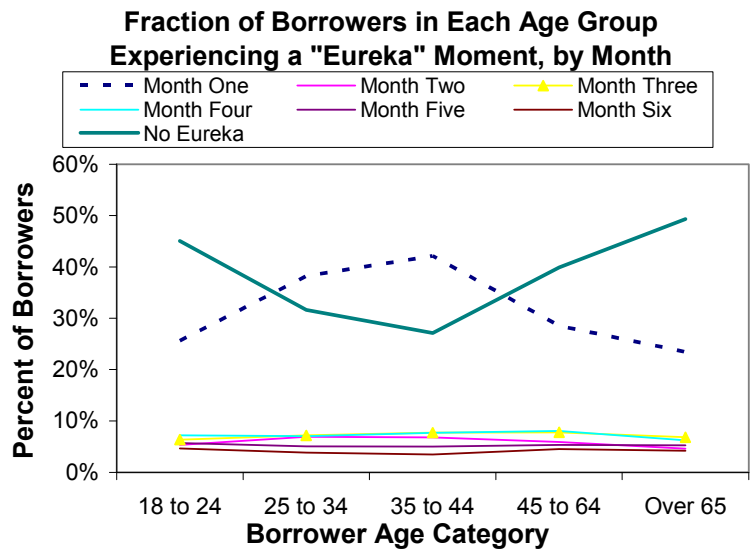

Propensity of Ever Experiencing a "Eureka" Moment by Borrower Age

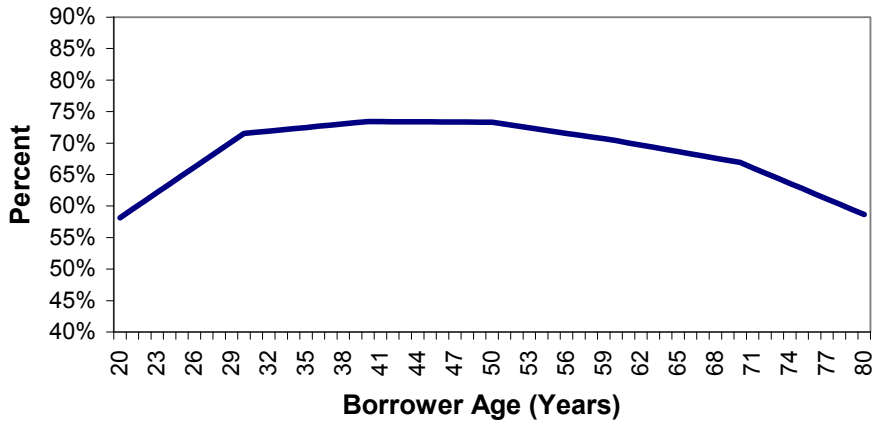

Figure 6: The left panel plots the fraction of borrowers in each age category who experience a "eureka" moment in a given month. The right panel plots the propensity of ever experiencing a "eureka" moment by borrower age.

section 4.4, we generally discuss possible explanations which may apply to this and the other markets we consider. ${ }^{20}$

\subsubsection{Home Equity Loans and Lines of Credit}

Figure 7 plots the fitted values on the splines for age for home equity loans and lines of credit. The lines have pronounced U-shape, showing that the relatively young and old have APRs that can be fifty basis points or more higher than the middle-aged.

For these two examples, we believe we understand the mechanism leading to the differences by age: borrower misestimation of house values. The amount of collateral offered by the borrower, as measured by the loan-to-value (LTV) ratio, is an important determinant of loan APRs. Higher LTVs imply higher APRs, since the fraction of collateral is lower. At the financial institution that provided our data, borrowers first estimate their home values, and ask for a credit loan or credit line falling into one of three categories depending on the implied borrower-generated LTV estimate. The categories correspond to LTVs of 80 percent or less; LTVs of between 80 and 90 percent; and LTVs of 90 percent or greater. The financial institution then independently verifies the house value using an industry-standard methodology and constructs an LTC measure. The institution's LTV can therefore differ from the borrower's LTV. ${ }^{21}$

\footnotetext{
${ }^{20}$ We discuss the economic magnitudes of the costs for this and the following studies below. We also present in the on-line Appendix a formal hypothesis test for the U-shape; we reject the null hypothesis of a flat age-based pattern in 9 out of 10 cases.

${ }^{21}$ Agarwal et al. (2009) provides evidence that younger households are more likely to overstate their house value and older households are more likely to understate their house values. To get a better understanding of the incentives and compensation of the loan officers at this financial institution see Agarwal, Ambrose, Chomsisengphet, and Liu (2007). Bucks and Pence (2006) present evidence that borrowers do not generally have accurate estimates of their house values.
} 
Home Equity Loan and Line of Credit APR by Borrower Age

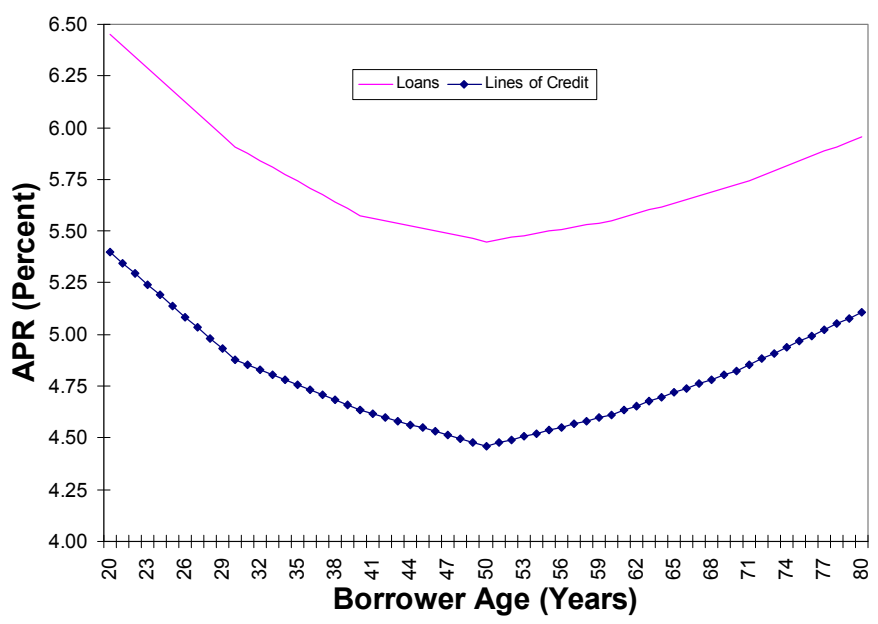

Figure 7: Home equity loan and line of credit APR by borrower age. The figure plots the residual effect of age after controlling for other observable characteristics, such as log(income) and measures of creditworthiness.

Loan pricing depends on the LTV category that the borrower falls into and not on the specific LTV value within that category. ${ }^{22}$ If the borrower has overestimated the value of the house, so that the financial institution's LTV is higher than the borrower's LTV, the institution will direct the buyer to a different loan with a higher interest rate corresponding to the higher LTV. In such circumstances, the loan officer is also given some discretion to depart from the financial institution's normal pricing schedule to offer a higher interest rate than the officer would have offered to a borrower who had correctly estimated her LTV. If the borrower has underestimated the value of the house, however, the financial institution need not direct the buyer to a loan with a lower interest rate corresponding to the financial institution's LTV (which is lower in this case than the borrower's LTV); the loan officer may simply choose to offer the higher interest rate associated with the borrower's LTV, instead of lowering the rate to reflect the lower financial institution's LTV. ${ }^{23}$

Since the APR paid depends on the LTV category and not the LTV itself, home value misestimation leads to higher interest rate payments if the category of the bank-LTV differs from the category of the borrower-LTV. If, in contrast, the borrower's estimated LTV was 60, but the true LTV was 70, the

\footnotetext{
${ }^{22}$ We have verified this practice in our dataset by regressing the APR on both the level of the bank-LTV and dummy variables for whether the bank-LTV falls into one of the three categories. Only the coefficients on the dummy variables were statistically and economically significant. Ben-David (2007) also shows that there are discrete jumps in lending rates at LTV cutoff points.

${ }^{23}$ Even if the financial institution's estimate of the true house value is inaccurate, that misestimation will not matter for the borrower as long as other institutions use the same methodology.
} 

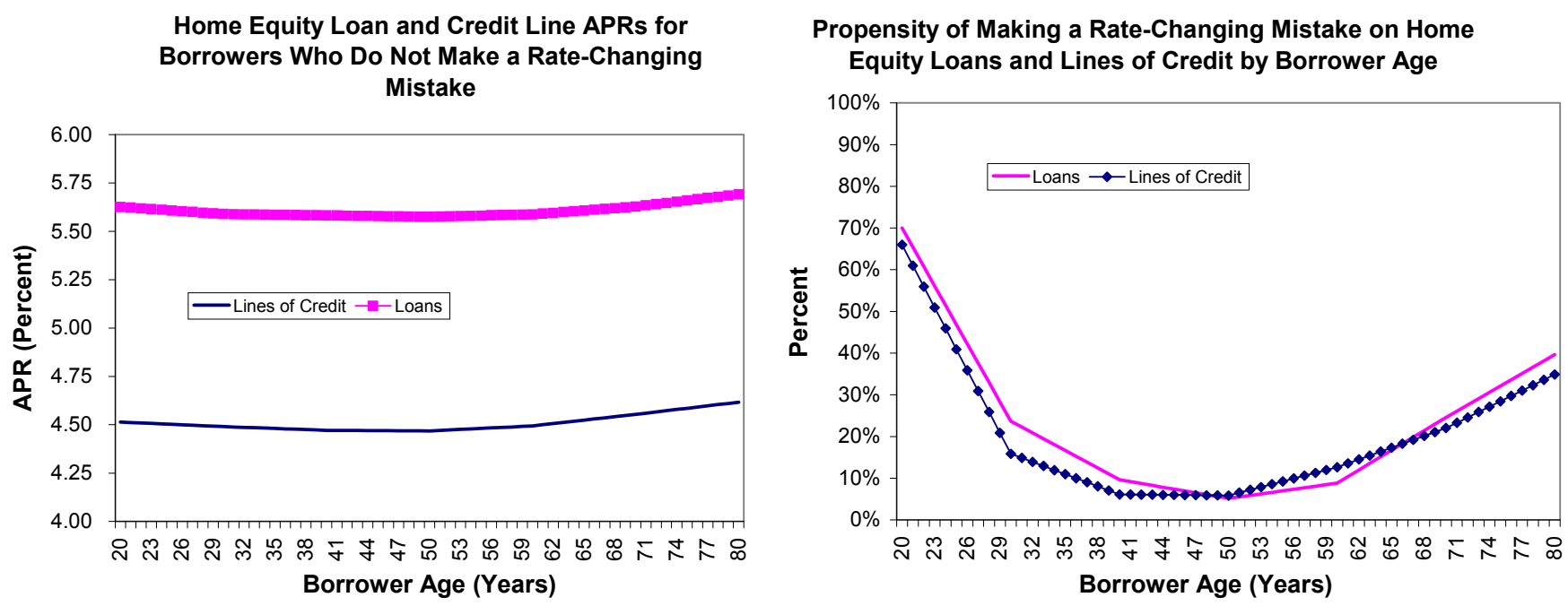

Figure 8: The left panel plots the residual effects of age on home equity loan and line of credit APRs for those borrowers who do not make a rate-changing mistake. The right panel plots the propensity of making a rate-changing mistake by age.

borrower would still qualify for the highest quality loan category $(\mathrm{LTV}<80)$ and would not suffer an effective interest rate penalty. We define a Rate-Changing Mistake ( $R C M$ ) to have occurred when the borrower-LTV category differs from the bank-LTV category - for instance, when the borrower estimates an LTV of 85 but the bank calculates an LTV of 75 (or vice versa). ${ }^{24}$ We find that, on average, making a RCM increases the APR by 125 basis points for loans and 150 basis points for lines (controlling for other variables, but not age).

To highlight the importance of RCMs, we first study the APR for consumers who do not make a RateChanging Mistake. The left panel of figure 8 plots the fitted values from re-estimating the regressions of APRs on borrower characteristics and age splines but now conditioning on borrowers who do not make a RCM. The plots show only slight differences in APR paid by age. The APR difference for a home equity loan for a borrower at age 70 over a borrower at age 50 has shrunk from 36 basis points to 8 basis points; for a home equity line of credit, it has shrunk from 28 basis points to 4 basis points. For a borrower at age 20, the APR difference over a borrower at age 50 has shrunk to 3 basis points for home equity loans and 3 basis points for home equity lines of credit. We conclude that, conditional on not making a RCM, the APR is essentially flat with age. So the U-shape of the APR is primarily driven by Rate-Changing Mistakes.

We next study who makes a RCM. The right panel of figure 8 plots the probability of making a RCM by age for home equity loans and home equity lines, respectively. The figures show U-shapes for both. Borrowers at age 70 have a 16 (19) percentage point greater chance of making a mistake than borrowers

\footnotetext{
${ }^{24}$ Recall that the categories are less than 80,80 to 90 , and greater than 90 .
} 
at age 50 for home equity loans (lines); borrowers at age 20 have a 35 (41) percentage point greater chance of making a mistake than borrowers at age 50. The unconditional average probability of making a rate-changing mistake is 24 percent for loans and 18 percent for lines.

This age effect is consistent with the cost of a RCM calculated above and the additional probability of making a RCM by age. For example, a 70-year old has a 16 and 19 percent additional chance of making a RCM for loans and lines, respectively. Multiplying this by the average APR cost of a RCM for home equity lines and loans of about 150 and 125 basis points, respectively, gives an expected incremental APR paid of about 26 and 23 basis points. These differences are very close to the estimated differences of about 23 basis points for loans and of about 28 basis points for lines.

We conclude that in the example of home equity lines and loans, we have identified the channel for the U-shape of the APR as a function of age (as always, controlling for other characteristics). Younger and older consumers have a greater tendency to misestimate the value of their house, which leads to a RCM, which leads them to borrow at an increased APR. On the other hand, for consumers who do not make a Rate-Changing Mistake, the APR is essentially independent of age. Hence, this channel explains quantitatively the higher APR paid by younger and older adults.

Given the large costs associated with a Rate-Changing Mistake, one might ask why borrowers do not make greater effort to more accurately estimate their house values. One possibility is that potential borrowers may not be aware that credit terms will differ by LTV category; or, even if they are aware of this fact, they may not know how much the terms differ by category. This particular aspect of loan pricing may thus be a shrouded attribute, in the sense of Gabaix and Laibson (2006).

\subsection{Seven Other Financial Choices}

In this section, we present results on all seven other financial choices we studied: credit card interest rates; auto loan interest rates; mortgage interest rates; small business credit card interest rates; and three types of credit card fees (over limit, late payment, and cash advance). In all seven cases, plots of fitted values on the coefficients on the age splines are U-shaped by age, although the magnitudes of the U-shapes vary by financial choice. In each case, in the underlying regressions we have tried to control for other variables that might explain differences in the cost of financial choices by age. Data and regression results are presented in the online appendix. 


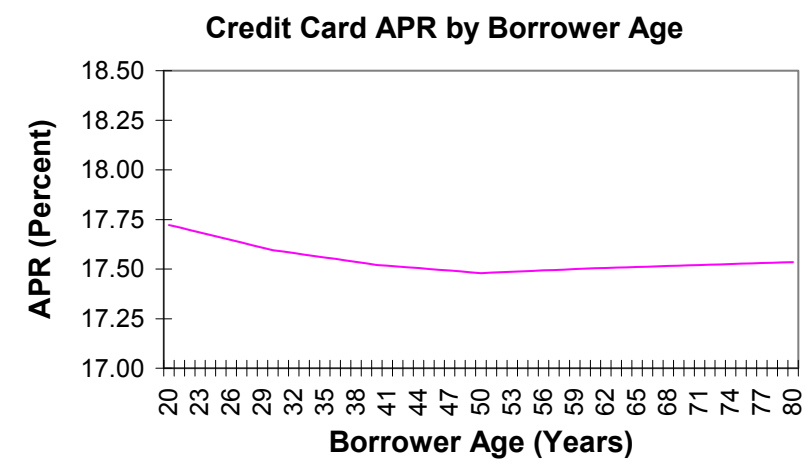

Mortgage APR by Borrower Age

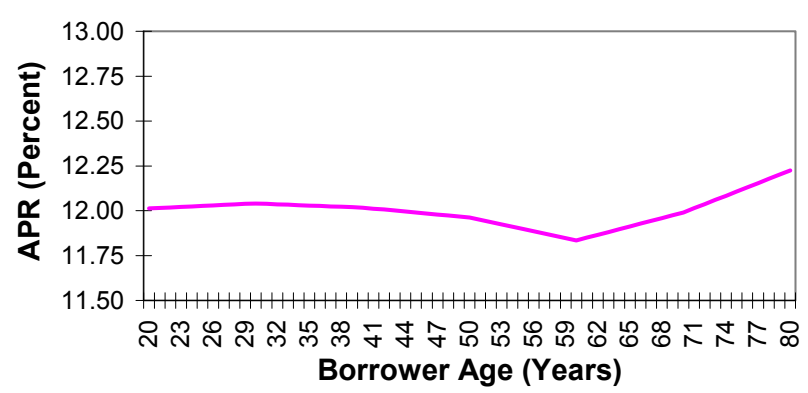

Auto Loan APR by Borrower Age

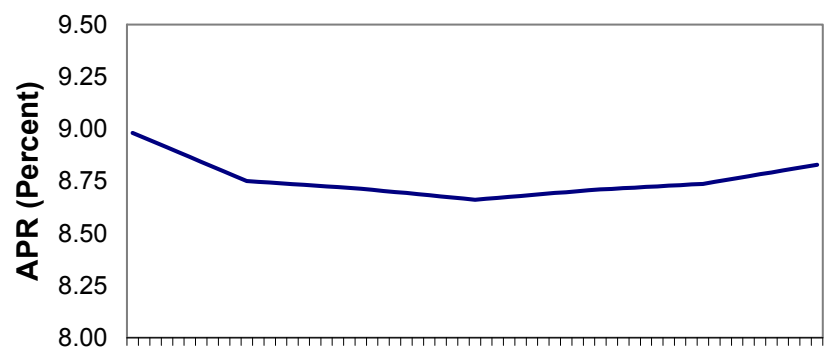

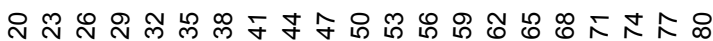
Borrower Age (Years)

\section{Small Business Credit Card APR by Borrower Age}

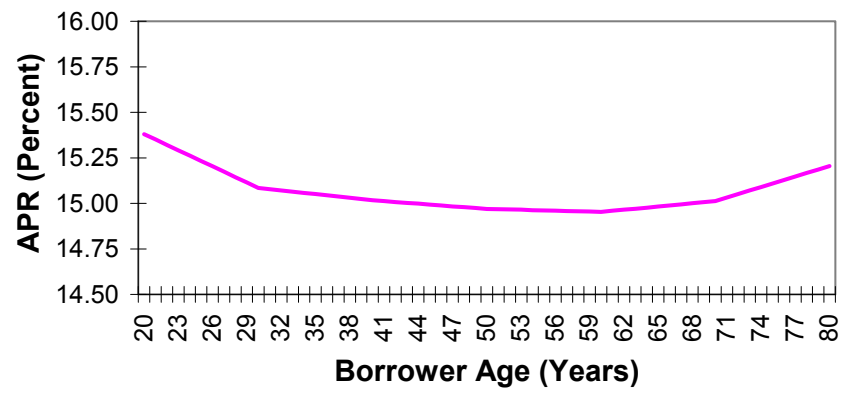

Frequency of Fee Payment by Borrower Age

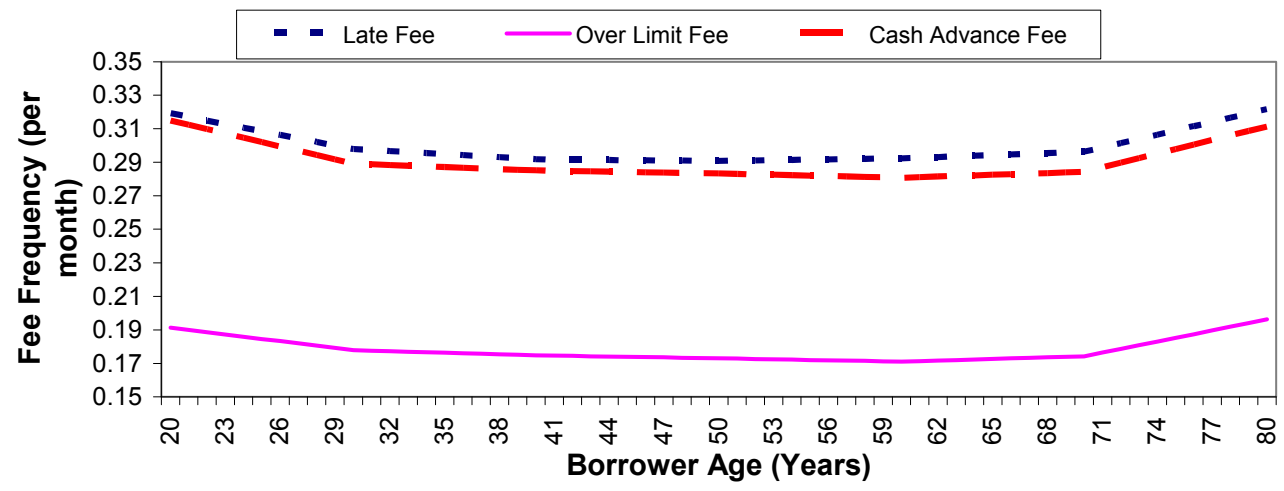

Figure 9: These figures plot the residual effects of age after controlling for other characteristics, on APRs or propensity to pay fees. 


\begin{tabular}{|l|r|r|}
\hline & Age of Peak Performance & Standard Error \\
\hline Home Equity Loans-APR & 55.9 & 4.2 \\
Home Equity Lines-APR & 53.3 & 5.2 \\
Eureka Moment & 45.8 & 7.9 \\
Credit Card-APR & 50.3 & 6.0 \\
Auto Loans-APR & 49.6 & 5.0 \\
Mortgage-APR & 56.0 & 8.0 \\
Small Business Credit Card-APR & 61.8 & 7.9 \\
Credit Card Late Fee & 51.9 & 4.9 \\
Credit Card Over Limit Fee & 54.0 & 5.0 \\
Credit Card Cash Advance Fee & 54.8 & 4.9 \\
\hline Average over the 10 Studies & 53.3 & 4.3 \\
\hline
\end{tabular}

Table 3: Age at which financial mistakes are minimized, for each case study

\subsection{The Peak of Performance}

Visual inspection of the age splines for the ten case studies suggests that fees and interest rates paid are minimized in the late 40 s or early 50s. To estimate the minimum more precisely, we re-estimate each model, replacing the splines from 40 to 50 and from 50 to 60 with a single spline running from 40 to 60 , and the square of that spline. In Table 3, we report the location of the "age of reason": the point at which financial mistakes are minimized. The mean age of reason appears to be at 53.3 years. The standard deviation calculated by treating each study as a single data point is 4.3 years.

The study with the lowest age of peak performance is the eureka moment task. Interestingly, the eureka task is arguable the most dependent on analytic capacity and least dependent on experience (since the kinds of balance transfer offers that we study were new financial products when our data was collected). It is not surprising that the peak age for succeeding at that task would be earlier than the peak age for the other tasks. However, since we do not have a rigorous measure of the "difficulty" of a task, the interpretation of the eureka case remains speculative.

It would be useful to measure such effects in other decision domains (e.g. savings choices, asset allocation choices beyond stocks, and healthcare choices). We have described a simple procedure for doing this: (1) identify the general shape of age effects, as in equation (1), using controls and age splines; (2) estimate a linear-quadratic form to localize the peak of performance. Korniotis and Kumar (2008a) confirm our U-shape hypothesis in their study of investment skills.

It may be also possible to develop models that predict the location of peak performance. There is a growing consensus that analytically intensive problems - like mathematics - are associated with younger peak ages (see Simonton 1988, Galenson 2005, and Weinberg and Galenson 2005). Analogously, problems that require more experiential training have older peak ages. For instance, Jones (2006) finds that the peak age for natural scientists has drifted higher over the twentieth century. Relative to 100 years ago, more experience now needs to be accumulated to reach the cutting edge of scientific fields. In our third case study, we found that what is arguably the most analytically demanding task - deducing the best way to exploit "interest-free" balance transfers - is associated with the youngest age of peak performance. It 
would be useful to study the association between analytically demanding problems and young peak ages.

\subsection{Possible Explanations}

Each credit market has idiosyncratic factors that may contribute to the hump-shaped age patterns that we have measured. The recurrence of that hump-shaped pattern across all ten outcomes suggests that the regularities may also have some common underlying explanations. In this section, we discuss such common explanations. We consider cognitive age effects, selection effects, and cohort effects. We do not find evidence for selection effects or cohort effects that could explain our results, but our data does not enable us to definitively rule out these factors.

Age-related Effects. One possible explanation for the U-shaped pattern of mistakes is a combination of two age-based effects: diminishing returns to learning and age-based declines in analytic function, as we saw in section 2. Relatively young borrowers have low levels of experience and a high degree of analytic function, while older borrowers have high levels of experience but relatively lower levels of analytic function. We discuss these mechanisms below and explain how these offsetting lifecycle trends produce a hump-shaped pattern in financial sophistication.

This hypothesis above also provides us with a possible explanation of the location of the peak of performance. We hypothesize that peak performance reflects a trade-off between rising experience and declining analytic function. If so, the sooner people start experimenting with a financial product, the earlier the peak of performance should be. To evaluate this hypothesis for each financial product, we first construct the distribution of the ages of the users of this product in our data set and calculate the age at the 10th percentile of the distribution, which we call "age $\mathrm{e}_{10 \%}$ ". This is a proxy for the age at which people start using the product. We then regress the location of the peak of performance on age $10 \%$. We find: Peak $=33+0.71 \times$ age $_{10 \%},\left(R^{2}=0.62, n=10\right.$; the s.e. on the coefficients are respectively 5.7 and 0.19). ${ }^{25}$ We reject the null hypothesis of no relationship between Peak and age $10 \%$. Products that are used later in life tend to have a later performance peak.

Selection Effects. The cross-sectional age effects that we measure are probably also partially attributable to differences in the pool of borrowers by age group: a selection effect. For example, in the total population of US households, retirees borrow less than other adults (matching a prediction of the lifecycle consumption model). Older adults who are borrowing may therefore be unrepresentative of the population of all older adults. Likewise, older adults who are borrowing might be less financially savvy than 30 or 50 year-old borrowers (since borrowing might be less of a "bad signal" at these lower ages). ${ }^{26}$ Below, we describe several ways of measuring of the role of sample selection in determining our results..

Lack of financial sophistication in relatively older (or younger) borrowers should be reflected in the borrowers having lower levels of education, income, or net worth compared with non-borrowers of the

\footnotetext{
${ }^{25}$ The effect is robust to the choice of the 10th percentile. For instance, the correlation between peak age and median age (of users for the product, in our data set) is 0.83 .

${ }^{26}$ They could also be riskier, in ways not captured by the risk measures we include, a hypothesis that we consider (and reject) below.
} 
same age. To make such comparisons, we calculate the ratio of the median characteristic of borrowers to the median characteristics of all members of the respective age group. We want to determine whether these ratios differ across different age groups. In other words, are borrowers differentially selected across different age groups? Since our proprietary dataset only contains information on borrowers we cannot use our dataset to make these calculations. However, we can make such comparisons using the Survey of Consumer Finances (SCF).

For the 1989, 1998, 2001, and 2004 surveys, we compute the ratios of income, education, and net worth for borrowers to the population as a whole, by age group; results are presented in the online appendix. We find that within age groups, borrowers almost always have higher levels of income and education than the population as a whole, and often have higher levels of net worth. Moroever, older borrowers appear to have relatively higher levels of income and education relative to their peers than middle-aged borrowers do. Hence these data suggest that selection effects by age go in the opposite direction: older borrowers appear to be a better pool than middle-aged borrowers.

We present additional results in the online appendix showing that borrowing by age does not appear to vary by race, and that older borrowers do not appear to have disproportionately lower incomes, FICO score, or higher debt levels. None of these analyses lend support to the idea that sample selection effects contribute to the U-shape patterns that we see in the data. If in fact a higher proportion of older borrowers are unsophisticated, then that lack of sophistication is somehow evident only in borrowing rates and fee payments, and not in credit scores, default rates, education levels, income or net worth. While we concede that this is a logical possibility, we do not know of an explanation for why such a lack of sophistication would appear so selectively in the data.

Cohort Effects. Older borrowers in our cross-section are likely to make relatively less sophisticated financial choices because they belong to cohorts that have less human capital than younger cohorts (e.g. Flynn, 1984). For example, older cohorts may be less mathematically literate than younger cohorts. In addition, older cohorts may use less sophisticated search technologies - for instance, older cohorts may be less inclined to use the internet to compare financial products. Finally, older cohorts may have grown up with different financial products than the products that are now available from financial intermediaries.

In the absence of a true panel dataset with information of twenty years or more, we cannot measure the role of cohort effects to explain the U-shape relative to other explanations. However, several facts make us think that cohort effects do not provide a complete explanation for the U-shaped patterns in our data.

First, education-based cohort effects do not explain the pattern of declining mistakes that we observe over the first half of the adult lifecycle. Second, we observe the U-shaped pattern over a broad range of products; while some of these products, such as mortgages, have seen substantial changes in their institutional characteristics over time, others, such as auto loans, have not. Third, if cohort effects were important, we would expect to see differences in APRs between male and female borrowers on the grounds that the current cohort of older female borrowers has tended to be less involved in financial decision-making than their male contemporaries. We find no substantive differences between the groups. Finally, for two products-auto loans and credit cards-we have data from 1992, ten years earlier than the data used for our 
other studies. Replicating our analysis for these data show the same U-shapes.

In summary, cohort effects are probably present in our data, though we doubt that they play an important role in explaining the U-shaped pattern. Cohort effects are most likely to make some contribution to the decline in performance that we measure after middle age. The improvement in performance up to middle age is harder to explain with cohort stories, though some preference-based cohort story might be generating this pattern. ${ }^{27}$

Risk Effects. Some of our results could be driven by unobserved variation in default risk that is not reflected in the risk measures - like FICO - that we use as control variables. For instance, the U-shape of APRs could be due to a U-shape of default by age. We test this alternative hypothesis by analyzing default rates of credit cards, auto loans, and home equity loans and credit lines. Specifically, we estimate a linear regression in which the default rate is modeled as a weighted sum of an age spline, log income, and all of the standard risk measures that are in our data. When we plot fitted values by age, we find a pronounced inverted U-shape for home equity loans and lines-implying that the young and old have lower default rates (see the online appendix for the chart). Credit cards and auto loans show a slight inverted U-shape, and small business credit cards are about flat. Hence these results contradict the hypothesis that our APR results are driven by an unmeasured default risk. Finally, note that age-dependent default risks would not explain the observed patterns in credit card fee payments or in the suboptimal use of credit card balance transfers.

Opportunity Cost of Time. Some age effects could be generated by age-variation in the opportunity cost of time (Aguiar and Hurst, 2007). However, standard opportunity-cost effects would predict that retirees pay lower prices, which is not what we observe in our data. Nevertheless, our findings and those of the Aguiar and Hurst article are not contradictory. Shopping for a familiar commodity - for instance, a gallon of milk - is much less analytically demanding than shopping for a complicated and somewhat unfamiliar product that can differ across many dimensions - for instance, a mortgage. Hence, we are not surprised to see older adults shop more effectively for food at the same time that they lose ground in relatively complex domains - like shopping for mortgage. In addition, shopping at stores and supermarkets may be a more pleasant activity than shopping at banks and other lenders, leading consumers to do more intensive shopping for food than for loans.

The 2007 Survey of Consumer Finances provides some support for the idea that shopping intensity for borrowing decreases with age. That survey asked borrowers whether they shop around for borrowing money or obtaining credit a great deal, moderately, or not at all. For borrowers under age 35, 24 percent report shopping around a great deal, 60 percent moderately, and 15 percent not at all. The corresponding figures for those aged 75 or greater are 15 percent for shopping a great deal, 40 percent for shopping moderately, and 46 percent for not shopping at all. A full table of results by SCF age class, and the text of the survey question, are provided in the on-line Appendix.

Discrimination and Other Supply Factor. The presence of age effects might also be interpreted as evidence for some kind of age discrimination. Banks may explicitly choose to charge older and younger

\footnotetext{
${ }^{27}$ See Malmendier and Nagel (2008) for examples of preference based cohort effects.
} 
borrowers higher APRs, or may simply market products that happen to have higher APRs or fees more aggressively to the young or old. We believe these explanations to be unlikely for two reasons. First, the U-shaped pattern shows up in contexts such as fee payments and failures to optimally use balance transfer offers in which discrimination is not relevant (since the products are the same and all card holders face the same rules). Second, firms avoid age discrimination for legal reasons or to avoid the costs of negative publicity. $^{28}$

\subsection{On the Economic Magnitude of the Effects}

The effects we find have a wide range of dollar magnitudes, reported in Table 4 . We estimate that, for home-equity lines of credit, 75 -year-olds pay about $\$ 265$ more each year than 50-year-olds, and 25-year-olds pay about $\$ 295$ more. For other quantities, say, credit card fees, the implied age differentials are small roughly $\$ 10-\$ 20$ per year for each kind of fee. The importance of the U-shaped effects we estimate goes beyond the economic significance of each individual choice, however: it lies in the fact that the appearance of a U-shaped pattern of costs in such a wide variety of circumstances points to a phenomenon that might apply to many areas. ${ }^{29}$ An important question is whether the U-shape of mistakes translates into other decision choice domains, including saving, asset allocation, and healthcare.

In domains in which we do not have data, the effects might be larger. For instance, our sample probably does not contain older adults with acute dementia, for which the effects might be stronger. In addition, section 7 we present a quantification of the fraction of GDP that may be wasted because of poor financial decision making.

\section{Other work on economic decision-making over the lifecycle}

Our analysis is part of recent literature studying the effects of aging and cognitive function on the use of financial instruments (Willis 2007, McArdle et al 2009). This literature is part of a broader literature on "household finance" (Campbell 2006). In their work on financial literacy, Lusardi and Mitchell find evidence consistent with an inverse-U shape of financial proficiency. Lusardi and Mitchell (2006) find a decline in financial knowledge after age 50. Lusardi and Mitchell (2007) also find an inverse U-shape in the mastery of basic financial concepts, such as the ability to calculate percentages or simple divisions.

In light of our findings, other researchers have offered to look for age patterns of financial mistakes in their own data sets. Lucia Dunn has reported to us that the Ohio State Survey on credit cards shows a U-shaped pattern of credit card APR terms by age (Dunn, personal communication). Fiona Scott Morton has reported that in her data set of indirect auto loans (made by banks and finance companies using the dealer as an intermediary; see Scott Morton et al., 2003), loan markups show a U-shaped pattern (Scott Morton, personal communication). Luigi Guiso finds that, when picking stocks, consumers achieve

\footnotetext{
${ }^{28}$ Charles, Hurst and Stephens (2008) show that racial differences in lending rates exist at auto finance companies, but not at banks.

${ }^{29}$ For example, Korniotis and Kumar (2008a) confirm our U-shape hypothesis in their study of investment skills.
} 


\begin{tabular}{|c|c|c|c|c|}
\hline \multicolumn{5}{|c|}{ Cost by Product } \\
\hline \multirow{2}{*}{ Product } & APR (bp) or Probability (\%) Difference & \multicolumn{2}{c|}{ Annual Cost Difference } \\
\cline { 2 - 5 } & Age 25-Age 50 & Age 75-Age 50 & Age 25-Age 50 & Age 75-Age 50 \\
\hline Home Equity Loans & 73 & 40 & $\$ 284$ & $\$ 146$ \\
\hline Home Equity Lines & 68 & 51 & $\$ 296$ & $\$ 265$ \\
\hline "Eureka" & 8 & 11 & $\$ 37$ & $\$ 13$ \\
\hline Credit Card APR & 17 & 5 & $\$ 2$ & $\$ 1$ \\
\hline Auto Loans & 20 & 12 & $\$ 8$ & $\$ 4$ \\
\hline Mortgage & 6 & 15 & $\$ 25$ & $\$ 62$ \\
\hline Small Business Credit Card & 26 & 14 & $\$ 3$ & $\$ 2$ \\
\hline Credit Card Late Fee & 2 & 2 & $\$ 8$ & $\$ 8$ \\
\hline Credit Card Over Limit Fee & 1 & 1 & $\$ 4$ & $\$ 4$ \\
\hline Credit Card Cash Advance Fee & 2 & 1 & $\$ 8$ & $\$ 4$ \\
\hline
\end{tabular}

Table 4: This table computes the difference in annual costs of each product borne by 25-year-old and 75 -year-old borrowers relative to 50-year-old borrowers. For home equity loans and lines of credit, credit cards, auto loans, mortgages, and small business credit cards, the annual cost difference is the product of the APR difference and the average debt levels by age given in the on-line Appendix. For "Eureka," it is the probability difference of experiencing a "eureka" moment multiplied by the APR difference multiplied by the amount of the balance transferred. For the three types of credit card fees, it is the probability difference of paying the fee multiplied by a fee amount of $\$ 35$. For these last three, the calculations likely understate the amount of the fee, since they do not incorporate interest rate changes that may be triggered by multiple fee payments or the interest paid on cash advance balances.

their best Sharpe ratios at about age 43, and this effect appears to be entirely driven by the participation margin (Guiso, personal communication). Ernesto Villanueva finds that mortgage APRs in Spanish survey data (comparable to the U.S. Survey of Consumer Finances) are U-shaped by age (Villanueva, personal communication).

A relationship between age and performance has been noted in many nonfinancial contexts. Survey data suggests that labor earnings peak around age 50 (Gourinchas and Parker, 2002) or after about 30 years of experience (Murphy and Welch, 1990). Shue and Luttmer (forth.) find that older and younger voters disproportionately make more errors in voting. Graham, Harvey and Puri (2008) find that older CEOs tend to be more risk averse. ${ }^{30}$

A recent literature reports systematic differences in "rationality" between groups of people, particularly in financial decision-making. Schnolnick, Massoud, and Saunders (2008) find that more educated people make fewer mistakes on their credit cards, and Agarwal, Driscoll, Gabaix and Laibson (2009) reach a similar conclusion concerning wealthier people. Stango and Zinman (2008) document that naive consumers substantially underestimate loan interest rates when inferred from principal, maturity, and monthly payments. Korniotis and Kumar (2008b) find that smarter investors obtain better risk-adjusted returns (see also Korniotis and Kumar (forth.)). In experimental contexts, Frederick (2005) identifies a measure of "analytical IQ": people with higher scores on cognitive ability tasks tend to exhibit fewer/weaker psy-

\footnotetext{
${ }^{30}$ See Simonton (1988) for a survey.
} 
chological biases. Benjamin, Brown, and Shapiro (2006) find that subjects with higher test scores, or less cognitive load, display fewer behavioral biases.

Several researchers have looked at the response of consumers to low, introductory credit card rates ('teaser' rates) and at the persistence of otherwise high interest rates. Shui and Ausubel (2004) show that consumers prefer credit card contracts with low initial rates for a short period of time to ones with somewhat higher rates for a longer period of time, even when the latter is ex post more beneficial. Consumers also appear 'reluctant' to switch contracts (Agarwal. et. al. 2007). DellaVigna and Malmendier (2004) theorize that financial institutions set the terms of credit card contracts to reflect consumers' poor forecasting ability over their future consumption. Many of those effects are discussed in "behavioral industrial organization," a literature that documents and studies markets with behavioral consumers and rational firms: examples from this literature include DellaVigna and Malmendier (2004), Gabaix and Laibson (2006), Heidhues and Koszegi (2008), Malmendier and Shanthikumar (2007), Mullainathan and Shleifer (2005), Spiegler (2006). In some of those papers, it is important to have both naive and sophisticated consumers. Our paper suggests than those naive consumers will disproportionately be younger and older adults.

\section{$6 \quad$ Regulatory responses}

In this section, we discuss nine mutually compatible policy options (and some hybrids). We discuss the policy options both specifically with respect to older adults and more generally with respect to regulations that may be appropriate for financial decision-makers of all ages.

We analyze the pros and cons of these different regulatory models, without arguing for adoption of any one of them. Strong regulatory interventions, like those we discuss below, have the potential to generate large social benefits and large social costs.

\subsection{Nine policy frameworks}

The nine policy options are discussed in approximate order from the least paternalistic to the most paternalistic. This ordering is somewhat arbitrary since the options have multiple dimensions which are not generally ordered in the same way.

\subsubsection{Laissez faire}

Laissez faire is surely not the first-best policy. We have already pointed out that half of decision-makers between age 80 and 89 are significantly cognitively impaired. Competitive equilibrium is unlikely to be characterized by efficient competition when agents make significant cognitive errors.

For example, there is a growing body of anecdotal evidence that over-priced financial products are being targeted at older adults. The competitive equilibrium works as follows: Rents arise, because older adults will make bad decisions (e.g., overpaying for financial services, or simply losing their money in fraudulent schemes). The rents are partially dissipated because aggressive/manipulative sales tactics are costly. Moreover, when the marketing behavior is fraudulent, the seller faces probabilistic legal punishment. 
In equilibrium, the zero-profit condition applies, but the social allocation is inefficient. Intuitively, for the seller to spend $\$ 1$ of her own resources (e.g. time, probabilistic legal defense fees) to convince a pool of older adults into giving her rents of $\$ 1$, generates a social dead-weight loss of $\$ 1$ and an excess profit of $\$ 0$. In equilibrium, wasteful marketing and bad products will survive even if competition eliminates all excess profits. ${ }^{31}$

However, laissez faire policies are nevertheless serious candidates on our list of optimal policies, since the laissez faire approach could be second-best optimal. Strong regulatory interventions are problematic for many familiar reasons. Even well-intentioned policy-makers may make mistakes. Regulations are usually administratively costly. Regulations will harm the interests of households who are financially sophisticated or who have sophisticated and trustworthy advisors. Finally, policy-makers may have conflicts of interest. For these reasons, we do not rule out laissez faire policies.

In addition, laissez faire policies are compatible with voluntary "advanced directives." Specifically, rational households which recognize the possibility of their own future cognitive decline should set up ex-ante protective mechanisms, like family oversight, financial advisers, and formal trusts.

However, such delegation-based solutions are limited by seven factors: (1) failure to understand, when completely cognitively healthy, the possibility of one's own future cognitive decline; (2) the mistaken belief that one will recognize one's own cognitive decline as it occurs, and respond optimally to it, by progressively delegating decision-making as the decline occurs; (3) procrastination in establishing advanced directives; (4) difficulties that external parties face in determining when key thresholds for cognitive decline have been crossed, so that control can be transferred efficiently; (5) administrative cost, particularly when the protection is being provided by a third party like a bank or a law office; (6) a lack of financially sophisticated family members, who are able to make good financial decisions for the declining adult; (7) a lack of trustworthy family members.

Item seven is particularly important, since family members are often counter-intuitively poorly positioned to play an oversight role. Of course, many family members have strong intra-family altruism and intimate knowledge of each other's preferences. However, family members also face a conflict of interest since they are usually the primary residual claimants of the estate. Hence, it will often be the case that older adults do not have an unconflicted, low-cost agent to whom they can delegate decision-making authority.

\subsubsection{Disclosure}

Full and fair disclosure has been the primary goal of financial regulation systems since the 19th century. Moreover, disclosure is at the heart of many current Congressional proposals. Legislation that strengthens disclosure requirements has recently been introduced in many different domains, including mutual fund fees, 401(k) fees, and mortgage origination fees.

However, we are skeptical that improved disclosure will be effective in improving financial choices. Even

\footnotetext{
${ }^{31}$ See Gabaix and Laibson (2006) for a related argument.
} 
for cognitively healthy populations, there is scant evidence that increases in disclosure improve decisionmaking. In a series of recent studies on middle-aged adults, disclosure/education manipulations made surprisingly little difference. In one study, employees with low savings rates were randomly assigned to a treatment in which they were paid $\$ 50$ to read a short survey explaining their $401(\mathrm{k})$ plan, including a calculation of how much money they would personally gain by taking full advantage of the match. Relative to a control group, this treatment group did not change their average 401(k) savings rates (Choi et al. 2008a). The bankruptcy of Enron (and the corresponding year of intense media coverage) had no effect on the willingness of newly hired workers at other firms to choose to invest their 401(k) contributions in employer stock. This was even true for newly hired workers at other firms in Houston (Choi et al. 2005). Employer sponsored financial education seminars have little effect on 401(k) enrollment (Madrian and Shea, 2001b). A new easy-to-read prospectus proposed by the SEC - the "summary prospectus" has no effect on investor choices (Beshears et al. 2008a). Finally, making fees overwhelmingly salient does not lead investors to minimize them, even when investors are allocating real money among index funds. In one study, subjects are asked to allocate $\$ 10,000$ among four S\&P 500 index funds. To help with their choice, the subjects are told what an index fund is, given a one page summary sheet that compares the fees of the four index funds, and given the four prospectuses. Only $10 \%$ of the subjects put all $\$ 10,000$ in the S\&P 500 index fund with the lowest costs (Choi et al. 2008b).

These studies were all conducted on adults in the workforce. It is likely that disclosure would be even less effective on retired older adults experiencing significant declines in cognitive function.

Finally, we wish to emphasize that we are not opposed to disclosure. There is no evidence that it hurts and it is certainly possible that it makes a small positive difference. For example, the summary prospectus study mentioned above found that shortening and simplifying mutual fund prospectuses saved trees and decision time, even if didn't have any effect on the chosen asset allocation. So when improved disclosure is inexpensive (or cost-reducing), it is surely a good idea. But we should not expect disclosure to resolve our regulatory concerns.

\subsubsection{Libertarian paternalism - advice, defaults, and other "nudges"}

In the last decade, a growing body of research has suggested that gentle institutional "nudges" can improve behavior without mandating any particular behavior. Thaler and Sunstein (2003, 2008) refer to such interventions as libertarian paternalism. The social planner is acting like a paternalist by nudging behavior in one direction, but simultaneously maintaining a libertarian stance by allowing the actor to reject the nudge (at minimal cost). Prominent examples in this literature include automatic (opt-out) enrollment in 401(k) plans (Madrian and Shea 2001a, Choi et al. 2002) and automatic savings rate escalators (Thaler and Benartzi 2004).

In practice, such nudges work when the nudge is aligned with the intentions of the actor ("I want to be enrolled in my 401(k) plan and I'm grateful that my employer is enrolling me automatically."). But nudges are rejected when the nudge is misaligned with the goals of the actor being nudged. For example, when workers are automatically enrolled at a savings rate that is deemed to be too high (e.g., 12\% of income), 
almost all of the workers opt out of this default contribution rate (Beshears et al. 2009). Likewise, automatic annuitization of DB accumulations is often rejected in favor of lump sum payouts (Mottola and Utkus, 2007).

Nudges succeed when the person being nudged (1) agrees with the nudge and (2) is not beset by opposing forceful nudges. In the case of 401(k) automatic enrollment, households overwhelming perceive that they save too little (Choi et al. 2002) and there is no third party that can gain a significant rent by convincing the household not to enroll in the employer's 401(k) plan. In other words, no third party has a strong incentive to nudge in the "other" direction.

Unfortunately, benevolent institutional nudges emanating from the government (or other agents) will probably not be protective for older adults. These benevolent nudges will be outweighed by malevolent nudges emanating from marketers and unscrupulous relatives. Older adults with low levels of financial literacy and/or significant cognitive impairment may be no match for highly incentivized parties with malevolent interests and ample opportunities to nudge in the wrong direction.

Here too, we aren't opposed to using nudges to partially protect older adults (and other vulnerable economic agents). However, we suspect that nudges will only be weakly protective in an environment where older adults are soft (and increasingly wealthy) targets for economic agents with conflicts of interest.

\subsection{4 "Driving" license}

Another proposal is to require that financial decision-makers be licensed if they want to make non-trivial decisions (Alesina and Lusardi, 2006). For instance, investors could be required to pass such a licensing test if they want to opt out of safe harbor investment products.

Such a licensing proposal would need to overcome several logistical problems. Can a test be devised that reliably separates qualified from unqualified investors (without generating too much type I and type II error)? Can the test be administered at a reasonable social cost? If the test is administered over the web, what would prevent coaching (by parties with conflicts of interest)? Who would be required to take the test? What would the frequency of testing be? Would this frequency be high enough to catch people as they transition (often very quickly) into a state of significant cognitive impairment? Would such a test be politically feasible if it primarily targeted older adults?

\subsubsection{Fiduciary}

Regulators could increase the fiduciary duties of individuals that sell financial products. For instance, all sales of financial products to individuals could be required to be conducted by an agent with a fiduciary duty.

The word fiduciary originates from the Latin words fides and fiducia, respectively faith and trust. Under common law, fiduciaries are legally bound to act at all times for the sole benefit and interest of a beneficiary - the principle. Moreover, the fiduciary is obligated to avoid conflicts of interest and selfdealing. Because of these legal obligations, the principle can trust the fiduciary to do the right thing. In an influential judicial decision, Benjamin Cardozo wrote, "A [fiduciary] is held to something stricter than 
the morals of the marketplace. Not honesty alone, but the punctilio of honor the most sensitive, is the standard for behavior." 32

In the United States, many types of advisers are obligated to act as fiduciaries. Lawyers, guardians, executors, trustees, conservators (of the estates of incompetent persons), corporate directors, corporate officers, and majority shareholders, all bear fiduciary duties. Investment advisers have a fiduciary duty, which is legislated in the Investment Advisers Act of 1940. As we mentioned in the introduction of this paper, the Employee Retirement Investment Savings Act (ERISA) establishes that the employer that sponsors a retirement plan - e.g., a 401(k) - bears a fiduciary duty for decisions that affect plan participants. Moreover, ERISA establishes that plan participants have the right to sue for breaches of fiduciary duty.

However, many types of financial representatives and salespeople are not fiduciaries - for example, an annuity salesperson cold-calling a potential client. It is therefore legally permissible that such salespeople receive large commissions (often shrouded from the client) for selling financial products with large markups. A substantial fraction of financial services are being sold by agents that do not have a fiduciary relationship to their clients. For example, registered representatives of securities broker-dealer firms are not considered investment advisors and consequently do not have a full fiduciary duty. Brokers' duties are established in the Securities Act of 1934, which does not set a fiduciary standard.

This implies that many workers effectively have much greater regulatory protection than retirees. 401(k) plans and other defined contribution plans are regulated by ERISA, which establishes a strong fiduciary duty. IRA's, which receive roll-over money from 401(k) accounts, have a much lower level of protection, since representatives of securities broker-dealer firms are not full-fledged fiduciaries. Of course, nobody forces retirees to roll their savings out of 401(k)'s. However, the overwhelming majority of 401(k) assets do roll out to IRA's during retirement. The financial services industry has a strong incentive to encourage this flow, since fees are usually higher outside of $401(\mathrm{k})$ accounts.

Mandating fiduciary relationships (even weak fiduciary relationships) between sellers and buyers of financial services would incent financial service firms to design and market products that meet high standards. However, mandating fiduciary relationships might also generate new administrative/compliance costs and slow down financial innovation. If these inefficiencies were considerable, a fiduciary duty could be mandated only in special circumstances - for example, only when the individual buying the financial product is above some age threshold (e.g., 75). Another partial solution would be to either (i) require that IRA asset managers have the same fiduciary duty as 401(k) plan sponsors, or (ii) strongly discourage rollovers from 401(k)'s to IRA's.

\subsubsection{Mandatory advanced directives}

We are primarily concerned with the impact of cognitive decline on financial decision-making. One way to address this problem is to require older adults to develop a financial advanced directive before they

\footnotetext{
${ }^{32}$ Though Cardozo would eventually sit on the Supreme Court, this landmark decision came from his earlier tenure on the New York Court of Appeals. Meinhard v. Salmon, 164 N.E. 545 (N.Y. 1928), held that business partners have a fiduciary duty in the course of activities associated with their partnership.
} 
reach age 70. For example, the advanced directive could be limited to one of three templates.

i. The principle appoints a standard fiduciary. This fiduciary would need to approve all "significant" financial transactions after the investor/principle turns age 75. A significant financial transaction might be defined as any transaction representing more than an age-contingent percent of the net worth of the principle. The individual would pre-set this threshold at the time the advanced directive is created. To make this process easier, there would be a default definition of "significant financial transaction," that begins at $50 \%$ of net worth at age 75 and then falls to $1 \%$ by age 110 . Sellers of financial services might not know if a particular transaction is greater than or less than the relevant threshold for a particular principle. If the seller does not get formal approval from the principle's fiduciary and it is subsequently determined that the transaction exceeded the relevant threshold, the transaction could be nullified by the principle (or the principle's representatives). In addition, the advanced directive would stipulate who would judge mental competency and how control of the principle's assets would evolve in the event that the principle was no longer mentally competent. Finally, the details of the advanced directive (including the choice of the fiduciary) could be changed at any time if the principle can demonstrate mental competency.

ii. The principle appoints a family member (or a friend) in the fiduciary role. This family member would act with a legal fiduciary duty, which would be explained to the family member. Everything else would operate the same way it would with an external fiduciary.

iii. The principle opts into a safe harbor that eliminates the need for a fiduciary. This option would appeal to people who do not have substantial assets and would therefore not find a fiduciary to be cost-effective.

Requiring a mandatory advanced directive poses several problems. First, such a mandate might be perceived as an unfair (targeted) restriction by some older adults. Second, the imposition of a fiduciary will create transactions costs. Third, the creation of a safe harbor will be politically contentious and will doubtless invoke a great deal of lobbying. An independent agency would probably need to be appointed to (partially) insulate the safe harbor regulations from political pressure.

\subsubsection{Protected assets: a lifecycle safe harbor}

A portion of a retiree's financial assets could be protected in a mandatory safe harbor. This would have three basic components, which are illustrated below.

First, an asset base would be identified. This would probably include all forms of savings that have benefited from federal tax relief, such as qualified defined contribution plans and all types of IRA's.

Second, a portion of this asset base would be safe-harbored. For example, at age $59 \frac{1}{2},{ }^{33}$ every account in

\footnotetext{
${ }^{33}$ This transfer to the safe harbor would occur just before early withdrawal penalties are terminated (at age $59 \frac{1}{2}$ ). The transfer would invoke no penalty (since the assets are staying in the retirement savings system). Individuals who try to avoid the transfer to the safe harbor (by prematurely withdrawing assets from their tax-deferred accounts) would face a $10 \%$ penalty.
} 
the asset base would be required to distribute $50 \%$ of the balance into a safe harbor account. If an investor had three different retirement accounts in the asset base, each account would automatically distribute $50 \%$ of its balance into a safe harbor account. In principle, the safe harbor account(s) could be managed by the same company that managed the original account(s), obviating the need for any direct government involvement.

Third, the investor would choose among a limited range of highly regulated low-cost options inside the safe harbor. These options might include: (1) an annuity, (2) a variable annuity, (3) a bond fund, and (4) a lifecycle fund. Finally, the account would have a minimum and a maximum rate of draw down. The minimum rate would reproduce the current rules on RMDs (required minimum distributions) from tax deferred accounts. ${ }^{34}$ The maximum rate, which would rise with age, is set to preserve the assets so they provide a non-trivial stream of retirement income until death.

Such a system would provide four benefits. First, a substantial fraction of the retiree's assets would be protected from high fees and other types of suboptimal investments. Second, because assets in the safe harbor would be pooled into a small number of investment vehicles, scale economies would be achieved (and adverse selection problems might be mitigated). Third, retirees would be (partially) constrained from spending down their assets prematurely. Fourth, society would broadly benefit because household savings would cover a larger fraction of long-term care and other medical expenses. ${ }^{35}$

At first glance, the proposal above may seem novel. But it is actually just a generalization of existing mandatory annuitization schemes that are commonplace in Europe, Latin America, and Asia (Antolin, Pugh and Stewart, 2008).

The system proposed here comes with two potential disadvantages. First, it meaningfully restricts individual choice, by requiring households to invest some of their retirement savings in a limited menu of assets and by constraining their consumption path. Second, it creates the potential for political manipulation by empowering a regulator to select (and monitor) the asset menu. As we argued above, an independent agency might be needed to insulate the regulator.

\subsubsection{Default regulatory approval - supplements model}

Until this point, we have focused on interventions that primarily target the individual investor. Regulations could instead target the financial products themselves. We now review two different regimes that take this approach. In the current subsection, we discuss the regulatory model that is used for nutritional supplements.

The Dietary Supplement Health and Education Act of 1994 established a novel regulatory framework for supplements. ${ }^{36}$ Unlike food additives and drugs, dietary supplements do not need to be approved by the Food and Drug Administration (FDA) before they are brought to market. Moreover, dietary supplements

\footnotetext{
${ }^{34}$ Note that Roth IRAs are not currently covered by lifetime RMDs.

${ }^{35}$ Under the proposal made here, fewer assets could be transferred inter-vivos to one's children, so those assets would be available to cover some of the long-term care costs that would otherwise be borne by Medicaid.

${ }^{36}$ Dietary supplements, which are also known as nutritional supplements, include vitamins, minerals, botanical/herbal remedies, fiber, fatty acids, amino acids, and other substances that are believed to improve health.
} 
are not subject to ex-ante safety and efficacy testing. Instead, the supplement manufacturer does its own due diligence, applying safety and marketing rules that have been established by the FDA. The manufacturer is responsible for ensuring that its supplement adheres to these ex-ante regulatory standards for safety and truthful labeling. The manufacturer does not even need to register the supplement with the FDA. The FDA is responsible for taking action against any unsafe supplements that it identifies in the marketplace. ${ }^{37}$

This system implies that dietary supplements have default regulatory approval. Financial products could be regulated like dietary supplements. Safety and quality standards would be established by the relevant regulator, which would typically be the Securities and Exchange Commission. A rigorous and time-consuming regulatory review process would generally not be required for a new product. Instead, financial service firms would evaluate their own products to determine whether they complied with ex-ante regulatory standards. Such a system would encourage innovation and minimize administrative costs/delays.

Naturally, this system would work well if the regulator could successfully identify socially optimal exante standards. However, the regulator might find it difficult to establish such guidelines. We also note that socially optimal standards would need to be based on the combined characteristics of the product being marketed and the investor who is purchasing that product. For instance, products that might be appropriate for young investors (e.g., an equity-based leveraged ETF), may be inappropriate for an 85 -year-old retiree.

\subsubsection{Requirement for explicit regulatory approval of financial products}

Our final framework is the regulatory model currently used by the FDA for drugs (other than dietary supplements). New drugs must undergo extensive, documented testing for safety and efficacy. This testing takes years and is generally extremely costly to the pharmaceutical firm that is developing the drug. New drugs can not be sold before they are formally approved by the FDA. Moreover, new drugs are sold by prescription until the FDA formally approves them in a separate process for "over the counter" sales.

Financial products could also be put through an ex-ante review process. In principle financial products could be tested in small-scale trials. For example, a new credit product could be offered (at regular cost) to 10,000 clients during a trial period. Their anonymized behavior could be studied and they could be anonymously surveyed about their experiences. Consider the following examples of potential questions that would be answered by customers who adopted the product:

- "Do you feel that this product generates value that exceeds the fees you are paying for it?"

- "What are the fees on this product?" [Don't Know would be an option here.]

- "Would you recommend this product to any of your friends?"

- "In your view, should this product be approved for sale by the [financial regulator]."

\footnotetext{
${ }^{37}$ http://www.fda.gov/Food/DietarySupplements/default.htm
} 
Naturally, a product could be approved even if a sizeable minority of customers did not understand it or did not like it. However, if a large enough fraction of adopters expressed reservations about its value or did not understand its costs, this would be grounds for further study and/or a rejection of the application for approval. The regulator would try to judge the aggregate benefits and harms generated by the product, recognizing the possibility that many consumers with small harms might be offset by a small number of beneficiaries with large gains.

Surveys like this could be designed by the financial regulator. Alternatively, such survey design could be outsourced to a third party monitored by the regulator (e.g., the RAND corporation).

Such testing would be socially costly. Testing would delay the release of a new product, increase costs for financial service firms, and decrease innovation. However, testing would also improve screening of socially undesirable products. The net social benefit of this testing is not easy to evaluate.

Finally, note that testing could occur after a product was released. For example, the financial regulator could have the authority to compel a financial services firm to run the analysis above on products that are deemed ex-post to be potentially problematic. Such ex-post selection for testing might be superior to ex-ante testing. Financial service firms would be incented to design products that were not likely to attract the potentially costly attention of the regulator.

\section{Seven Open Questions for Future Research}

This paper makes three different points. First, we reported evidence that older adults experience substantial declines in analytic cognitive function (longitudinally). Then, we reported evidence that economic behavior and economic mistakes show strong age-based patterns (in the cross-section), even among a population of individuals who are screened to be prime borrowers. Finally, we discussed nine potential policy responses. Throughout the policy discussion, we emphasized that we are agnostic about what regulatory interventions (if any) should be adopted. We don't think that the jury is in on many different dimensions of the problem. Economic behavior among older adults is still poorly understood. Moreover, even if older adults are making substantial financial mistakes, it is not clear what a well-intentioned policymaker should do about it. We need a lot more research - including field experiments that study different regulatory regimes - before the best solutions can be identified. ${ }^{38}$

In this conclusion, we emphasize the open questions that we hope academic researchers and policy makers will consider as they wrestle with these problems in the future.

1. How widespread and important are the losses due to poor financial decision-making?

(a) What fraction of wealth is lost because of poor choices? What are the utility costs? In our analysis of economic behavior, we were only able to study decisions with relatively moderate costs - e.g. credit card fees. We believe that the costs analyzed in the current paper are just

\footnotetext{
${ }^{38}$ The law and economics literature also studies those issues. See e.g. Bar-Gill (2008) and Marotta-Wurgler (2007).
} 
the tip of the iceberg. We studied these particular markets because of the high quality of the associated data. But the bulk of the mistakes that are probably being made lie elsewhere. Older adults make many decisions with potentially enormous costs. Should I refinance my home and draw down some of my equity? Should I buy a complicated (high fee) annuity? Should I cash out my current annuity (paying a surrender charge) so I can buy a "better" annuity? Should I invest a substantial fraction of my wealth in a high return CD (that is being sold to me by a broker calling from an off-shore bank)? Should I invest a substantial fraction of my wealth in a structured finance product (that has a high return and I am assured is completely safe)? Should I participate in a real estate investment pool (minimum investment \$100,000)? Measuring and aggregating these costs is an important research program. To get a sense, of how this might add up, consider a few quantitative examples. The annuity market accounts for wealth dissipation equal to around $6 \%$ of the value of each annuity that is purchased (i.e., $6 \%$ of $\$ 265$ billion in 2008 , or $\$ 16$ billion per year). ${ }^{39}$ Korniotos and Kumar (2008) estimate that older investors with accounts at a discount brokerage earn $3 \%$ to $5 \%$ less in risk-adjusted equity returns than other clients of the discount broker. If older investors in aggregate earn just $0.5 \%$ less than other adult investors, this would amount to approximately $0.5 \%$ of $\$ 10$ trillion, or $\$ 50$ billion of underperformance per year. ${ }^{40}$

(b) If agents are losing wealth, are these transfers or just deadweight losses? As an order of magnitude for the stakes, French (2009) estimates the total fees paid in active management to be about $0.7 \%$ of the market value of equity per year, which is equivalent to about $0.7 \%$ of GDP in the US. This may mostly be a deadweight loss, because the active traders (as well as the marketing experts who advertise these funds) could be productively engaged in other activities. The active traders are engaged primarily in trying (usually unsuccessfully) to transfer wealth from other people to their clients. The transfers themselves are not a dead weight loss, but the time spent attempting to achieve those transfers is. Physics Ph.D.s might be usefully employed in labs rather than in hedge funds.

2. What demographic characteristics predict poor financial decision-making?

In this paper, we have only used data on age, but clearly other demographic measures (years of education, field of education) would be helpful. In addition, we would also like to know if cognitive tests are predictive of poor financial decision-making, and if so, what kinds of cognitive tests (e.g., knowledge-based, logic-based, etc.). Is it possible to inexpensively and accurately measure the current level of cognitive function or predict future changes in that level?

\footnotetext{
${ }^{39}$ See http://www.limra.com/PDFs/newscenter/databank/AnnuityEstimates99_08.pdf for the volume of the annuities market. A typical commission on the sale of an annuity ranges from $6 \%$ to $12 \%$ of the face value of the contract (communication with an executive in the annuity industry). Annuities with small or non-existent commissions represent a minor part of the overall marketplace, though such low-cost annuities do exist.

${ }^{40}$ In 2008 the Federal Reserve estimated that households owned financial assets worth $\$ 35$ trillion, excluding deposits (Flow of Funds). We estimate that about one third of that wealth is owned by households with a head age 65 or older.
} 
3. To what extent do people anticipate and/or recognize their own cognitive decline?

We do not know whether people fully anticipate their future likelihood of cognitive decline. We also do not know whether people are able to recognize the decline in real-time and delegate their financial affairs or protect themselves in other ways (by politely closing the door when an annuity salesman knocks). We do not know how malleable older adults really are. The media is replete with anecdotes about 85-year-old widows who vaguely realize that they are experiencing some cognitive decline, but still fall prey to sophisticated and sociable brokers. Are these stories representative? Or are older adults able to protect themselves in the vast majority of cases because they recognize their own vulnerability?

4. Does financial education help with this?

Is it cost-effective? Is it relevant in an environment that's changing? As we discussed above, the evidence on the impact of financial education is mixed and not particularly encouraging. For example Agarwal et al. (2009) look at the role of financial counseling on mortgage decision making and find that counseling per say did not help consumers choose lower risk mortgage products.

5. Do third parties help?

Who should be empowered to serve as an external advisor or decision-maker (e.g., family, friends, independent trustees) ${ }^{41}$ Family members often make problematic trustees (as illustrated in cases ranging from King Lear to Brooke Astor). How prevalent are such problems? What is the evidence on the effectiveness of trustees, conditional on the type of trustee? How does the market for fiduciaries operate?

6. What is the market response to this situation?

There are theoretical reasons to worry that the market mechanism might be inefficient in the market for advice. Advice markets suffer from information asymmetries between the recipients and the providers of advice (see the survey in Dulleck and Kerschbamer, 2006). In markets with inattentive consumers and shrouded attributes (Gabaix and Laibson 2006), perverse situations with high fees can persist as bona fide economic equilibria. This happens when there are enough naive consumers, and the only profitable business model is to offer a product with low base prices and high "surprise" fees. How important empirically are these perverse market equilibria? Are the professional fiduciaries trustworthy, or not? There is much anecdotal evidence of problems (e.g., high fees), but a systematic quantification is needed.

7. What is the appropriate regulatory response?

If the market for third-party advice and fiduciary services functioned well, the market equilibrium would have three phases. Early in life, agents would write a plan of consumption and investment,

\footnotetext{
${ }^{41}$ See Li (2009) for empirical evidence on financial advice by family members.
} 
contingent on major events (including cognitive decline). In late life, cognitive testing and observation would identify the onset of significant cognitive decline. After crossing this pre-specified threshold, the original contingent plan would be enforced by a fiduciary (or a financial product with a statecontingent payout scheme). Indeed, the market space has provided financial products with some of these features. For example, annuities eliminate complex asset decumulation decisions. More sophisticated institutions will be designed. However, for all of the reasons reviewed in this paper, the unregulated market solution may not work well. Government intervention is probably desirable, but the ideal form of that intervention remains unclear. More empirical analysis and field experiments are needed to identify the regulatory response that balances the marginal costs and benefits of activist policies.

\section{References}

Agarwal, Sumit, Gene Amromin, Zahi, Ben-David, Souphala Chomsisengphet, and Douglas Evanoff (2009) "The Effects of Financial Education on Household Financial Decision Making: Evidence from a Natural Experiment of Mortgage Advice.” Working Paper, Federal Reserve Bank of Chicago.

Agarwal, Sumit, John C. Driscoll, Xavier Gabaix and David I. Laibson (2009). "Learning in the Credit Card Market." Working Paper, Harvard University.

Agarwal, Sumit, Souphala Chomsisengphet, Chunlin Liu and Nicholas S. Souleles (2007). "Do Consumers Choose the Right Credit Contracts?" Working Paper, Federal Reserve Bank of Chicago.

Aguiar, Mark and Eric Hurst (2007). "Lifecycle Prices and Production," American Economic Review, 97(5), pp. 1533-59.

Alesina, Alberto and Annamaria Lusardi (2006), "Driving Your Financial Investment? Perhaps a License is Needed." Working Paper, Dartmouth College.

Antolin, P., C. Pugh and F. Stewart (2008), "Forms of Benefit Payment at Retirement," OECD Working Papers on Insurance and Private Pensions, No. 26, OECD publishing.

Ausubel, Lawrence M. (1991). "The Failure of Competition in the Credit Card Market." American Economic Review, 81(1), pp. 50-81.

Bar-Gill, Oren (2008). "The Law, Economics and Psychology of Subprime Mortgage Contracts," Cornell Law Review, 94, pp. 1073.

Ben-David, Itzhak (2007). "Manipulation of Collateral Values by Borrowers and Intermediaries." Working Paper, University of Chicago Graduate School of Business.

Benjamin, Daniel, Sebastian A. Brown and Jesse Shapiro (2006) "Who is Behavioral? Cognitive Ability and Anomalous Preferences." Working Paper, University of Chicago. 
Beshears, John, James J. Choi, David Laibson, and Brigitte C. Madrian. (2008a) "How Does Simplified Disclosure Affect Individuals' Mutual Fund Choices?” NBER Working Paper No. 14589.

Beshears, John, James J. Choi, David Laibson, and Brigitte C. Madrian. (2006) "Simplification and Saving " NBER Working Paper No. 12659.

Beshears, John, James J. Choi, David Laibson, and Brigitte C. Madrian (2008b). "The Importance of Default Options for Retirement Saving Outcomes: Evidence from the United States" In Stephen J. Kay and Tapen Sinha, editors, Lessons from Pension Reform in the Americas.

Bucks, Brian and Karen Pence (2006), "Do Homeowners Know their House Values and Mortgage Terms?" Finance and Economics Discussion Paper Series, Federal Reserve Board.

Campbell, John Y. (2006). "Household Finance," Journal of Finance, 61 (4), pp. 1553-1604.

Canner, Glenn B., Thomas A. Durkin and Charles A. Luckett (1998). "Recent Developments in Home Equity Lending." Federal Reserve Bulletin, 84(4) , pp. 241-251.

Carstensen, Laura L. (2006) "The Influence of a Sense of Time on Human Development," Science, 312, pp. 1913-15.

Cattell R. B. (1987) Intelligence: Its structure, growth and action. New York: Elsevier.

Charles, Kerwin Kofi, Erik Hurst and Melvin Stephens, Jr. (2008). "Explaining Racial Differences in Vehicle Loan Rates," American Economic Review, Papers and Proceedings 98(2), 315-20

Choi, James J., David Laibson, and Brigitte C. Madrian (2005). "Are Empowerment and Education Enough? Underdiversification in 401(k) Plans." Brookings Papers on Economic Activity.

Choi, James J., David Laibson, and Brigitte C. Madrian (2008a). "\$100 Bills on the Sidewalk: Suboptimal Investment in 401(k) Plans." NBER Working Paper No. 11554.

Choi, James J., David Laibson, and Brigitte C. Madrian (2008b). "Why Does the Law of One Price Fail? An Experiment on Index Mutual Funds" NBER Working Paper No. 12261.

Choi, James J., David Laibson, Brigitte C. Madrian, and Andrew Metrick (2002). "Defined Contribution Pensions: Plan Rules, Participant Decisions, and the Path of Least Resistance" In James Poterba, editor, Tax Policy and the Economy,.

DellaVigna, Stefano and Ulrike Malmendier (2004). "Contract Theory and Self-Control: Theory and Evidence." Quarterly Journal of Economics, 119(2), pp. 353-402.

Denburg, Nathalie L., Daniel Tranel, Antoine Bechara (2005). "The ability to decide advantageously declines prematurely in some normal older persons," Neuropsychologia 43, pp. 1099-1106

Dulleck, Uwe and Rudolf Kerschbamer (2006) "On Doctors, Mechanics, and Computer Specialists: The Economics of Credence Goods." Journal of Economic Literature, 44(1), pp. 5-42. 
Ferri, C., M. Prince, C. Brayne, H. Brodaty, L. Fratiglioni, M. Ganguli, K. Hall, K. Hasegawa, H. Hendrie, Y. Huang (2006) "Global prevalence of dementia: a Delphi consensus study." The Lancet, 366(9503), pp. 2112-2117.

Flynn, J. R. (1984). "The Mean IQ of Americans: Massive Gains 1932 to 1978". Psychological Bulletin, 95, pp. $29-51$.

Fratiglioni Laura, Diana De Ronchi and Hella Agüero Torres (1999). "Worldwide Prevalence and Incidence of Dementia." Drugs 83 Aging, 15(5), pp. 365-375.

Frederick, Shane (2005). "Cognitive Reflection and Decision Making", Journal of Economic Perspectives, 19(4), pp. $25-42$.

French, Kenneth (2009), "The Cost of Active Investing", Journal of Finance.

Gabaix, Xavier and David I. Laibson (2006). "Shrouded Attributes, Consumer Myopia, and Information Suppression in Competitive Markets." Quarterly Journal of Economics, 121(2), pp. 505-540.

Gabaix, Xavier, David I. Laibson, Guillermo Moloche and Stephen Weinberg (2006), "Costly Information Acquisition: Experimental Analysis of a Boundedly Rational Model," American Economic Review, 96 (4), pp. 1043-1068.

Galenson, David (2005). Old Masters and Young Geniuses: Two Life Cycles of Artistic Activity. Princeton, NJ: Princeton University Press.

Gourinchas, Pierre-Olivier, and Jonathan Parker (2002). "Consumption Over the Life Cycle." Econometrica, 70(1), pp. $47-89$.

Graham, John R., Campbell R. Harvey, and Manju Puri (2008) "Managerial Attitudes and Corporate Actions." Working Paper, Fuqua School of Business, Duke University.

Griliches, Zvi (1977). "Estimating the Returns to Schooling: Some Econometric Problems." Econometrica 45(1), pp. $1-22$.

Gross, David B. and Nicholas S. Souleles (2002). "Do Liquidity Constraints and Interest Rates Matter for Consumer Behavior? Evidence from Credit Card Data." Quarterly Journal of Economics, 117(1), pp. 149-185.

Heidhues, Paul, and Botond Koszegi (2008), "Exploiting Naivete about Self-Control in the Credit MarketAbstract," Working Paper, University of California, Berkeley.

Jones, Benjamin F.(2006). "Age and Great Invention" Working paper, Northwestern University.

Korniotis, George and Alok Kumar (2008a). "Do Older Investors Make Better Investment Decisions?" Working paper, Federal Reserve Board.

Korniotis, George and Alok Kumar (2008b). "Superior Information or a Psychological Bias? A Unified Framework with Cognitive Abilities Resolves Three Puzzles" Working paper, Federal Reserve Board. 
Korniotis, George and Alok Kumar (forth.). "Cognitive Abilities, Investor Sophistication, and Investment Decisions," Chapter 30 in Behavioral Finance, edited by Kent Baker and John Nofsinger, John Wiley \& Sons, Inc., Hoboken, New Jersey.

Langa, Kenneth M., B.L. Plassman, R.B. Wallace, A.R. Herzog, Steven Heeringa, Mary Beth Ofstedal, J.R. Burke, G.G. Fisher, N.H. Fultz, M.D. Hurd, G.G. Potter, W.L. Rodgers, D.C. Steffens, David Weir, and Robert Willis. (2005). "The aging, demographics, and memory study: Study design and methods." Neuroepidemiology, 25 (4), pp. 181-191.

Li, Geng (2009). "Information Sharing and Stock Market Participation: Evidence from Extended Families." Working Paper, Federal Reserve Board.

Lusardi, Annamaria and Olivia S. Mitchell (2006), "Financial Literacy and Planning: Implications for Retirement Wellbeing," Working paper, Dartmouth College.

Lusardi, Annamaria and Olivia S. Mitchell (2007), "Financial Literacy and Retirement Preparedness: Evidence and Implications for Financial Education Programs," Business Economics, January 2007, 42(1) pp. 35-44.

Madrian, Brigitte and Dennis F. Shea (2001a). "The Power of Suggestion: Inertia in 401(k) Participation and Savings Behavior." Quarterly Journal of Economics, 116(4), pp. 1149-1187.

Madrian, Brigitte C. and Dennis F. Shea (2001b). "Preaching to the Converted and ConvertingThose Taught: Financial Education in the Workplace," Working paper, University of Chicago.

Malmendier, Ulrike and Stefan Nagel (2008) "Depression Babies: Do Macroeconomic Experiences Affect RiskTaking?" Working paper, University of California, Berkeley.

Malmendier, Ulrike, and Devin Shanthikumar (2007), "Are Small Investors Naive about Incentives?" Journal of Financial Economics, 85 (2), pp. 457-489.

Marotta-Wurgler, Florencia (2007). "What's in a Standard Form Contract? An Empirical Analysis of Software License Agreements." Journal of Empirical Legal Studies pp. 677-713.

Mather, Mara, and Laura Carstensen (2005). "Aging and Motivated Cognition: The Positivity Effect in Attention and Memory." Trends in Cognitive Science, 9(10), pp. 496-502.

McArdle, John, James Smith, and Robert Willis (2009). "Cognition and Economic Outcomes in the Health and Retirement Survey" forthcoming NBER volume edited by David Wise.

Mottola, Gary R. and Stephen P. Utkus (2007). "Lump Sum or Annuity? An Analysis of Choice in DB Pension Payouts." Vanguard Center for Retirement Research, 30(November).

Mullainathan, Sendhil, and Andrei Shleifer (2005), "The Market for News," American Economic Review, 95(6), pp. 1031-1053. 
Murphy, Kevin M. and Finis Welch (1990). "Empirical Age-Earnings Profiles." Journal of Labor Economics, 8(2), pp. 202-229.

Ofstedal, Mary Beth, Gwenith G. Fisher, Regula A. Herzog, 2005. "Documentation of Cognitive Functioning Measures in the Health and Retirement Study," HRS Documentation Report DR-006, March.

Park, Denise, and Norbert Schwarz eds. (1999), Cognitive Aging: A Primer. Psychology Press.

Plassman, B.L., K.M. Langa, G.G. Fisher, S.G. Heeringa, D.R. Weir, M.B. Ofstedal, J.R. Burke, M.D. Hurd, G.G. Potter, W.L. Rodgers, D.C. Steffens, J.J. McArdle, R.J. Willis, and R.B. Wallace. (2008) "Prevalence of Cognitive Impairment without Dementia in the United States." Annals of Internal Medicine 18 March, vol. 148, pp. 427-434.

Poterba, James, Steven Venti and David Wise. (2007). "New Estimates of the Future Path of 401(k) Assets," Working paper, MIT.

Salthouse, Timothy (2005), "Effects of aging on reasoning", Cambridge Handbook of Thinking and Reasoning. Cambridge, England: Cambridge University Press.

Salthouse, Timothy (forthcoming), "Executive Functioning," D.C. Park \& N. Schwarz (Eds.), Cognitive Aging: A Primer, 2nd edition, Psychology Press.

Salthouse, Timothy, David H. Schroeder and Emilio Ferrer (2004). "Estimating retest effects in longitudinal assessments of cognitive functioning in adults between 18 and 60 years of age," Developmental Psychology, 40(5), pp. $813-822$.

Scholnick, Barry, Nadia Massoud, and Anthony Saunders (2008). "The Impact of Wealth on Inattention: Evidence from Credit Card Repayments?" Working paper, University of Alberta.

Scott Morton, Fiona, Florian Zettelmeyer and Jorge Silva-Risso (2003). "Consumer Information and Discrimination: Does the Internet Affect the Pricing of New Cars to Women and Minorities?" Quantitative Marketing and Economics 1(1), pp. 65-92.

Shue, Kelly and Erzo F. P. Luttmer (forthcoming). "Who Misvotes? The Effect of Differential Cognition Costs on Election Outcomes." American Economic Journal: Economic Policy.

Shui, Haiyan and Lawrence M. Ausubel (2004) "Time Inconsistency in the Credit Card Market." Working paper, University of Maryland.

Simonton, D. K. (1988). "Age and Outstanding Achievement: What do we Know after a Century of Research?" Psychological Bulletin, 104, pp. 251-267.

Spiegler, Rani (2006), "The Market for Quacks," Review of Economic Studies, 73(4), pp. 1113-1131.

Stango, Victor and Jonathan Zinman (2008) "Exponential Growth Bias and Household Finance," Working paper, Dartmouth College. 
Thaler, Richard, and Shlomo Benartzi (2004) "Save More Tomorrow: Using Behavioral Economics to Increase Employee Savings," Journal of Political Economy, Vol. 112.1, Part 2, pp. S164-S187.

Thaler, Richard, and Cass Sunstein (2003) "Libertarian Paternalism" American Economic Review, Paper and Proceedings. May.

Thaler, Richard, and Cass Sunstein (2008) Nudge: Improving decisions about health, wealth, and happiness. New Haven, CT: Yale University Press.

Weinberg, Bruce A. and David A. Galenson (2005), "Creative Careers: The Life Cycle of Nobel Laureates in Economics" NBER Working Paper No. 11799.

Willis, Robert J. (2007) "Cognitive Economics and Human Capital" Presidential Address to Society of Labor Economists, Chicago, May.

Zinman, Jonathan (2007). "Where is the Missing Credit Card Debt? Clues and Implications." Working paper, Dartmouth College. 


\section{A Appendix: Data Description}

\section{A.1 "Eureka" Moments}

We use a proprietary panel data set from several large financial institutions, later acquired by a single financial institution, that made balance transfer offers nationally. ${ }^{42}$ The data set contains 14,798 individuals who accepted such balance transfer offers over the period January 2000 through December 2002. The bulk of the data consists of the main billing information listed on each account's monthly statement, including total payment, spending, credit limit, balance, debt, purchases, cash advance annual percentage rates (APRs), and fees paid. We also observe the amount of the balance transfer, the start date of the balance transfer teaser rate offer, the initial teaser APR on the balance transfer, and the end date of the balance transfer APR offer. At a quarterly frequency, we observe each customer's credit bureau rating (FICO) and a proprietary (internal) credit 'behavior' score. We have credit bureau data about the number of other credit cards held by the account holder, total credit card balances, and mortgage balances. We have data on the age, gender, and income of the account holder, collected at the time of account opening. In this sample, borrowers did not pay fees for the balance transfer

\section{A.2 Home Equity Loans and Lines of Credit}

We use a proprietary panel dataset constructed with records from a national financial institution that has issued home equity loans and home equity lines of credit. The lender has not specialized in subprime loans or other market segments. Between March and December 2002, the lender offered a menu of standardized contracts for home equity credits. ${ }^{43}$ Consumers chose (a) either a loan or a credit line; (b) either a first or second lien; and (c) an incremental loan amount and an estimate of her property value, corresponding to a loan-to-value (LTV) ratio of less than 80 percent, between 80 and 90 percent, or between 90 and 100 percent. In effect, the lender offered twelve different contract choices. ${ }^{44}$ In the results below, we run separate regressions for home equity loans and lines of credit, and, in each regression, we condition on not having a first mortgage and LTV bucket; hence we control for contract type. All loans have the same five-year maturity. For 75,000 such contracts, we observe the contract terms, borrower demographic information (age, years at current job, home tenure), financial information (income and debt-to-income ratio), and risk characteristics (credit (FICO) score, and LTV) ${ }^{45}$ We also observe borrower estimates of

\footnotetext{
${ }^{42}$ The offers were not made conditional on closing the old credit card account.

${ }^{43}$ Other interest rates in the economy varied considerably during this time period. One might therefore ask whether the age results we report below are an artifact of borrowers of different ages happening to disproportionately borrow earlier or later in the sample. We observe no pattern in the distribution by month of borrowing by age over the sample. In alternative versions of the regressions including dummy variables for the month of loan origination, we obtain nearly identical results.

${ }^{44}$ We focus on APR payment across contracts for four reasons. First, contracts do not differ in points charged or in other charges to the borrower. Second, we verify that, even conditioning on contract choice, some borrowers pay higher APRs than others. Third, we control for borrower risk characteristics. Fourth, we show in the paper that the residual variation in APRs is explained by the propensity to make an identifiable mistake in the loan acquisition process.

${ }^{45}$ We do not have internal behavior scores (a supplementary credit risk score) for these borrowers. Such scores are performance-based, and are thus not available at loan origination.
} 
their property values and the loan amount requested.

\section{A.3 Auto Loans}

We use a proprietary data set of auto loans originated at several large financial institutions that were later acquired by another institution. The data set comprises observations on 6,996 loans originated for the purchase of new and used automobiles. We observe loan characteristics including the automobile value and age, the loan amount and LTV, the monthly payment, the contract rate, and the time of origination. We also observe borrower characteristics including credit score, monthly disposable income, and borrower age.

\section{A.4 Mortgages}

We use a proprietary data set from a large financial institution that originates first mortgages in Argentina. Using data from one other country provides suggestive evidence about the international applicability of our findings. The data set covers 4,867 owner-occupied, fixed-rate, first mortgage loans originated between June 1998 and March 2000 and observed through March 2004. We observe the original loan amount, the LTV and appraised house value at origination, and the APR. We also observe borrower financial characteristics (including income; second income; years on the job; wealth measures, such as second house ownership, car ownership, and car value), borrower risk characteristics (Veraz score-a credit score similar to the U.S. FICO score-and mortgage payments as a percentage of after-tax income), and borrower demographic characteristics (age, gender, and marital status).

\section{A.5 Small Business Credit Cards}

We use a proprietary data set of small business credit card accounts originated at several large institutions that issued such cards nationally. The institutions were later acquired by a single institution. The panel data set covers 11,254 accounts originated between May 2000 and May 2002. Most of the business are very small, owned by a single family, and have no formal financial records. The dataset has all information collected at the time of account origination, including the business owner's self-reported personal income, the number of years the business has been in operation, and the age of the business owner. We observe the quarterly credit bureau score of the business owner.

\section{A.6 Credit Card Fees}

We use a proprietary panel dataset from several large financial institutions that offered credit cards nationally, later acquired by a larger financial institution. The dataset contains a representative random sample of about 128,000 credit card accounts followed monthly over a 36 month period (from January 2002 
through December 2004) ${ }^{46}$. The bulk of the data consists of the main billing information listed on each account's monthly statement, including total payment, spending, credit limit, balance, debt, purchases and cash advance annual percent rates (APRs), and fees paid. At a quarterly frequency, we observe each customer's credit bureau rating (FICO) and a proprietary (internal) credit 'behavior' score. We have credit bureau data about the number of other credit cards held by the account holder, total credit card balances, and mortgage balances. We have data on the age, gender and income of the account holder, collected at the time of account opening. Further details on the data, including summary statistics, are available in the on-line Appendix.

\footnotetext{
${ }^{46}$ The credit cards do not have annual fees, and do not differ in terms of rewards points or other benefits.
} 
On-line Appendix: Additional Results and Summary Statistics for Agarwal, Driscoll, Gabaix, and Laibson, Brookings Papers on Economic Activity

\section{B Summary Statistics}

\begin{tabular}{|c|r|r|r|r|}
\hline \multicolumn{2}{|c|}{ Table 1: Home Equity Loans and Credit Lines } \\
\hline & \multicolumn{2}{|c|}{ Loans } & \multicolumn{2}{|c|}{ Credit Lines } \\
\hline Description (Units) & Mean & Std. Dev. & Mean & Std. Dev. \\
\hline APR(\%) & 7.96 & 1.16 & 4.60 & 0.88 \\
\hline Borrower Age (Years) & 43 & 14 & 46 & 12 \\
\hline Income (\$, Annual) & 78,791 & 99,761 & 90,293 & 215,057 \\
\hline Debt/Income (\%) & 40 & 18 & 41 & 19 \\
\hline FICO (Credit Bureau Risk) Score & 713 & 55 & 733 & 49 \\
\hline Customer LTV (\%) & 66 & 26 & 62 & 24 \\
\hline Appraisal LTV (\%) & 69 & 29 & 64 & 23 \\
\hline Borrower Home Value Estimate (\$) & 196,467 & 144,085 & 346,065 & 250,355 \\
\hline Bank Home Value Estimate (\$) & 186,509 & 123,031 & 335,797 & 214,766 \\
\hline Loan Requested by Borrower (\$) & 43,981 & 35,161 & 61,347 & 50,025 \\
\hline Loan Approved by Bank (\$) & 42,871 & 33,188 & 60,725 & 51,230 \\
\hline First Mortgage Balance (\$) & 79,496 & 83,560 & 154,444 & 112,991 \\
\hline Months at Address & 92 & 122 & 99 & 129 \\
\hline No First Mortgage (\%) & 29 & 45 & 15 & 42 \\
\hline Second Home (\%) & 3 & 14 & 3 & 12 \\
\hline Condo (\%) & 8 & 18 & 6 & 17 \\
\hline Refinancing (\%) & 66 & 47 & 39 & 49 \\
\hline Home Improvement (\%) & 18 & 39 & 25 & 44 \\
\hline Consumption (\%) & 16 & 39 & 35 & 35 \\
\hline Self Employed (\%) & 7.9 & 27 & 7.8 & 27 \\
\hline Retired (\%) & 9.5 & 29 & 7.7 & 27 \\
\hline Homemaker (\%) & 1.4 & 12 & 1.3 & 11 \\
\hline Years on the Last Job & 6.3 & 8.1 & 7.6 & 9.1 \\
\hline
\end{tabular}




\begin{tabular}{|c|c|c|c|}
\hline \multicolumn{4}{|c|}{ Table 2: Credit Cards } \\
\hline Account Characteristics & Frequency & Mean & Std. Dev. \\
\hline Purchase APR & Monthly & 14.40 & 2.44 \\
\hline Interest Rate on Cash Advances (\%) & Monthly & 16.16 & 2.22 \\
\hline Credit Limit (\$) & Monthly & 8,205 & 3,385 \\
\hline Current Cash Advance $(\$)$ & Monthly & 148 & 648 \\
\hline Payment $(\$)$ & Monthly & 317 & 952 \\
\hline New Purchases $(\$)$ & Monthly & 303 & 531 \\
\hline Debt on Last Statement (\$) & Monthly & 1,735 & 1,978 \\
\hline Minimum Payment Due $(\$)$ & Monthly & 35 & 52 \\
\hline Debt/Limit (\%) & Monthly & 29 & 36 \\
\hline \multicolumn{4}{|l|}{ Fee Payment } \\
\hline Total Fees $(\$)$ & Monthly & 10.10 & 14.82 \\
\hline Cash Advance Fee $(\$)$ & Monthly & 5.09 & 11.29 \\
\hline Late Payment Fee $(\$)$ & Monthly & 4.07 & 3.22 \\
\hline Over Limit Fee $(\$)$ & Monthly & 1.23 & 1.57 \\
\hline Extra Interest Due to Over Limit or Late Fee $(\$)$ & Monthly & 15.58 & 23.66 \\
\hline Extra Interest Due to Cash Advances $(\$)$ & Monthly & 3.25 & 3.92 \\
\hline Cash Advance Fee Payments/Month & Monthly & 0.38 & 0.28 \\
\hline Late Fee Payments/Month & Monthly & 0.14 & 0.21 \\
\hline Over Limit Fee Payments/Month & Monthly & 0.08 & 0.10 \\
\hline \multicolumn{4}{|l|}{ Borrower Characteristics } \\
\hline FICO (Credit Bureau Risk) Score & Quarterly & 731 & 76 \\
\hline Behavior Score & Quarterly & 727 & 81 \\
\hline Number of Credit Cards & At Origination & 4.84 & 3.56 \\
\hline Number of Active Cards & At Origination & 2.69 & 2.34 \\
\hline Total Credit Card Balance $(\$)$ & At Origination & 15,110 & 13,043 \\
\hline Mortgage Balance $(\$)$ & At Origination & 47,968 & 84,617 \\
\hline Age (Years) & At Origination & 42.40 & 15.04 \\
\hline Income $(\$)$ & At Origination & 57,121 & 114,375 \\
\hline
\end{tabular}

Notes: The "Credit Bureau Risk Score" is provided by Fair, Isaac, and Company (FICO). The greater the score, the less risky the consumer is. The "Behavior Score" is a proprietary score based on the consumer's past payment history and debt burden, among other variables, created by the bank to capture consumer payment behavior not accounted for by the FICO score. 


\begin{tabular}{|l|r|r|}
\hline \multicolumn{3}{|c|}{ Table 3: Auto Loan APRs } \\
\hline Description (Units) & Mean & Std. Dev. \\
\hline APR(\%) & 8.99 & 0.90 \\
\hline Borrower Age (Years) & 40 & 21 \\
\hline Income (\$, Monthly) & 3416 & 772 \\
\hline LTV(\%) & 44 & 10 \\
\hline FICO (Credit Bureau Risk) Score & 723 & 64 \\
\hline Monthly Loan Payment (\$) & 229 & 95 \\
\hline Blue Book Car Value (\$) & 11,875 & 4,625 \\
\hline Loan Amount (\$) & 4172 & 1427 \\
\hline Car Age (Years) & 2 & 1 \\
\hline Loan Age (Months) & 12 & 8 \\
\hline
\end{tabular}

\begin{tabular}{|l|r|r|}
\hline \multicolumn{3}{|c|}{ Table 4: Mortgage Loans } \\
\hline & \multicolumn{2}{|c|}{ Loans } \\
\hline Description (Units) & Mean & Std. Dev. \\
\hline APR(\%) & 12.64 & 2.17 \\
\hline Borrower Age (Years) & 40.54 & 9.98 \\
\hline Income (\$) & 2,624 & 2,102 \\
\hline Monthly Mortgage Payment/Income (\%) & 22.84 & 12.12 \\
\hline Veraz (Credit Bureau Risk) Score & 686 & 253 \\
\hline LTV (\%) & 61 & 17 \\
\hline Loan Amount (\$) & 44,711 & 27,048 \\
\hline Years at Current Job & 9.43 & 8.01 \\
\hline Second House (\%) & 15.54 & 5.18 \\
\hline Car Ownership (\%) & 73.56 & 44.11 \\
\hline Car Value (\$) & 5,664 & 13,959 \\
\hline Gender (Female=1) & 30.96 & 46.24 \\
\hline Second Income (\%) & 20.44 & 40.33 \\
\hline Married (\%) & 71.32 & 45.23 \\
\hline Married with Two Incomes (\%) & 16.75 & 37.34 \\
\hline Self Employed (\%) & 13.87 & 34.57 \\
\hline Professional Employment (\%) & 15.78 & 36.46 \\
\hline Nonprofessional Employment (\%) & 52.78 & 49.93 \\
\hline Relationship with Bank (\%) & 10.40 & 30.52 \\
\hline
\end{tabular}




\begin{tabular}{|l|r|r|}
\hline \multicolumn{2}{|c|}{ Table 5: Small Business Credit Cards APRs } \\
\hline Description (Units) & Mean & Std. Dev. \\
\hline APR(\%) & 13.03 & 5.36 \\
\hline Borrower Age (Years) & 47.24 & 13.35 \\
\hline Line Amount (\$) & $9,623.95$ & $6,057.66$ \\
\hline Total Unsecured Debt & $12,627.45$ & $17,760.24$ \\
\hline FICO (Credit Bureau Risk) Score & 715.86 & 55.03 \\
\hline Mortgage Debt (\$) & $102,684.70$ & $160,799.57$ \\
\hline
\end{tabular}

\begin{tabular}{|c|c|c|c|c|c|}
\hline \multicolumn{6}{|c|}{ Table 6: Age Distribution by Product } \\
\hline Product & \multicolumn{5}{|c|}{ Age Percentile } \\
\cline { 2 - 6 } & $10 \%$ & $25 \%$ & $50 \%$ & $75 \%$ & $90 \%$ \\
\hline Home Equity Loans & 34 & 40 & 48 & 59 & 71 \\
\hline Home Equity Lines & 32 & 40 & 47 & 58 & 70 \\
\hline "Eureka" & 24 & 34 & 44 & 53 & 63 \\
\hline Credit Card & 25 & 34 & 44 & 57 & 68 \\
\hline Auto Loans & 27 & 35 & 45 & 57 & 67 \\
\hline Mortgage & 34 & 42 & 49 & 60 & 69 \\
\hline Small Business Credit Card & 37 & 43 & 53 & 62 & 72 \\
\hline Credit Card Late Fee & 25 & 35 & 45 & 58 & 67 \\
\hline Credit Card Over Limit Fee & 26 & 34 & 43 & 56 & 65 \\
\hline Credit Card Cash Advance Fee & 25 & 36 & 46 & 58 & 68 \\
\hline
\end{tabular}

\section{Regressions of APRs on Age and Other Characteristics}

This section presents the regression results underlying the U-shaped plots in the paper.

\section{C.1 Home Equity Loans and Lines of Credit}

Table 5 reports the results of estimating regressions of APRs (interest rates) on home equity loans on a spline for age and control variables. As controls, we use all borrower-related variables observed by the financial institution that might affect loan pricing, including credit risk measures, house and loan characteristics, and borrower financial and demographic characteristics. The control variables all have the expected sign, and most are statistically significant, although some of them lack economic significance. ${ }^{47}$

\footnotetext{
${ }^{47}$ Note that although we include all observed variables on the borrower, R-squareds are not 100 percent. In part, this reflects the fact that bank loan pricing models also depend on other variables external to the borrower, such as the cost of funds. Banks may also reassess their lending standards, depending on macroeconomic or other factors. As long as such factors are not correlated with consumer age, the regression coefficients on age will correctly report the impact of age on APR. We have also formally tested this by including dummies for the month of loan origination in the regression, and found little difference in the results.
} 
The measure of credit risk, the log of the FICO score, is statistically significant but with a negligible magnitude. Discussions with people who work in the industry reveal that financial institutions generally use the FICO score to determine whether a loan offer is made, but conditional on the offer being made, do not use the score to do risk-based pricing. The results here, and for the other consumer credit products discussed below, are consistent with this hypothesis.

Loan APRs do depend strongly on the absence of a first mortgage (reducing the APR) and whether the property is a second home or a condominium. The absence of a first mortgage reduces the probability of default and raises the amount that might be recovered conditional on a default. Second homes and condominiums are perceived as riskier properties. Log income and log years on the job also have large and negative effects on APRs, as expected, since they indicate more resources available to pay off the loan and perhaps less risk in the latter case. The largest effects on APRs come from dummy variables for LTV ratios between 80 and 90 percent and for ratios greater than 90 percent. This is consistent with different LTV ratios corresponding to different contract choices. ${ }^{48}$

Table 8 reports a regression of the APRs from home equity lines on a spline for age and the same control variables used for the home equity loans regression. The control variables have similar effects on home equity line APRs as they did on home equity loan APRs.

\footnotetext{
${ }^{48}$ We estimate three variants as a specification check. First, we allow the FICO scores, income, and LTV ratios to have quadratic and cubic terms. This allows us to make sure that the nonlinear effects with age that we see are not a consequence of omission of potential nonlinear effects of other control variables. Second and third, we allow the splines to have knot points at every five years, and have a dummy for each age, to ensure that the smoothing caused by the use of ten-year splines does not artificially create a U-shape. In all three cases, our results are not qualitatively or quantitatively changed.
} 


\begin{tabular}{|l|r|r|}
\hline \multicolumn{3}{|c|}{ Home Equity Loan APR } \\
\hline & Coefficient & Std. Error \\
\hline Intercept & 8.01105 & 0.1041 \\
Log(FICO Score) & -0.0021 & 0.0001 \\
Loan Purpose-Home Improvement & 0.0160 & 0.0136 \\
Loan Purpose-Rate Refinance & -0.0081 & 0.0113 \\
No First Mortgage & -0.1911 & 0.0097 \\
Log(Months at Address) & 0.0021 & 0.0039 \\
Second Home & 0.3870 & 0.0259 \\
Condominium & 0.4088 & 0.0165 \\
Log(Income) & -0.0636 & 0.0077 \\
Debt/Income & 0.0033 & 0.0002 \\
Log(Years on the Job) & -0.0242 & 0.0039 \\
Self Employed & 0.0104 & 0.0159 \\
Home Maker & -0.0330 & 0.0419 \\
Retired & 0.0350 & 0.0224 \\
Log(House Value) & 0.0010 & 0.0003 \\
Log(Loan Amount) & 0.0179 & 0.0059 \\
Age < 30 & -0.0542 & 0.0081 \\
Age 30-40 & -0.0334 & 0.0042 \\
Age 40-50 & -0.0125 & 0.0047 \\
Age 50-60 & 0.0100 & 0.0038 \\
Age 60-70 & 0.0173 & 0.0074 \\
Age > 70 & 0.0232 & 0.0102 \\
LTV 80-90 & 0.5583 & 0.0098 \\
LTV 90+ & 1.4982 & 0.0111 \\
State Dummies & YES & \\
\hline Number of Observations & 0.7938 & \\
Adjusted R-squared & & \\
\hline
\end{tabular}

Table 7: The first column gives coefficient estimates for a regression of the APR of a home equity loan on a spline with age as its argument, financial control variables $(\log (\mathrm{FICO})$ credit risk score, income, and the debt-to-income-ratio), and other controls (state dummies, a dummy for loans made for home improvements, a dummy for loans made for refinancing, a dummy for no first mortgage on the property, months at the address, years worked on the job, dummies for self-emplyed, retiree, or homemaker status, and a dummy if the property is a condominium). 


\begin{tabular}{|l|r|r|}
\hline \multicolumn{3}{|c|}{ Home Equity Line of Credit APR } \\
\hline & Coefficient & Std. Error \\
\hline Intercept & 7.8521 & 0.0567 \\
Log(FICO Score) & -0.0011 & $<0.0001$ \\
Loan Purpose-Home Improvement & 0.0543 & 0.0051 \\
Loan Purpose-Rate Refinance & -0.0384 & 0.0046 \\
No First Mortgage & -0.1480 & 0.0053 \\
Log(Months at Address) & -0.0159 & 0.0019 \\
Second Home & 0.3257 & 0.0131 \\
Condominium & 0.3929 & 0.0077 \\
Log(Income) & -0.1438 & 0.0037 \\
Debt/Income & 0.0044 & 0.0001 \\
Log(Years on the Job) & -0.0162 & 0.0020 \\
Self Employed & 0.0132 & 0.0071 \\
Home Maker & -0.0807 & 0.0211 \\
Retired & 0.0136 & 0.0107 \\
Log(House Value) & 0.0013 & 0.0004 \\
Log(Loan Amount) & 0.0156 & 0.0048 \\
Age < 30 & -0.0519 & 0.0049 \\
Age 30-40 & -0.0244 & 0.0023 \\
Age 40-50 & -0.0174 & 0.0022 \\
Age 50-60 & 0.0151 & 0.0034 \\
Age 60-70 & 0.0212 & 0.0062 \\
Age > 70 & 0.0284 & 0.0151 \\
LTV 80-90 & 0.4982 & 0.0049 \\
LTV 90+ & 1.6477 & 0.0079 \\
State Dummies & YES & \\
\hline Number of Observations & 0.6240 & \\
Adjusted R-squared & & \\
\hline
\end{tabular}

Table 8: The first column gives coefficient estimates for a regression of the APR of a home equity lines of credit on a spline with age as its argument, financial control variables ( $\log$ (FICO) credit risk score, income, and the debt-to-income-ratio), and other controls (state dummies, a dummy for loans made for home improvements, a dummy for loans made for refinancing, a dummy for no first mortgage on the property, months at the address, years worked on the job, dummies for self-employed, retiree, or homemaker status, and a dummy if the property is a condominium). 


\begin{tabular}{|l|r|r|}
\hline Propensity of ever experiencing a "Eureka" Moment \\
\hline & Coefficient & \multicolumn{2}{|c|}{ Std. Error } \\
\hline Intercept & 0.2587 & 0.0809 \\
Age $<30$ & 0.0134 & 0.0026 \\
Age 30-40 & 0.0019 & 0.0005 \\
Age 40-50 & -0.0001 & $<0.0001$ \\
Age 50-60 & -0.0029 & 0.0009 \\
Age 60-70 & -0.0035 & 0.0008 \\
Age > 70 & -0.0083 & 0.0072 \\
Some High School & -1.6428 & 0.9570 \\
High School Graduate & -0.6896 & 0.8528 \\
Some College & -0.4341 & 0.8944 \\
Associate's Degree & -0.2439 & 0.4537 \\
Bachelor's Degree & 0.3280 & 0.5585 \\
Graduate Degree & 0.6574 & 0.3541 \\
Log(FICO) & 0.0102 & 0.0019 \\
Log(Limit) & 0.0120 & 0.0022 \\
Log(Income) & -0.0044 & 0.0067 \\
\hline Number of Observations & 3,622 & \\
Adjusted R-squared & 0.1429 & \\
\hline
\end{tabular}

Table 9: This table reports estimated coefficients from a panel regression of the month in which the borrower did no more spending on the balance transfer card (the "Eureka" moment) on a spline with age as its argument and other control variables.

\section{C.2 "Eureka Moments"}

Table 9 reports the results of a regression of a dummy variable for ever having a Eureka moment on a spline for age and controls for credit risk $(\log (\mathrm{FICO}))$, fraction of education by category in the same zip code, gender, and $\log ($ income $) .{ }^{49}$. Credit risk is included because higher scores may be associated with greater financial sophistication. Similarly, we would expect borrowers with higher levels of education to be more likely to experience Eureka moments We do not directly observe education levels by borrower; we use ZCTA-level (Zip Code Tabulation Area) census data to compute the fraction of people by zip code in each education category (omitting the category of less than high-school education to avoid collinearity). The only statistically significant category is the fraction of adults with graduate degrees in the zip code, which has a positive effect on the probability of having a Eureka moment. The coefficients on the age spline imply that young adults and older adults are less likely to experience Eureka moments.

\section{C.3 Credit Card APRs}

Table 10 reports the results of regressing credit card APRs at account origination on a spline with age as its argument and other control variables. As controls, we again use information observed by the

\footnotetext{
${ }^{49}$ Although we report an OLS regression for ease in interpreting the coefficients, we have also run the regression as a logit and found similar results.
} 


\begin{tabular}{|l|r|r|}
\hline \multicolumn{3}{|c|}{ Credit Card APR } \\
\hline & Coefficient & Std. Error \\
\hline Intercept & 14.1393 & 3.0293 \\
Age $<30$ & -0.0127 & 0.0065 \\
Age 30-40 & -0.0074 & 0.0045 \\
Age 40-50 & -0.0041 & 0.0045 \\
Age 50-60 & 0.0023 & 0.0059 \\
Age 60-70 & 0.0016 & 0.0183 \\
Age $>$ 70 & 0.0016 & 0.0363 \\
Log(Income) & -0.0558 & 0.0801 \\
Log(FICO) & -0.0183 & 0.0015 \\
Total Number of Cards & 0.7715 & 0.7406 \\
Home Equity Balance & 0.0003 & 0.0022 \\
Mortgage Balance & -0.0000 & $<0.0001$ \\
\hline Number of Observations & 92,278 & \\
Adjusted R-squared & 0.1124 & \\
\hline
\end{tabular}

Table 10: This table gives coefficient estimates for a regression of the APR of a credit card on a spline with age as its argument, financial control variables $(\log (\mathrm{FICO})$ credit risk score, income, home equity debt balance and mortgage balance).

financial institution that may influence pricing. As before, we find that credit scores have little impact on credit card APRs. APRs rise with the total number of cards, though the effect is not statistically significant. Other controls, including the total card balance, log income, and balances on other debt, do not have economically or statistically significant effects on credit card APRs. ${ }^{50}$

\section{C.4 Auto Loans}

Table 11 reports the results of regressing the APR paid for auto loans on an age-based spline and control variables. Here, FICO credit risk scores have a statistically and economically significant impact on loan terms-a one percent increase in FICO score reduces auto loan APRs by about 10 basis points. This may be a consequence of bank loan pricing models that take FICO scores as inputs. Higher incomes lower APRs and higher debt-to-income ratios raise them, though the magnitudes of the effects are small. We also include car characteristics, such as type and age, as one of us has found those variables to matter for APRs in other work (Agarwal, Ambrose, and Chomsisengphet, 2007)-though we note that the financial institutions do not directly condition their loans on such variables. We also include loan age and state dummies.

\footnotetext{
${ }^{50}$ An alternative specification including the total number of cards and total balance on cards yielded nearly identical results. Note that we are not able to include the financial institution's own internal credit score (also known as the behavior score), since that variable cannot be computed by the institution until the borrower's payment behavior is observed, and is thus unavailable at account opening.
} 


\begin{tabular}{|l|r|r|}
\hline \multicolumn{3}{|c|}{ Auto Loan APR } \\
\hline & Coefficient & Std. Error \\
\hline Intercept & 11.4979 & 1.3184 \\
Age $<30$ & -0.0231 & 0.0045 \\
Age 30-40 & -0.0036 & 0.0005 \\
Age 40-50 & -0.0054 & 0.0005 \\
Age 50-60 & 0.0046 & 0.0007 \\
Age 60-70 & 0.0031 & 0.0017 \\
Age > 70 & 0.0091 & 0.0042 \\
Log(Income) & -0.3486 & 0.0176 \\
Log(FICO) & -0.0952 & 0.0059 \\
Debt/Income & 0.0207 & 0.0020 \\
Japanese Car & -0.0615 & 0.0270 \\
European Car & -0.0127 & 0.0038 \\
Loan Age & 0.0105 & 0.0005 \\
Car Age & 0.1234 & 0.0031 \\
State Dummies & YES & \\
Quarter Dummies & YES & \\
\hline Number of Observations & 6,996 & \\
Adjusted R-squared & 0.0928 & \\
\hline
\end{tabular}

Table 11: This table gives coefficient estimates from a regression of the APR of an auto loan on a spline with age as its argument, financial control variables $(\log (\mathrm{FICO})$ credit risk score, income, and the debt-toincome ratio), and other controls (state dummies, dummies for whether the car is Japanese or European, loan age, and car age). 


\begin{tabular}{|l|r|r|}
\hline \multicolumn{3}{|c|}{ Mortgage APR } \\
\hline & Coefficient & Std. Error \\
\hline Intercept & 12.4366 & 4.9231 \\
Age $<30$ & 0.0027 & 0.0046 \\
Age 30-40 & -0.0023 & 0.0047 \\
Age 40-50 & -0.0057 & 0.0045 \\
Age 50-60 & 0.0127 & 0.0093 \\
Age 60-70 & 0.0155 & 0.0434 \\
Age > 70 & 0.0234 & 0.0881 \\
Log(Income) & -0.2843 & 0.1303 \\
Log(Credit Score) & -0.1240 & 0.0217 \\
Debt/Income & 0.0859 & 0.2869 \\
Loan Term & -0.0114 & 0.0037 \\
Loan Term Squared & -0.0000 & $<0.0001$ \\
Loan Amount & -0.0000 & $<0.0001$ \\
Loan to Value & 0.1845 & 0.0187 \\
Years on the Job & -0.0108 & 0.0046 \\
Second Home & 0.1002 & 0.1014 \\
Auto & 0.1174 & 0.0807 \\
Auto Value & 0.0000 & 0.0000 \\
Gender (1=Female) & 0.0213 & 0.0706 \\
Married & -0.0585 & 0.0831 \\
Two Incomes & -0.1351 & 0.1799 \\
Married with Two Incomes & -0.0116 & 0.1957 \\
Employment: Professional & -0.0438 & 0.1174 \\
Employment:Non-Professional & 0.0853 & 0.1041 \\
Merchant & -0.1709 & 0.1124 \\
Bank Relationship & -0.2184 & 0.1041 \\
\hline Number of Observations & 4,867 & \\
Adjusted R-squared & 0.1004 & \\
\hline
\end{tabular}

Table 12: This table reports the estimated coefficients from a regression of mortgage APR on a spline with age as its argument and financial and demographic control variables.

\section{C.5 Mortgages}

Table 12 reports results of regressing the mortgage APR on an age-based spline and control variables. As controls, we again use variables observed by the financial institution that may affect loan pricing, including risk measures (credit score, income, mortgage payment as a fraction of income, and LTV), and various demographic and financial indicators (gender, marital status, a dummy variable for car ownership, and several others - these coefficients are not reported to save space). The coefficients on the controls are again of the expected sign and generally statistically significant, though of small magnitude.

The coefficients on the age spline are positive below age 30, then negative through age 60 and positive thereafter. 


\begin{tabular}{|l|r|r|}
\hline \multicolumn{3}{|c|}{ Small Business Credit Card APR } \\
\hline & Coefficient & Std. Error \\
\hline Intercept & 16.0601 & 0.6075 \\
Age $<30$ & -0.0295 & 0.0081 \\
Age 30-40 & -0.0068 & 0.0040 \\
Age 40-50 & -0.0047 & 0.0038 \\
Age 50-60 & -0.0017 & 0.0055 \\
Age 60-70 & 0.0060 & 0.0209 \\
Age $>70$ & 0.0193 & 0.0330 \\
Years in Business 1-2 & -0.5620 & 0.1885 \\
Years in Business 2-3 & -0.7463 & 0.1937 \\
Years in Business 3-4 & -0.2158 & 0.1031 \\
Years in Business 4-5 & -0.5100 & 0.0937 \\
Years in Business 5-6 & -0.4983 & 0.0931 \\
Log(FICO) & -0.0151 & 0.0008 \\
Number of Cards & 0.1379 & 0.0153 \\
Log(Total Card Balance) & $<0.0001$ & $<0.0001$ \\
Log(Total Card Limit) & $<0.0001$ & $<0.0001$ \\
\hline Number of Observations & 11,254 & \\
Adjusted R-squared & 0.0933 & \\
\hline
\end{tabular}

Table 13: This table reports the estimated coefficients from a regression of the APR for small business credit cards on a spline with the business owner's age as its argument and other control variables (dummies for years in business, $\log$ (FICO) credit risk score, number of cards, total card balance, and total card limit).

\section{C.6 Small Business Credit Cards}

Table 13 reports the results of regressing the APR for small business credit cards on an age-based spline and control variables. As with individual credit card accounts, we control for the FICO score of the business owner, the total number of cards, card balance, and card limit. We also include dummy variables for the number of years the small business has been operating - we expect APRs to fall for businesses with longer operating histories. All control variables are statistically significant and have the expected sign, though only the dummies for years in business have substantial magnitudes.

\section{C.7 Credit Card Fees}

Certain credit card uses involve the payment of a fee. Some kinds of fees are assessed when terms of the credit card agreement are violated. Other fees are assessed for use of services.

In the next three sections, we focus on three important types of fees: late fees, over limit fees, and cash advance fees. ${ }^{51}$ We describe the fee structure for our dataset below.

\footnotetext{
${ }^{51}$ Other types of fees include annual, balance transfer, foreign transactions, and pay by phone. All of these fees are relatively less important to both the bank and the borrower. Few issuers (the most notable exception being American Express) continue
} 
1. Late Fee: A late fee of between $\$ 30$ and $\$ 35$ is assessed if the borrower makes a payment beyond the due date on the credit card statement. If the borrower is late by more than 60 days once or by more than 30 days twice within a year, the bank may also impose 'penalty pricing' by raising the APR to over 24 percent. The bank may also choose to report late payments to credit bureaus, adversely affecting consumers' FICO scores. ${ }^{52}$ If the borrower does not make a late payment during the six months after the last late payment, the APR will revert to its normal (though not promotional) level.

2. Over Limit Fee: An over limit fee - also between $\$ 30$ and $\$ 35$ - is assessed the first time the borrower exceeds his or her credit limit. Over limit violations generate penalty pricing that is analogous to the penalty pricing that is imposed as a result of late fees. ${ }^{53}$

3. Cash Advance Fee: A cash advance fee - which is the greater of 3 percent of the amount advanced, or $\$ 5$ - is levied for each cash advance on the credit card. Unlike the first two fees, this fee can be assessed many times per month. It does not cause the imposition of penalty pricing. However, the APR on cash advances is typically greater than the APR on purchases, and is usually 16 percent or more.

Payment of these fees is not generally a mistake. For example, if a card holder is vacationing in Tibet, it may not be optimal to arrange a credit card payment for that month. However, payments of fees are sometimes mistakes, since the fee payment can often be avoided by small and relatively costless changes in behavior. For instance, late fees are sometimes due to memory lapses that could be avoided by putting a reminder in one's calendar.

We use the same data set as that used for the credit card APR case study discussed above.

Table 14 presents panel regressions for each type of fee. In each of the three regressions, we regress a dummy variable equal to one if a fee is paid that month on an age-based spline and control variables. Hence, the coefficients give the conditional effects of the independent variables on the propensity to pay fees.

The control variables differ from those of the preceding six examples. Now we control for factors that might affect the propensity to pay a fee, which are not necessarily the same as factors that might lead borrowers to default or otherwise affect their borrowing terms. "Bill Existence" is a dummy variable equal to one if a bill was issued last month; borrowers will only be eligible to pay a late fee if a bill was issued. "Bill Activity" is a dummy variable equal to one if purchases or payments were made on the card; borrowers will only be eligible to pay over limit or cash advance fees if the card was used. "Log(Purchases)" is the log of the amount purchased on the card, in dollars; we would expect that the propensity to pay over limit and cash advance fees would be increasing with the amount of purchases. "Log(FICO)" is the credit risk score,

to charge annual fees, largely as a result of increased competition for new borrowers (Agarwal et al., 2005). The cards in our data do not have annual fees. We study balance transfer behavior using a separate data set below. The foreign transaction fees and pay by phone fees together comprise less than three percent of the total fees collected by banks.

${ }^{52}$ The financial institution generally reports such information to credit bureaus and imposes penalty pricing after two months of late payment.

${ }^{53}$ As with the late fee, such penalty pricing is generally imposed after two months of exceeding the credit limit. 


\begin{tabular}{|l|r|r|r|r|r|r|}
\hline & \multicolumn{2}{|l|}{ Late Fee } & \multicolumn{2}{l|}{ Over Limit Fee } & \multicolumn{2}{l|}{ Cash Adv. Fee } \\
\hline & \multicolumn{1}{|c|}{ Coeff. } & Std. Err. & \multicolumn{1}{c|}{ Coeff. } & Std. Err. & \multicolumn{1}{c|}{ Coeff. } & Std. Err. \\
\hline Intercept & 0.2964 & 0.0446 & 0.1870 & 0.0802 & 0.3431 & 0.0631 \\
Age $<30$ & -0.0021 & 0.0004 & -0.0013 & 0.0006 & -0.0026 & 0.0011 \\
Age 30-40 & -0.0061 & 0.0003 & -0.0003 & 0.0001 & -0.0004 & 0.0002 \\
Age 40-50 & -0.0001 & $<0.0001$ & -0.0002 & $<0.0001$ & -0.0002 & $<0.0001$ \\
Age 50-60 & -0.0002 & $<0.0001$ & -0.0002 & $<0.0001$ & -0.0003 & $<0.0001$ \\
Age 60-70 & 0.0004 & 0.0002 & 0.0003 & 0.0001 & 0.0004 & $<0.0001$ \\
Age > 70 & 0.0025 & 0.0013 & 0.0003 & 0.0001 & 0.0004 & $<0.0001$ \\
Bill Existence & 0.0153 & 0.0076 & 0.0104 & 0.0031 & 0.0055 & 0.0021 \\
Bill Activity & 0.0073 & 0.0034 & 0.0088 & 0.0030 & 0.0055 & 0.0021 \\
Log(Purchases) & 0.0181 & 0.0056 & 0.0113 & 0.0023 & 0.0179 & 0.0079 \\
Log(Behavior) & -0.0017 & 0.0000 & -0.0031 & 0.0012 & -0.0075 & 0.0036 \\
Log(FICO) & -0.0016 & 0.0007 & -0.0012 & 0.0003 & -0.0015 & 0.0005 \\
Debt/Limit & -0.0066 & 0.0033 & 0.0035 & 0.0013 & 0.0038 & 0.0012 \\
\hline Acct. Fixed Eff. & YES & & YES & & YES & \\
Time Fixed Eff. & YES & & YES & & YES & \\
\hline Number of Obs. & 3.9 Mill. & & 3.9 Mill. & & 3.9 Mill. & \\
Adj. R-squared & 0.0378 & & 0.0409 & & 0.0388 & \\
\hline
\end{tabular}

Table 14: This table reports coefficients from a regression of dummy variables for credit card fee payments on a spline for age, financial control variables $(\log (\mathrm{FICO})$ credit risk score, internal bank behavior risk score, debt over limit) and other control variables (dummies for whether a bill existed last month, for whether the card was used last month, the dollar amount of purchases, and account- and time- fixed effects).

and "Log(Behavior)" is an internal risk score created by the bank to predict late and delinquent payment beyond that predicted by the FICO score. Higher scores mean less risky behavior. The scores are lagged three months because they are only updated quarterly. We would expect the underlying behavior leading to lower credit risk scores would lead to higher fee payment. "Debt/Limit" is the ratio of the balance of credit card debt to the credit limit; we would expect that having less available credit would raise the propensity to pay over limit fees, and possibly other fees.

For late fee payments - column one of the table - all control variables have the expected signs and are statistically significant, though they are also small in magnitude. Note that some control variables may partly capture the effects of age-related cognitive decline on fees. For example, if increasing age makes borrowers more likely to forget to pay fees on time, that would both increase the propensity to pay late fees and decrease credit and behavior scores. Hence, the estimated coefficients on the age splines may understate some age-related effects.

Coefficients on the age splines are uniformly negative for splines through age 50; negative or weakly positive for the spline between age 50 and 60; and positive with increasing slope for splines above age 50. 


\section{Locating the Peak of Performance}

We run the following regression, where $F$ is the outcome associated respectively with each of the 10 studies:

$$
\begin{aligned}
F & =\alpha+\beta \times \operatorname{Spline}(\text { Age })_{\text {Age } \notin[40,60]}+\gamma \times \text { Controls }+\epsilon \\
& +a \times \operatorname{Spline}(\text { Age })_{\text {Age } \in[40,60]}+b \cdot \operatorname{Spline}(\text { Age })_{\text {Age } \in[40,60]}^{2}
\end{aligned}
$$

Here Spline $(A g e)$ is a piecewise linear function that takes consumer age as its argument (with knot points at ages 30,40, 60 and 70). Spline $(A g e)_{A g e \notin[40,60]}$ represents the splines outside of the [40,60] age range,

while Spline $(A g e)_{A g e \in[40,60]}$ is the linear spline with knot points at 40 and 60 . Hence, for age between 40 and 60 , the above formulation is implicitly quadratic in age:

$$
F=\text { Controls }+a \times \text { Age }+b \times \text { Age }^{2} .
$$

The peak of performance is defined as the value that minimizes the above function:

$$
\text { Peak }=-a /(2 b) .
$$

We calculate the asymptotic standard errors on Peak using the delta method, so that the standard error of Peak is the standard error associated with the linear combination:

$$
-1 /(2 b) \cdot(\text { Coefficient on age })+a /\left(2 b^{2}\right) \cdot(\text { Coefficient on age })^{2} .
$$

We next do a formal test for a peak effect. In regression (2), the null hypothesis of a peak effect is: (i) $b>0$, and (ii) Peak $=-a /(2 b) \in[40,60]$. Together these conditions imply that mistakes follow a U-shape, with a peak that is between 40 and 60 years of age. For criterion (i), we note that the $b$ coefficients are positive for all 10 studies. For 9 of the 10 studies, $b$ is significantly different from zero (the credit card APR study is the exception). ${ }^{54}$ For criterion (ii), a peak in the 40-60 age range can not be rejected for all ten studies. 


\begin{tabular}{|c|c|c|c|}
\hline \multicolumn{4}{|c|}{ Average Debt Levels by Age } \\
\hline & \multicolumn{3}{|c|}{ Age } \\
\hline Product & 25 & 50 & 75 \\
\hline Home Equity Loans & $\$ 38,879$ & $\$ 46,057$ & $\$ 36,601$ \\
\hline Home Equity Lines & $\$ 43,477$ & $\$ 56,891$ & $\$ 52,031$ \\
\hline Balance Transferred & $\$ 2,723$ & $\$ 3,123$ & $\$ 2,422$ \\
\hline Credit Card & $\$ 1,426$ & $\$ 1,778$ & $\$ 1,203$ \\
\hline Auto Loans & $\$ 3,782$ & $\$ 4,031$ & $\$ 3,554$ \\
\hline Mortgage & $\$ 40,645$ & $\$ 47,337$ & $\$ 41,403$ \\
\hline Small Business Credit Card & $\$ 1,321$ & $\$ 1,479$ & $\$ 1,275$ \\
\hline
\end{tabular}

Table 15: Average Debt Levels by Age

\section{E Average Debt Levels by Age}

\section{F Additional Results on Possible Explanations for the U-Shaped Pat- terns}

\section{F.1 Age Effects}

The measured age-related decline in analytic performance results from both age effects and cohort effects, but the available panel data implies that the decline is primarily driven by age effects (Salthouse, Schroeder, and Ferrer, 2004). ${ }^{55}$ Medical pathologies represent one important pathway for age effects. For instance, dementia is primarily attributable to Alzheimer's Disease (60\%) and vascular disease (25\%). The prevalence of dementia doubles with every five additional years of lifecycle age (Fratiglioni, De Ronchi, and Agüero-Torres, 1999). There is a growing literature that identifies age-related changes in cognition (see Park and Schwarz, 1999; and Denburg, Tranel, and Bechara 2005). ${ }^{56}$

Specifically, suppose Analytic Capital declines linearly with age, so that Analytic Capital $=\alpha-a g e / \beta$. Suppose Experiential Capital is accumulated with diminishing returns: Experiential Capital $=\ln ($ age $\left.\gamma a g e_{0}\right)$, where $a g e_{0}$ is the actual age at which people start using the product, and $\gamma a g e_{0}<a g e_{0}$ is the effective age at which people start using the product (so $\gamma<1$ ). The effective age is less than the actual age, since consumers get indirect experience (observation and advice) as a result of their interactions with other people who use the product. The additive model - Performance is equal to the sum of Analytic Capital and Experiential Capital - implies that peak performance occurs at Peak $=\beta+\gamma a g e_{0}$. Hence, peak performance is later when people start using the product later in life.

\footnotetext{
${ }^{54}$ To save space, we only report the $t$-statistics associated with the $b$ coefficients. Following the order of the table in the text, they are: $2.20,4.55,7.80,8.77,17.05,1.61,4.57,2.91,3.08,2.67$.

${ }^{55}$ See Flynn (1984) for a discussion of cohort effects.

${ }^{56}$ Mather and Carstensen (2005) and Carstensen (2006) identify a different type of age-variation in cognitive preferences. Subjects with short time horizons or older ages attend to negative information relatively less than subjects with long time horizons or younger ages.
} 


\section{F.2 Selection Effects}

The first three columns of data in Table 16 report a cross-tabulation from a 3 by 5 by 3 matrix. We cross an age-group (ages 25-35, 45-55 and 65-75), with a specific type of borrowing (with credit card balances, housing debt, home equity lines of credit, vehicle loans, and home equity loans), with a specific measure of sophistication (education, income, net worth). Each entry is a ratio of the median sophistication measure for a specific borrower group and age group, divided by the median sophistication measure for the corresponding (total) age group. Standard errors calculated through the delta method are in parentheses. Data is from the 2004 Survey of Consumer Finances (SCF). 


\begin{tabular}{|c|c|c|c|c|}
\hline \multicolumn{5}{|c|}{$\begin{array}{l}\text { Ratio of Median Borrower Characteristics } \\
\text { to Whole Group Characteristics } \\
\text { By Age Group and Debt Type, } 2004 \text { SCF }\end{array}$} \\
\hline \multirow[b]{2}{*}{ Debt Type } & \multirow[b]{2}{*}{ Characteristic } & \multicolumn{3}{|c|}{ Age Group } \\
\hline & & $25-35$ & $45-55$ & $65-75$ \\
\hline \multirow{6}{*}{$\begin{array}{c}\text { Credit Card } \\
\text { Balance }\end{array}$} & \multirow[t]{2}{*}{ Education } & 1.00 & 1.00 & 1.00 \\
\hline & & $(0.01)$ & $(<0.01)$ & $(0.01)$ \\
\hline & \multirow[t]{2}{*}{ Income } & 1.15 & 1.03 & 1.05 \\
\hline & & $(0.03)$ & $(0.02)$ & $(0.06)$ \\
\hline & \multirow[t]{2}{*}{ Net Worth } & 1.14 & 0.91 & 0.58 \\
\hline & & $(0.11)$ & $(0.04)$ & $(0.05)$ \\
\hline \multirow{6}{*}{$\begin{array}{c}\text { Housing } \\
\text { Debt }\end{array}$} & \multirow[t]{2}{*}{ Education } & 1.07 & 1.00 & 1.08 \\
\hline & & $(0.01)$ & $(0.01)$ & $(0.01)$ \\
\hline & \multirow[t]{2}{*}{ Income } & 1.45 & 1.26 & 1.42 \\
\hline & & $(0.04)$ & $(0.03)$ & $(0.05)$ \\
\hline & \multirow[t]{2}{*}{ Net Worth } & 3.39 & 1.53 & 1.08 \\
\hline & & $(0.26)$ & $(0.06)$ & $(0.09)$ \\
\hline \multirow{6}{*}{$\begin{array}{l}\text { Home Equity } \\
\text { Lines of Credit }\end{array}$} & \multirow[t]{2}{*}{ Education } & 1.07 & 1.14 & 1.08 \\
\hline & & $(0.04)$ & $(0.01)$ & $(0.03)$ \\
\hline & \multirow[t]{2}{*}{ Income } & 1.95 & 1.39 & 1.65 \\
\hline & & $(0.10)$ & $(0.04)$ & $(0.12)$ \\
\hline & \multirow[t]{2}{*}{ Net Worth } & 5.48 & 2.45 & 1.99 \\
\hline & & $(0.55)$ & $(0.23)$ & $(0.24)$ \\
\hline \multirow{6}{*}{$\begin{array}{l}\text { Home Equity } \\
\text { Loans }\end{array}$} & \multirow[t]{2}{*}{ Education } & 0.86 & 1.00 & 1.33 \\
\hline & & $(0.18)$ & $(0.02)$ & $(0.05)$ \\
\hline & \multirow[t]{2}{*}{ Income } & 0.68 & 0.86 & 1.48 \\
\hline & & $(0.02)$ & $(0.03)$ & $(0.17)$ \\
\hline & \multirow[t]{2}{*}{ Net Worth } & 0.37 & 1.41 & 1.97 \\
\hline & & $(4.51)$ & $(0.23)$ & $(0.12)$ \\
\hline \multirow{6}{*}{$\begin{array}{l}\text { Vehicle } \\
\text { Loans }\end{array}$} & \multirow[t]{2}{*}{ Education } & 1.00 & 1.00 & 1.00 \\
\hline & & $(0.01)$ & $(<0.01)$ & $(<0.01)$ \\
\hline & \multirow[t]{2}{*}{ Income } & 1.33 & 1.18 & 1.45 \\
\hline & & $(0.03)$ & $(0.02)$ & $(0.07)$ \\
\hline & \multirow[t]{2}{*}{ Net Worth } & 1.54 & 1.11 & 0.78 \\
\hline & & $(0.13)$ & $(0.06)$ & $(0.06)$ \\
\hline \multirow[t]{2}{*}{ Memo } & \% with Debt & 81 & 83 & 53 \\
\hline & Median Debt & $\$ 61,800$ & $\$ 81,800$ & $\$ 23,100$ \\
\hline
\end{tabular}

Table 17: Each entry in this table reports the ratio of the median value of a borrower characteristic within an age group to the median value of the characteristic for all members of that age group. The last two rows report the fraction by age group with debt and the median amount of debt. 
Adverse selection will show up as lower ratios for younger and older borrowers compared to middle-aged borrowers. In other words, adverse selection is present when the ratios of medians in the first and third columns are lower than the ratio of medians in the second column. In contrast, entries in bold reverse this pattern; that is, the bold entries are the ones for which sample selection is advantageous and not adverse. Over seventy percent of the ratios for the 25-35-year-olds are greater than the comparable ratios for the 45-55-year-olds, suggesting that selection tends to generates an advantage for younger borrowers relative to middle-aged borrowers.

Likewise, two-thirds of the ratios for the 65-75-year-olds are greater than the comparable ratios for the 45-55-year-olds. Older borrowers consistently display relatively advantageous selection on education and income compared to middle-aged borrowers. Net worth represents an exception to this pattern, implying that older borrowers are adversely selected for net worth compared to middle-aged borrowers. However, there is one exception to this exception. Older borrowers with home equity lines of credit have advantageous selection for net worth, consistent with the findings of Canner, Durkin and Luckett (1998).

The last two rows of the table report, the fraction of borrowers by age group having any debt and the median value of debt (conditional on having any). These rows show that, although the fraction of households having debt and the median level of debt both fall sharply from ages 45-55 to ages 65-75, over half of older households still have debt, and have a substantial amount of it.

The next table reports comparable results for the 1989, 1998, and 2001 SCFs. 


\begin{tabular}{|c|c|c|c|c|c|c|c|c|c|c|}
\hline \multicolumn{11}{|c|}{$\begin{array}{c}\text { Ratio of Median Borrower Characteristics to Whole Group Characteristics } \\
\text { By Age Group and Debt Type }\end{array}$} \\
\hline & $\mathrm{SCF}$ & \multicolumn{3}{|c|}{1989} & \multicolumn{3}{|c|}{1998} & \multicolumn{3}{|c|}{2001} \\
\hline \multirow{2}{*}{$\begin{array}{l}\text { Debt } \\
\text { Type }\end{array}$} & \multirow[b]{2}{*}{ Char. } & \multicolumn{3}{|c|}{ Age Group } & \multicolumn{3}{|c|}{ Age Group } & \multicolumn{3}{|c|}{ Age Group } \\
\hline & & $25-35$ & $45-55$ & $65-75$ & $25-35$ & $45-55$ & $65-75$ & $25-35$ & $45-55$ & $65-75$ \\
\hline \multirow{6}{*}{$\begin{array}{c}\text { Credit } \\
\text { Card } \\
\text { Balance }\end{array}$} & Educ. & 1.00 & 1.08 & 1.00 & 1.08 & 1.00 & 1.00 & 1.08 & 0.93 & 1.00 \\
\hline & & $(0.01)$ & $(0.01)$ & $(0.01)$ & $(0.01)$ & $(0.01)$ & $(0.02)$ & $(0.01)$ & $(0.01)$ & $(0.01)$ \\
\hline & Inc. & 1.33 & 1.14 & 0.88 & 1.21 & 1.02 & 0.96 & 1.10 & 0.98 & 1.00 \\
\hline & & $(0.04)$ & $(0.03)$ & $(0.06)$ & $(0.03)$ & $(0.02)$ & $(0.01)$ & $(0.30)$ & $(0.27)$ & $(0.05)$ \\
\hline & Net & 1.69 & 1.08 & 0.56 & 1.53 & 0.91 & 0.61 & 1.06 & 0.77 & 0.59 \\
\hline & Worth & $(0.19)$ & $(0.05)$ & $(0.04)$ & $(0.12)$ & $(0.04)$ & $(0.03)$ & $(0.09)$ & $(0.04)$ & $(0.06)$ \\
\hline \multirow{6}{*}{$\begin{array}{c}\text { Housing } \\
\text { Debt }\end{array}$} & Educ. & 1.00 & 1.08 & 1.00 & 1.08 & 1.00 & 1.08 & 1.08 & 1.00 & 1.08 \\
\hline & & $(0.01)$ & $(0.01)$ & $(0.02)$ & $(0.01)$ & $(0.01)$ & $(0.02)$ & $(0.01)$ & $(<0.01)$ & $(0.01)$ \\
\hline & Inc. & 1.54 & 1.31 & 1.25 & 1.45 & 1.28 & 1.76 & 1.44 & 1.34 & 1.56 \\
\hline & & $(0.05)$ & $(0.03)$ & $(0.04)$ & $(0.04)$ & $(0.02)$ & $(0.08)$ & $(0.04)$ & $(0.03)$ & $(0.09)$ \\
\hline & Net & 4.41 & 1.45 & 0.98 & 2.91 & 1.63 & 1.11 & 3.32 & 1.47 & 1.12 \\
\hline & Worth & $(0.39)$ & $(0.06)$ & $(0.14)$ & $(0.21)$ & $(0.07)$ & $(0.07)$ & $(0.26)$ & $(0.06)$ & $(0.12)$ \\
\hline \multirow{6}{*}{$\begin{array}{c}\text { Home } \\
\text { Equity } \\
\text { Lines } \\
\text { of } \\
\text { Credit }\end{array}$} & Educ. & 1.00 & 1.17 & 1.17 & 1.15 & 1.14 & 1.33 & 1.08 & 1.08 & 1.00 \\
\hline & & $(0.01)$ & $(0.03)$ & $(0.07)$ & $(0.02)$ & $(0.02)$ & $(0.05)$ & $(0.05)$ & $(0.12)$ & $(0.04)$ \\
\hline & Inc. & 2.83 & 1.83 & 1.31 & 2.06 & 1.40 & 1.91 & 1.93 & 1.5 & 2.22 \\
\hline & & $(0.13)$ & $(0.17)$ & $(0.03)$ & $(0.09)$ & $(0.06)$ & $(0.10)$ & $(0.14)$ & $(0.05)$ & $(0.28)$ \\
\hline & Net & 11.10 & 1.84 & 3.68 & 6.09 & 1.66 & 6.35 & 6.59 & 2.06 & 2.15 \\
\hline & Worth & $(0.81)$ & $(0.12)$ & $(0.75)$ & $(0.50)$ & $(0.10)$ & $(0.25)$ & $(0.94)$ & $(0.16)$ & $(0.17)$ \\
\hline \multirow{6}{*}{$\begin{array}{l}\text { Home } \\
\text { Equity } \\
\text { Loans }\end{array}$} & Educ. & 0.92 & 1.00 & 0.92 & 1.23 & 0.93 & 1.00 & 1.23 & 0.93 & 1.33 \\
\hline & & $(0.08)$ & $(0.04)$ & $(0.05)$ & $(0.09)$ & $(0.02)$ & $(0.06)$ & $(0.01)$ & $(0.03)$ & $(0.01)$ \\
\hline & Inc. & 1.38 & 1.14 & 1.25 & 2.27 & 1.26 & 1.57 & 1.00 & 1.29 & 0.78 \\
\hline & & $(0.05)$ & $(0.15)$ & $(0.17)$ & $(0.34)$ & $(0.04)$ & $(0.30)$ & $(0.10)$ & $(0.35)$ & $(0.40)$ \\
\hline & Net & 15.40 & 3.22 & 0.54 & 5.85 & 1.76 & 0.84 & 1.83 & 2.65 & 0.79 \\
\hline & Worth & $(2.64)$ & $(0.31)$ & $(0.07)$ & $(3.40)$ & $(0.05)$ & $(0.14)$ & $(0.40)$ & $(0.31)$ & $(0.65)$ \\
\hline \multirow{6}{*}{$\begin{array}{l}\text { Vehicle } \\
\text { Loans }\end{array}$} & Educ. & 1.00 & 1.00 & 1.00 & 1.00 & 1.00 & 1.00 & 1.08 & 1.08 & 1.00 \\
\hline & & $(0.01)$ & $(0.01)$ & $(0.02)$ & $(0.01)$ & $(0.01)$ & $(<0.01)$ & $(0.01)$ & $(0.03)$ & $(0.01)$ \\
\hline & Inc. & 1.38 & 1.15 & 1.31 & 1.21 & 1.10 & 1.30 & 1.28 & 1.15 & 1.26 \\
\hline & & $(0.04)$ & $(0.03)$ & $(0.04)$ & $(0.03)$ & $(0.03)$ & $(0.09)$ & $(0.03)$ & $(0.03)$ & $(0.08)$ \\
\hline & Net & 1.98 & 1.02 & 0.64 & 1.50 & 0.95 & 0.76 & 1.60 & 1.02 & 0.83 \\
\hline & Worth & $(0.20)$ & $(0.05)$ & $(0.04)$ & $(0.13)$ & $(0.04)$ & $(0.06)$ & $(0.14)$ & $(0.05)$ & $(0.12)$ \\
\hline
\end{tabular}

Table 18: Each entry in this table reports the ratio of the median value of a borrower characteristic within an age group to the median value of the characteristic for all members of that age group. 


\section{F.2.1 Incorporating Sample Selection Information into the Regressions of APR and Fees on Age}

We use these ratios to construct three indicator variables for changing financial sophistication of the pool of borrowers. For each type of borrowing in Table 16 , define $R_{i}^{e d u c}, R_{i}^{\text {inc }}$, and $R_{i}^{\text {netw }}$ to be the ratio of borrower to non-borrower characteristics corresponding to borrower $i$ 's age group for education, income, and net worth, respectively. For example, a 33-year-old home equity line of credit borrower would have $R_{i}^{\text {educ }}=1.07, R_{i}^{\text {inc }}=1.95$, and $R_{i}^{\text {netw }}=5.48$. Then define $Z_{i}^{\text {educ }}=R_{i}^{\text {educ }} / R_{45-55}^{\text {educ }}, Z_{i}^{\text {inc }}=R_{i}^{\text {inc }} / R_{45-55}^{\text {inc }}$, and $Z_{i}^{\text {netw }}=R_{i}^{\text {netw }} / R_{45-55}^{\text {netw }}$. The $Z$ variables normalize each of the $R$ variables by the peer-group ratio of 45-55-year-olds. Thus, for a 33-year-old home equity line of credit borrower, $Z_{i}^{\text {educ }}=1.07 / 1.14=0.94$, $Z_{i}^{\text {inc }}=1.95 / 1.39=1.40$, and $Z_{i}^{\text {netw }}=5.48 / 2.45=2.24$.

The $Z$ variables are intended to capture potential deterioration in the borrower pool by age, using borrowers age $45-55$ as a baseline. If for a borrower a $Z$ variable is greater than one, that means, at that borrower's age and for that characteristic, borrowers generally have better characteristics relative to non-borrowers than is the case for 45-55-year-olds. The converse is true if $Z<1$.

Since we have more than one indicator of deterioration in the borrower pool, and all indicators are potentially noisy, we assume that each $Z$ variable depends on both an unobserved (or latent) measure of borrower pool deterioration $D$ and the set of Controls included in equation 1, and augment the latter with $D$. Thus, the full system of equations is:

$$
\begin{aligned}
F & =\alpha+\beta \times \operatorname{Spline}(\text { Age })+\gamma \times \text { Controls }+\theta \times D+\epsilon \\
Z^{\text {educ }} & =\lambda^{e d u c} \times \text { Controls }+\delta^{e d u c} \times D+\nu^{e d u c} \\
Z^{i n c} & =\lambda^{i n c} \times \text { Controls }+\delta^{\text {inc }} \times D+\nu^{\text {inc }} \\
Z^{\text {netw }} & =\lambda^{\text {netw }} \times \text { Controls }+\delta^{\text {netw }} \times D+\nu^{\text {netw }},
\end{aligned}
$$

where the error terms are assumed to be uncorrelated with each other. If sample selection is driving the results, we would expect the coefficient $\beta$ on $\operatorname{Spline}(\mathrm{Age})$ in the first equation to be zero and the coefficient $\theta$ on the unobserved pool deterioration variable $D$ to be negative.

Note that an alternative way to proceed would be to directly put one of the $Z$ variables into the first equation instead of $D$ and use the other two $Z$ variables as instruments (as discussed in Wooldridge 2007 and Griliches 1977). That approach, although consistent, is not efficient and has the disadvantage of requiring one to choose which variable goes into the regression and which to serve as instruments-in this case, three possibilities. The latent variable approach described above is both consistent and efficient and represents the optimal combination of instrumental variable estimates.

We estimate the latent variable model for all four types of borrowing for which we have SCF data-home equity loans, home equity lines of credit, credit cards, and auto loans- via maximum likelihood, using the SAS TCALIS procedure. For brevity, we present the results just for home equity loans; results for other 
types of lending are qualitatively similar. Estimates for the main equation are presented in Table 19. Note that the estimate for the coefficient on $D$ is negative and statistically insignificant. Moreover, the point estimate is not large enough to explain the large differences in APRs that we observe for younger and older borrowers. This analysis does not support the idea that deterioration in the pool of borrowers by age is an important driver of the U-shape patterns we see. 


\begin{tabular}{|l|r|r|}
\hline \multicolumn{3}{|c|}{ Home Equity Loan APR } \\
\hline & Coefficient & Std. Error \\
\hline Intercept & 7.5822 & 0.1236 \\
Log(FICO Score) & -0.0017 & 0.0006 \\
Loan Purpose-Home Improvement & 0.0148 & 0.0116 \\
Loan Purpose-Rate Refinance & -0.0068 & 0.0100 \\
No First Mortgage & -0.1680 & 0.0090 \\
Log(Months at Address) & 0.0019 & 0.0037 \\
Second Home & 0.3188 & 0.0221 \\
Condominium & 0.3633 & 0.0149 \\
Log(Income) & -0.0605 & 0.0066 \\
Debt/Income & 0.0033 & 0.0002 \\
Log(Years on the Job) & -0.0211 & 0.0038 \\
Self Employed & 0.0088 & 0.0149 \\
Home Maker & -0.0315 & 0.0362 \\
Retired & 0.0315 & 0.0210 \\
Age < 30 & -0.0461 & 0.0073 \\
Age 30-40 & -0.0280 & 0.0039 \\
Age 40-50 & -0.0111 & 0.0041 \\
Age 50-60 & 0.0087 & 0.0033 \\
Age 60-70 & 0.0160 & 0.0066 \\
Age $>$ 70 & 0.0207 & 0.0087 \\
LTV 80-90 & 0.5453 & 0.0094 \\
LTV 90+ & 1.4697 & 0.0108 \\
Log(House Value) & 0.0009 & 0.0002 \\
Log(Loan Amount) & 0.0176 & 0.0057 \\
D & -0.2121 & 0.2644 \\
State Dummies & YES & \\
\hline Number of Observations & 16,683 & \\
\hline
\end{tabular}

Table 19: The first column gives coefficient estimates for a regression of the APR of a home equity loan on a spline with age as its argument, financial control variables $(\log (\mathrm{FICO})$ credit risk score, income, and the debt-to-income-ratio), other controls (state dummies, a dummy for loans made for home improvements, a dummy for loans made for refinancing, a dummy for no first mortgage on the property, months at the address, years worked on the job, dummies for self-emplyed, retiree, or homemaker status, and a dummy if the property is a condominium), and a latent variable D for deterioration of the pool of borrowers. 
Home Equity Loan APR by Borrower Age

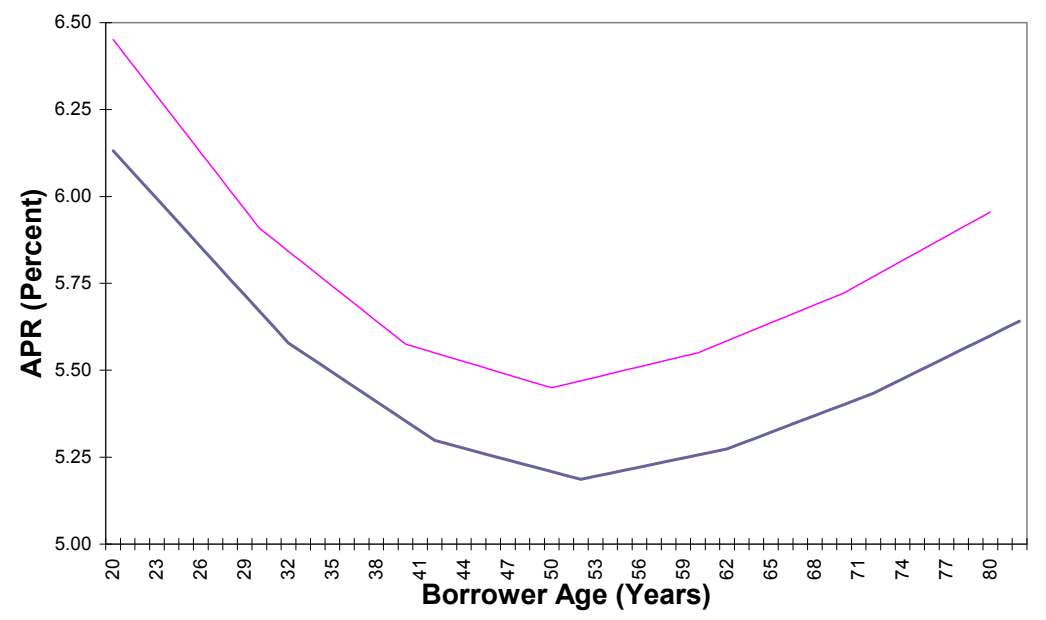

Figure 10: This figure plots fitted values of two regression of home equity loan APRs on a spline for age, with other controls. The darker line plots estimates for a four-equation model with a latent variable for deterioration in the pool of borrowers, as described in the text. The lighter line plots estimates without that latent variable.

Figure 10 plots the new fitted values for the age spline along with the old fitted values for the age splines. Both sets of fitted values display nearly the same pattern-which was to be expected, since the SCF ratios generally showed that the pools of relatively young and old borrowers generally had better levels of education, income, and net worth relative to their peers than the pool of middle-aged borrowers.

Taken as a whole, these results suggest that borrowers are generally better-educated, have higher income, and are wealthier than non-borrowers; older borrowers have higher levels of education and income, but lower net worth levels, relative to their peers than do middle-aged borrowers; and younger borrowers have higher education, income, and net worth levels relative to their peers than do middle-aged borrowers These results do not offer support to the idea that differential adverse selection in the borrowing pool by age is responsible for the U-shapes by age that we see; indeed, many of the results appear to go in the opposite direction.

\section{F.2.2 Comparing Characteristics by Race}

Another potential explanation for the U-shape patterns in APRs and fees is that they may reflect a combination of discrimination and a U-shape in the fraction of borrowers by racial group. If banks charge higher rates to African Americans, and larger fractions of younger borrowers and older borrowers are African American, we would expect to see rates for younger and older borrowers to be higher than middle-aged borrowers.

Table 20 uses SCF data to compute the racial composition of borrowers by borrowing category and 


\begin{tabular}{|c|c|cccc|}
\hline \multicolumn{6}{|c}{ Racial Composition of Borrowers, by Borrowing Category and Age Group (SCF) } \\
\hline \multirow{5}{*}{ Credit Card } & Age Group & White & African American & Hispanic & Other \\
\cline { 2 - 6 } & $25-35$ & 66.6 & 17.3 & 12.6 & 3.6 \\
& $45-55$ & 72.9 & 12.8 & 8.2 & 6.1 \\
Home Equity & $65-75$ & 81.8 & 12.8 & 4.7 & 0.8 \\
\cline { 2 - 6 } Line of Credit & $25-35$ & 93.8 & 0 & 3.1 & 3.1 \\
& $45-55$ & 92.2 & 2.1 & 2.1 & 3.6 \\
\cline { 2 - 6 } Home Equity Loan & $65-75$ & 88.6 & 6.8 & 4.6 & 0 \\
\cline { 2 - 6 } & $25-35$ & 66.7 & 0 & 33.3 & 0 \\
Vehicle Loan & $45-55$ & 90.5 & 4.8 & 4.8 & 0 \\
& $65-75$ & 100 & 0 & 0 & 0 \\
\cline { 2 - 6 } & $25-35$ & 71.8 & 15.4 & 9.0 & 3.8 \\
& $45-55$ & 78.7 & 9.7 & 6.4 & 5.3 \\
& $65-75$ & 88.2 & 7.0 & 4.8 & 0 \\
\hline
\end{tabular}

Table 20: Each entry gives the fraction of borrowers within the given age group and borrowing category by race.

age group. In no case does the fraction of non-white borrowers show a U-shape by age. Moreover, the changes that we do observe are relatively small in magnitude. ${ }^{57}$

\section{F.2.3 Comparing Older Adults to Younger Adults in Our Sample}

As an alternative approach to evaluating the importance of selection effects, we ask whether the older adults in our sample have comparable socio-economic characteristics to the other adults in our sample. Figure 11 shows that credit-worthiness (FICO) scores on home equity loans and lines show a U-shape by age distribution. In other words, older and younger borrowers in our sample, are less risky than middleaged borrowers in our sample. Figure 12 shows that LTV ratios decline substantially with age, indicating that older borrowers in our sample are devoting a relatively smaller fraction of their assets to servicing home equity loans and lines. Likewise, Appendix Table A9 shows that debt levels rise from age 25 to 50 and then decline to age $75 .{ }^{58}$ Finally below, we report that default rates are lower for older borrowers in our sample relative to younger borrowers. These analyses suggest that the older borrowers in our sample compare favorably (in terms of risk characteristics) to the other borrowers in our sample.

We also find that average income for home equity loan borrowers rises from $\$ 76,000$ for those aged less than 30 , and about the same to those between 30 and 40 to a peak of $\$ 88,500$ for those between 40 and 50 , and then declines to about $\$ 69,000$ for those between 60 and 70 and $\$ 62,000$ for those over 70 . These relative income levels are consistent with the pattern of earnings measured in studies of representative populations of US households (e.g. Gourinchas and Parker, 2002).

\footnotetext{
${ }^{57}$ For a five percentage point change in sample composition to explain a 75 basis point increase, for example, discrimination would have to increase borrowing costs by about $\frac{75}{0.05}=1500$ basis points.

${ }^{58}$ In comparing the debt levels with those from survey data, one should bear in mind that these data, from the lender, may be higher than those reported by individuals. Gross and Souleles (2002a, 2002b) document the under-reporting of credit card debt by individuals.
} 
All in all, the characteristics that we observe do not point to strong negative selection effects for the older adults in our sample. This is probably due to the fact that our sample only includes prime borrowers, and is thus truncated in a way that reduces some selection effects that might otherwise arise. In our sample average FICO score levels are much higher than those for the population as a whole; default rates are lower; and income levels are higher.

Figure 13 shows the results of re-estimating the regressions for home equity loans and lines of credit, now dropping data on all borrowers over the age of 60 . There is less reason to believe that the pool of borrowers below 60 are subject to sample selection problems. The results still show a U-shape, albeit somewhat less pronounced. ${ }^{59}$

In principle, an additional way to attempt to determine how selection effects affect our results would be to compare debt levels in our data to those in the SCF. However, this approach has two difficulties which make comparisons difficult. First, our data only captures borrowing from one financial institution. This is important for some categories, such as credit cards, in which consumers may borrow from several different institutions. This effect suggests that our data should understate the total amount of borrowing. Second, Gross and Souleles (2002) and Zinman (2007) have documented that the SCF and other selfreported surveys tend to greatly understate their amount of debt (by a factor of three or more). This effect suggests that our data should overstate the total amount of borrowing. In practice, the first effect appears to dominate: for example, in the $2001 \mathrm{SCF}$, average credit card debt holdings, conditional on having debt, by 70-79-year-olds is $\$ 3,471$, while for our sample for 75 -year olds the comparable number is $\$ 1,203$. Thus while our data show relatively little debt holding by the relatively old, conditional on having debt, those figures may be a consequence of having access to data from only one financial institution.

\section{F.3 Cohort Effects}

Figures 14 and 15 plot the residual effects of age on home equity line and loan APR for female and male borrowers, respectively. Both show a U-shaped pattern by age, with no substantive difference between the two groups.. Figures 16 and 17 replicate the plots of the fitted values of the effects of age on APR for this earlier dataset. Both plots show the same U-shape, with the minimum in the early 50s (like our results using later cross-sections). If our findings were driven by cohort effects, the U-shape should not reproduce itself in cross-sections from different years.

\section{F.4 Default Risk}

The figure below plots the effects of borrower age on default frequency, after controlling for other observable characteristics.

\footnotetext{
${ }^{59}$ This graph also reinforces the arguments above that potential higher riskiness of borrowers above age 60 is likely not responsible for the results.
} 


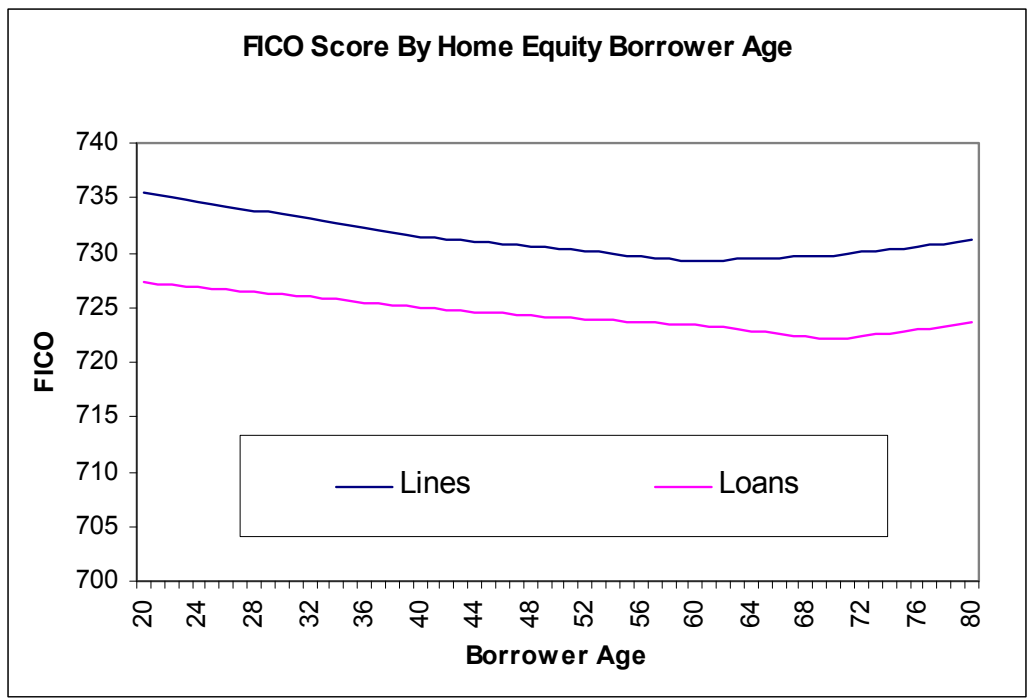

Figure 11: This figure plots the FICO (credit-worthiness) scores of home equity loan and line of credit borrowers by age. A high FICO score means a high credit-worthiness.

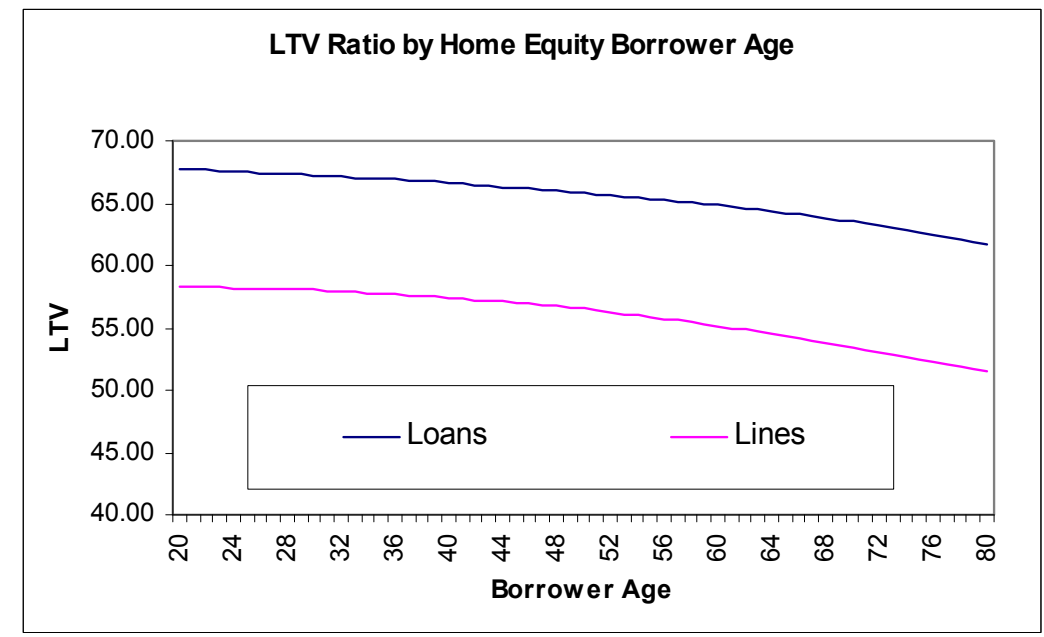

Figure 12: This figure plots the loan-to-value (LTV) ratio of home equity loan and line of credit borrowers by borrower age. 


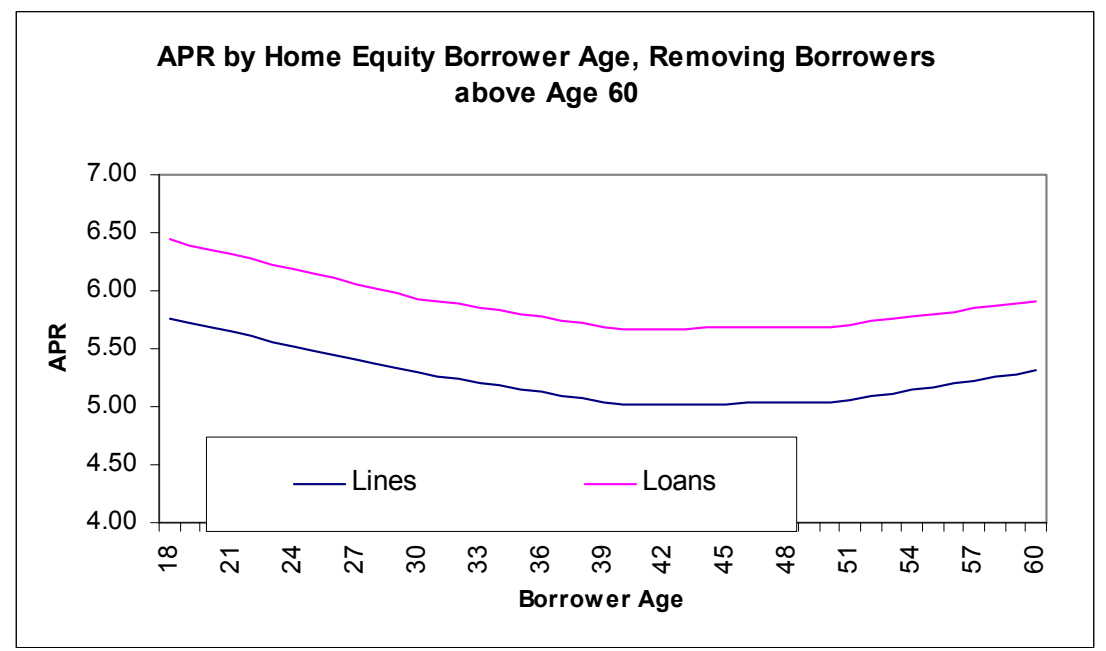

Figure 13: This figure plots the residual effect of age on home equity loan and line APRs, after controlling for other observable characteristics, such as $\log$ (income) and credit-worthiness. Observations on borrowers over age 60 have been dropped.

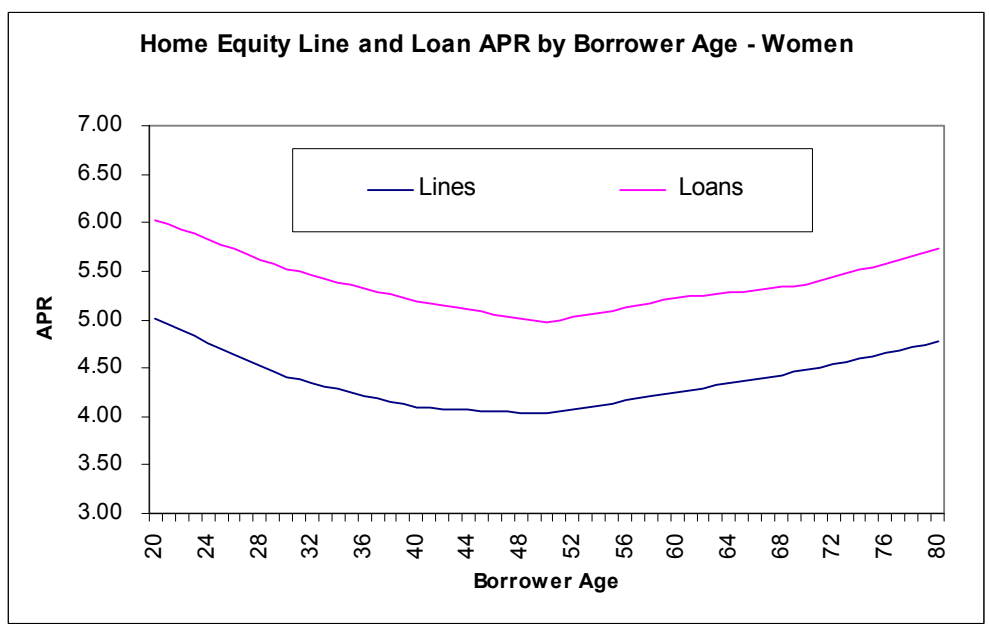

Figure 14: This figure plots the residual effect of age on home equity loan and line APRs for women, after controlling for other observable characteristics, such as $\log$ (income) and credit-worthiness. 


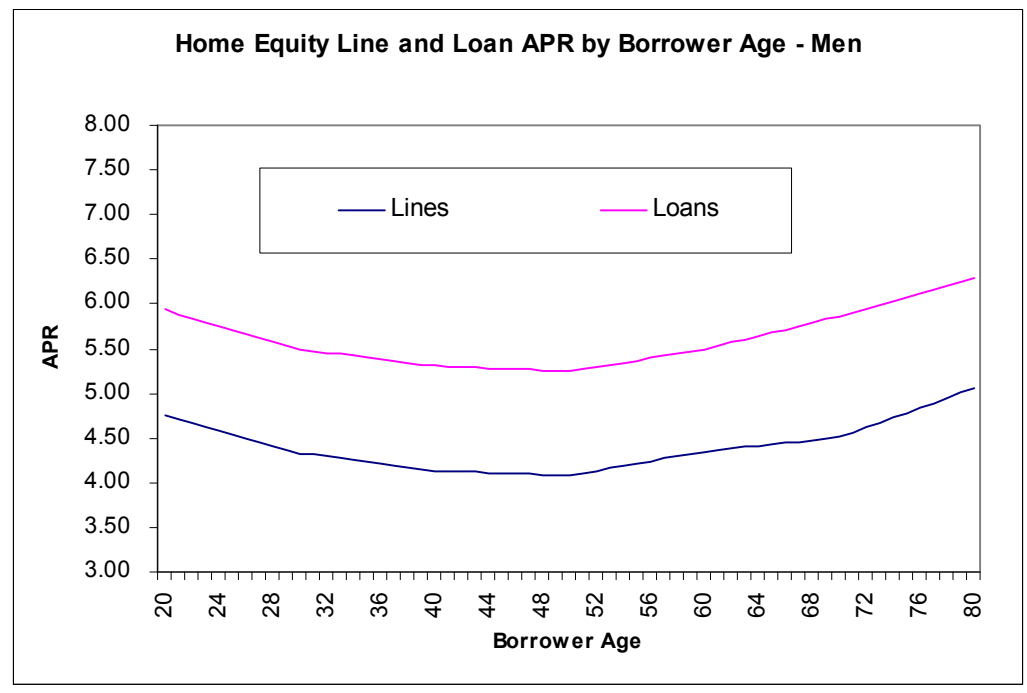

Figure 15: This figure plots the residual effect of age on home equity loan and line APRs for men, after controlling for other observable characteristics, such as $\log$ (income) and credit-worthiness.

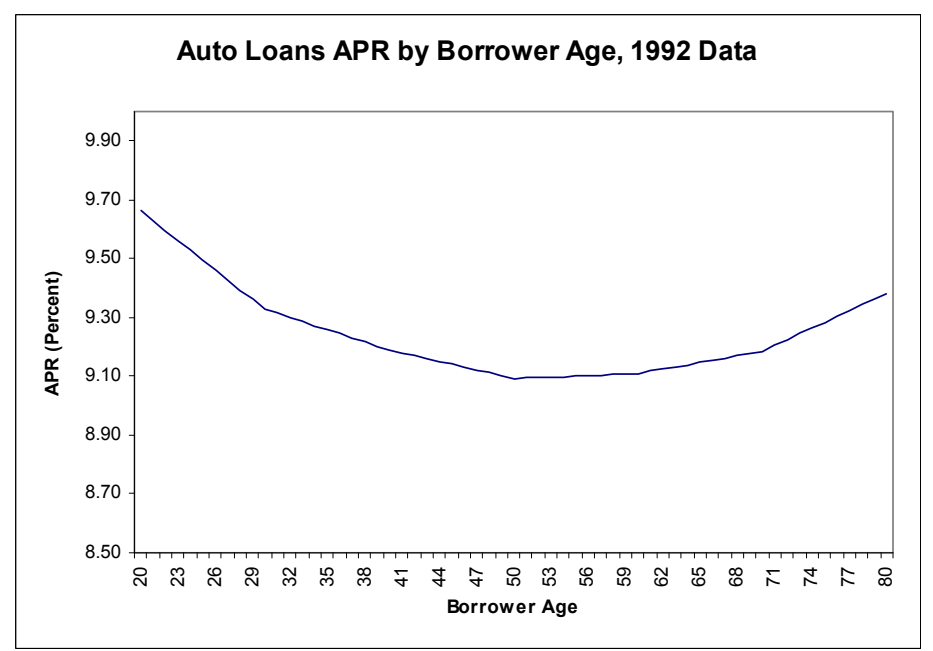

Figure 16: Auto loan APR by borrower age. The figure plots the residual effect of age, after controlling for other observable characteristics, such as $\log$ (income) and credit-worthiness. Data is from 1992. 


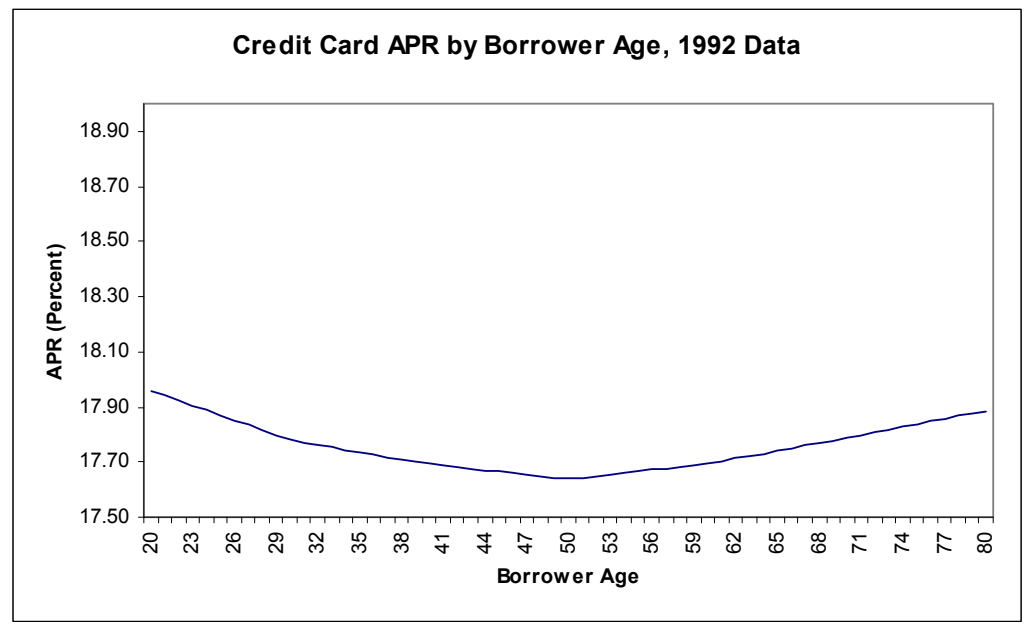

Figure 17: Credit card APR by borrower age. The figure plots the residual effect of age, after controlling for other observable characteristics, such as $\log$ (income) and credit-worthiness. Data is from 1992.

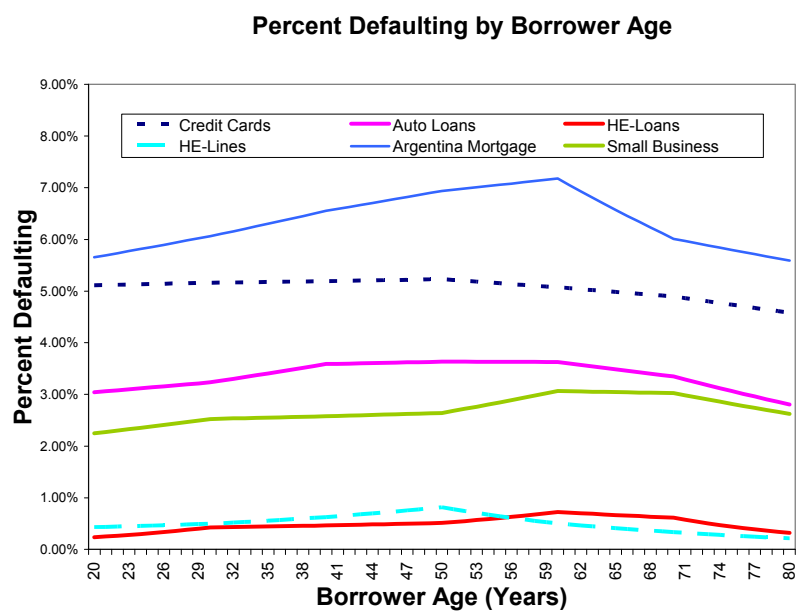

Figure 18: Default frequency by borrower age. The figure plots the residual effect of age, after controlling for other observable characteristics, such as $\log$ (income) and credit-worthiness. 


\section{F.5 Opportunity Cost}

The tables below provide results from two special questions in the 2007 Survey of Consumer Finances (SCF). The first question asks about shopping intensity for decisions about borrowing money or obtaining credit. At younger ages, the vast majority of respondents report doing a moderate or a great deal amount of shopping about borrowing decisions. Through age group 45-54, roughly 15 percent report doing almost no shopping. That latter percentage then increases rapidly, to 20 percent for 55-64-year-olds, 30 percent for 65-74-year-olds, and about 45 percent for those 75 and older. It appears that older adults are not using whatever extra time that they may have by virture of being retired to more intensively shop for borrowing decisions.

\begin{tabular}{|c|c|c|c|}
\hline Table 21: & \multicolumn{3}{|c|}{ Shopping Intensity for Borrowing Decisions } \\
\hline & \multicolumn{3}{|c|}{ Intensity of Shopping (\% reporting) } \\
\hline Age & A Great Deal & Moderate & Almost None \\
\hline Less than 35 & 24 & 61 & 15 \\
\hline $35-44$ & 28 & 58 & 13 \\
\hline $45-54$ & 25 & 60 & 15 \\
\hline $55-64$ & 27 & 53 & 21 \\
\hline $65-74$ & 24 & 46 & 30 \\
\hline 75 or More & 15 & 39 & 46 \\
\hline
\end{tabular}

The second question asks about sources of information used in making borrowing decisions. We again report results by age group in the table below. ${ }^{60}$ Respondents were asked to check all sources that applied; hence totals do not sum to 100. The data seem to show two types of patterns by age. Some sources of information show an inverse U-shape in usage by age-for example, both the relatively young and the relatively old use financial planners, financial professionals, magazines, and newspapers less than the middle-aged. Other sources of information show a decline by age; for example, about 60 percent of borrowers younger than 65 use friends at work for information, while about 30 percent of 65-74-year-olds and borrowers aged 75 or more use this source of information. Overall, borrowers age 65-74 and 75 and above appear to use fewer sources of all types of information than do borrowers at younger ages. Also note that although the fraction of respondents reporting they do not borrow rises substantial for borrowers at 65-74 and 75 and older, over 70 percent of respondents in the latter category are still borrowing (consistent with some of the results reported above).

\footnotetext{
${ }^{60}$ Definitions: "Financial Planner" is a lawyer, accountant, or financial planner; "Financial Professional" is a banker, broker, real estate broker, builder, dealer, or insurance agent; "Friend at Work" refers to friends or material from work or business contacts; "Internet" refers to internet or online services; "Magazine or Newspaper" refers to magazines, newspapers, or books; "Mail" refers to material in the mail, TV, radio, or other advertisements, or telemarkets; "Call Around" means the borrower reporting calling around for information; and "Self" means the respondent reported relying on themselves, shopping around, or doing other personal research.
} 


\begin{tabular}{|c|c|c|c|c|c|c|c|c|c|}
\hline \multicolumn{10}{|c|}{ Table 22: Sources of Information Used for Borrowing Decisions } \\
\hline & \multicolumn{9}{|c|}{ Information Source (\% reporting) } \\
\hline Age & $\begin{array}{c}\text { Fin. } \\
\text { Planner }\end{array}$ & $\begin{array}{l}\text { Fin. } \\
\text { Prof. }\end{array}$ & $\begin{array}{c}\text { Friend } \\
\text { at Work }\end{array}$ & Internet & $\begin{array}{c}\text { Mag. } \\
\text { or News. }\end{array}$ & Mail & $\begin{array}{c}\text { Call } \\
\text { Around }\end{array}$ & Self & $\begin{array}{c}\text { Don't } \\
\text { Borrow }\end{array}$ \\
\hline Less than 35 & 17 & 33 & 61 & 53 & 17 & 38 & 36 & 4 & 5 \\
\hline $35-44$ & 19 & 39 & 51 & 49 & 20 & 40 & 40 & 5 & 6 \\
\hline $45-54$ & 20 & 41 & 46 & 43 & 24 & 40 & 36 & 7 & 6 \\
\hline $55-64$ & 23 & 45 & 40 & 34 & 24 & 40 & 34 & 6 & 8 \\
\hline $65-74$ & 20 & 42 & 31 & 19 & 18 & 29 & 30 & 7 & 17 \\
\hline 75 or More & 17 & 38 & 31 & 4 & 13 & 16 & 15 & 2 & 28 \\
\hline
\end{tabular}

